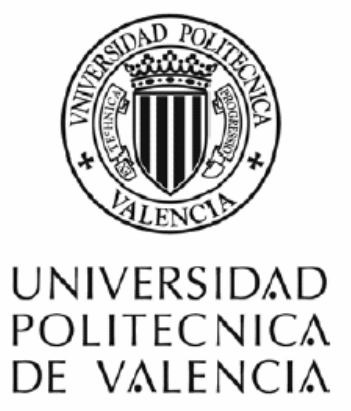

Departamento de Biotecnología

\title{
Mecanismos moleculares involucrados en \\ la citotoxicidad del agente antitumoral beta-lapachona
}

Lic. Mauricio Ariel Menacho-Márquez

Director: Dr. José R. Murguía

Tutor: Dr. Ramón Serrano 2007 

Agradezco a la mañana, por haberme despertado.

A mi mamá, por saber ser mucho más que eso. A mi papá, por enseñarme lo valioso que es ser un buen tipo. A mi tía Titi, por saber que es también mi mamá. A los tres, por vivir cada pequeño paso hoy y siempre, con tanto amor y orgullo.

Agradezco a la lluvia que moja mis pies cansados.

A Juan, mi marido y compañero de vida. Por seguir nadando. Por saber ser mi amor, mi cómplice y todo.

Agradezco al mundo, por haberme albergado.

A JoseRa, mi director de tesis. Por acompañarme en este camino y contagiarme entusiasmo. Por sus "mejor aún incluso" y por forjar mi carácter científico. Y a su familia, claro está.

A Eduardo, por haberme aceptado en su laboratorio y además, dejarme repetir. A Ramón y Mariche, por acogernos como parte de su grupo.

Agradezco a la llama, por haberme quemado.

A los compis con quienes he trabajado codo a codo: Abi y Carlos. Por todos los cafés, charlas, viajes, y momentos compartidos dentro y fuera del laboratorio.

A mis compañeros de laboratorio de Tenerife. A Ceci, Silvana, Silvia, Montse, Danny, Aridian, Ysamar, Fátima, Carmen, Alfredo, Cristi, David, Raimundo, Iván, Antonio, Juani y Débora, con quienes compartí un tiempo maravilloso. Por nuestros almuerzos, por seguirme desde Argentina, por el Circo del Sol y el clampeado de venas. Por los juegos, por ser tan cercanos, por estar ahí una y otra vez. Y por supuesto, muchas gracias también a Armando, Carmen y Almudena.

A mis compis en Valencia. A Mar y mis dos besitos de cada día. A Noe, por su frescura y compañerismo. A Fer, porque sí, bueno, si. A Markus y Payo, porque siento que es un placer trabajar con ellos. Y a mis nuevos compañeros: a Lynne, la ya doctora Steph, el rey de los chips Jorge y Jessica.

A los compañeros del laboratorio de Ramón: a Ramón mismo, Mariche, Lola, Guillem, Edu, Santiago, Regina, Cinta, Angela, Silvia, Gaetano, JM y Bea.

A Borja, Jorge y Pepe, por haber colaborado con tanto entusiasmo en este trabajo.

A las chicas de gestión económica, por aliviar los dolores de cabeza. 
Agradezco a la vida por dejarme vivirla.

A mi amigo JuanMa, por estar siempre y en todo momento. ¡Cómo te quiero tío!

A Vero y Matos, por la vida que compartimos en nuestro piso de la Finca España.

A Cris, una de las personas más nobles que he conocido.

A Lázaro, una lección de vida de la mano de mis chicos.

A Neus, MariLuz, Mir, Auror, Rosario y Pau, por acompañarnos en tantos momentos.

A mis compañeros de Jamón. A todos, pero en especial a mi Lolilla, claro.

Y al coro de la UPV, ¿por qué no? Por haberme permitido subir otra vez a un escenario.

Agradezco a la infancia por no haberme olvidado.

A mi hermano y mi cuñada. Y a las dos sobrinas más hermosas que pudiera uno imaginarse, mi Natu y mi Sele.

A mis primos Rita, Flo, Sandra, Marcelo, Hernán, Luciana, Pipo y Ali; y a la familia que ellos han traido.

A mi Nona, mi tía Olga, y mi prima Patri. Porque me sonríen desde donde están, y me han acompañado siempre.

A Bibi, la hermana que me dio la vida. A mis amigos del alma, Cucu, Nati, Pookie, Vic, Marian, David, Jenny, Yami, Ma José. A Dora. A mis amigos y compañeros de laboratorio en Argentina: a Kari, a Elena y todo el laboratorio de Molecular. A mis chicas Laura, Gaby, Lili y Vero, por enseñarme tanto, y a Mónica una jefaza.

Agradezco mi mente, mi palabra y mi canto. Agradezco a mi corazón por dejarme soñar. Agradezco a la gente por enseñarme a vivir. Agradezco mis virtudes, mis logros y mis fracasos. Agradezco mis lágrimas, mi dolor y mi quebranto. Agradezco a mis sueños por lanzarme hacia delante. Agradezco a las flores por dar sin recibir.

Y por sobre todas las cosas

Agradezco al Creador

Por dejarme encarnar

En este traje que llevo hoy... 
There is a crack in everything That's how the light gets in

(Leonard Cohen) 



\section{RESUMEN}

Beta-lapachona ( $\beta$-lap) es un agente antitumoral que induce apoptosis selectivamente en células tumorales. El mecanismo preciso de citotoxicidad de $\beta$-lap no es aún completamente comprendido. Aquí reportamos que $\beta$-lap produce un retraso en la progresión del ciclo celular en la transición G1/S, aumenta la fosforilación de la quinasa de control Rad53p y disminuye la supervivencia celular en la levadura de gemación Saccharomyces cerevisiae. Además, $\beta$-lap induce la fosforilación de histona H2A en la posición serina 129. Estas respuestas de control de ciclo son reguladas por las quinasas Mec1p y Tel1p. Mec1p se requiere para la fosforilación de Rad53p/histona H2A y supervivencia celular tras tratamiento con $\beta$-lap en cultivos asincrónicos, pero no para el retraso en la transición G1/S. La mutación $\Delta t e / 1$ aumenta la sensibilidad a $\beta$ lap en una cepa defectiva en mec1, y compromete las respuestas de los puntos de control de ciclo. La fosforilación de Rad53p y el retraso en $\mathrm{G} 1 / \mathrm{S}$ son completamente dependientes de un complejo Mre11pRad50p-Xrs2p (XMR) funcional, y mutantes en el complejo XMR son extremadamente sensibles al tratamiento con $\beta$-lap. Finalmente, $X R S 2$ y TEL 1 trabajan epistáticamente respecto a la sensibilidad a $\beta$ lap y Xrs2p se fosforila en un modo dependiente de Tel1p tras el tratamiento.

El tratamiento con $\beta$-lap también genera la producción de especies reactivas de oxígeno (ROS), la cual es bloqueada eficientemente por dicumarol, un inhibidor de NADH deshidrogenasas (NADH-DH). El tratamiento con dicumarol no afecta a la viabilidad ni a las respuestas 
de control activadas por la droga. Identificamos un mutante, defectivo en la NADH-DH mitocondrial Nde2p, que es resistente a la toxicidad de $\beta$-lap. $\beta$-lap induce la producción de ROS en este mutante, sin afectar la viabilidad o la progresión de ciclo. El mutante $\Delta$ nde2 presenta un retraso en la entrada en fase $S$ del ciclo celular, e hipersensibilidad a agentes que dañan el ADN. Nuestros datos indican que Nde2p es un determinante principal de la toxicidad de $\beta$ lap en levadura de gemación. Dado que existen ortólogos de Nde2p en el genoma humano, nuestros resultados podrían ser de significancia general para la acción antitumoral de $\beta$-lap.

El tratamiento con $\beta$-lap activa la ruta de control general de nutrientes. Además, la quinasa Gcn2p modula la toxicidad y las respuestas de ciclo tras el tratamiento con $\beta$-lap en un modo dependiente del complejo XMR, indicando que la quinasa Gcn2p contribuye a los mecanismos de control de daño al ADN en levadura. Por otra parte, Gcn2p regula funciones de control de ciclo a través de mecanismos que no involucran la fosforilación de elF2, sugiriendo que Gcn2p puede tener funciones adicionales además del control traduccional.

En conjunto, estos resultados indican que $\beta$-lap activa un mecanismo de control dependiente de Mre11-Tel1p en levadura en un modo dependiente de Nde2p. La evidencia presentada aquí es consistente con Nde2p como determinante de la toxicidad de $\beta$-lap, y revela una conexión inesperada entre las rutas de reparación del $A D N$, la quinasa Gcn2p y la función mitocondrial. 


\section{RESUM}

Beta-lapachona ( $\beta$-lap) és un agent antitumoral que induïx apoptosis selectivament en cèllules tumorals. El mecanisme precís de citotoxicitat de $\beta$-lap no és encara completament comprés. Per esta raó hem estudiat la toxicitat de la b-lap usant com a model experimental el rent Saccharomyces cerevisiae.

$\beta$-lap va produir un retard en la progressió del cicle cel-lular en la transició G1/S, va augmentar la fosforilació de la quinasa de control Rad53p i va disminuïr la supervivència cellular en el rent de gemmació Saccharomyces cerevisiae. A més, $\beta$-lap va induïr la fosforilació de histona H2A en la posició serina 129. Estes respostes de control de cicle van resultar regulades per les quinases Mec1p i Tel1p. Mec1p van resultar implicat en la fosforilació de Rad53p/histona $\mathrm{H} 2 \mathrm{~A}$ i supervivència cel-lular després del tractament amb $\beta$-lap en cultius asincrònics, però no en al retard en la transició G1/S. La mutació $\Delta t e / 1$ va augmentar la sensibilitat a $\beta$-lap en una cèl.lula defectiva en mec1, comprometent les respostes dels punts de control de cicle. La fosforilació de Rad53p i el retard en G1/S van ser completament dependents d'un complex Mre11p-Rad50p-Xrs2p (XMR) funcional, i els mutants en el complex de XMR van mostrar alta sensibilitat al tractament amb $\beta$-lap. Finalment, XRS2 i TEL1 van treballar epistáticament respecte a la sensibilitat a $\beta$-lap, observantse una fosforilació de Xrs2p dependent de Tel1p després del tractament. 
El tractament amb $\beta$-lap també va generar la producció d'espècies reactives d'oxigen (ROS), la qual va ser bloquejada eficientment per dicumarol, un inhibidor de NADH deshidrogenasas (NADH-DH). El tractament de dicumarol no va afectar la viabilitat ni a les respostes de control activades per la droga. Hem identificat un mutant, defectiu en la NADH-DH mitocondrial Nde2p, resistent a la toxicitat de $\beta$-lap. $\beta$-lap va induïr producció de ROS en este mutant, sense afectar la viabilitat o la progressió de cicle. El mutant $\Delta n d e 2$ va mostrar a més un retard en l'entrada en fase $S$ del cicle cel/lular, i hipersensibilitat a agents que danyen el ADN. Les nostres dades indiquen que Nde2p és un determinant principal de la toxicitat de $\beta$-lap en rent de gemmació.

El tractament amb $\beta$-lap va activar la ruta de control general de nutrients. A més, la quinasa Gcn2p va modular la toxicitat i les respostes de cicle dsprés del tractament amb $\beta$-lap en un mode dependent del complex XMR, indicant que la quinasa Gcn2p contribuïx als mecanismes de control de dany al ADN en rent. D'altra banda, Gcn2p va regular funcions de control de cicle a través de mecanismes que no involucren la fosforilació d'elF2, suggerint que Gcn2p pot tindre funcions addicionals a més del control traduccional.

En conjunt, estos resultats indiquen que $\beta$-lap activa un mecanisme de control dependent de Mre11-Tel1p en rent en un mode dependent de Nde2p. L'evidència presentada ací és consistent amb Nde2p com a diana molecular de $\beta$-lap, i revela una connexió inesperada entre les rutes de reparació del $A D N$, la quinasa $G c n 2 p$ i la funció mitocondrial. 


\section{SUMMARY}

Beta-lapachone ( $\beta$-lap) is an anticancer agent that selectively induces cell death in several human cancer cells. The mechanism of $\beta$-lap cytotoxicity is not yet fully understood. For that reason, we have studied $\beta$-lap toxicity using Saccharomyces cerevisiae as experimental model system.

$\beta$-lap treatment delayed cell cycle progression at the G1/S transition, incremented phosphorylation of the Rad53p checkpoint kinase and decreased cell survival in the budding yeast Saccharomyces cerevisiae. Furthermore, $\beta$-lap induced phosphorylation of histone $\mathrm{H} 2 \mathrm{~A}$ at serine 129 . These checkpoint responses were regulated by Mec1p and Tel1p kinases. Mec1p was required for Rad53p/histone $\mathrm{H} 2 \mathrm{~A}$ phosphorylation and cell survival following $\beta$-lap treatment in asynchronous cultures, but not for the G1/S delay. The tel1 $1 \Delta$ mutation increased sensitivity to $\beta$-lap in a mec1 defective strain and compromised checkpoint responses. Both Rad53p phosphorylation and $\mathrm{G} 1 / \mathrm{S}$ delay were fully dependent on a functional Mre11p-Rad50p Xrs2p (XMR) complex, and mutants in the XMR complex were hypersensitive to $\beta$-lap treatment. Finally, XRS2 and TEL1 worked epistatically regarding $\beta$-lap sensitivity and Xrs2 $p$ was phosphorylated in a Tel1p-dependent manner after $\beta$-lap treatment.

$\beta$-lap treatment also generated reactive oxygen species (ROS) which where efficiently blocked by dicoumarol, an inhibitor of NADH dehydrogenases (NADH-DH). Dicoumarol treatment did not affect 
viability or the checkpoint responses triggered by the drug. We have identified a mutant, defective in the mitochondrial NADH-DH Nde2p which was resistant to $\beta$-lap toxicity. $\beta$-lap elicited ROS production in this mutant, however affecting neither cell viability nor cell cycle progression. The nde $2 \Delta$ mutant exhibited a delayed cell cycle entry in S-phase and hypersensitivity to DNA damaging agents. Therefore, these data indicate that $\mathrm{Nde} 2 \mathrm{p}$ is the principal determinant of $\beta$-lap toxicity in budding yeast.

General control of nutrients pathway is activated after $\beta$-lap treatment. Furthermore, Gcn2p kinase modulates $\beta$-lap toxicity and checkpoint responses to treatment in an XMR dependent manner, indicating that the Gcn2p kinase contributes to DNA damage checkpoint control in budding yeast. Moreover, Gcn2p regulated checkpoint function by mechanisms other than elF2 $\alpha$ phosphorylation, suggesting that Gcn2p may have additional functions besides regulating translation.

Taken together, these findings indicate that $\beta$-lap activates an Mre11Tel1p checkpoint pathway in budding yeast via an Nde2p-dependent manner. The evidence presented here is consistent with Nde2p being the molecular target of $\beta$-lap, and highlights an unexpected connection between DNA repair pathways, Gcn2p kinase and mitochondrial function. 
ÍNDICE

página

ABREVIATURAS

INTRODUCCIÓN 3

1. Terapia antitumoral 5

2. Beta-lapachona 9

3. Levadura como sistema modelo para el estudio de drogas antitumorales $\quad 14$

4. Puntos de control de daño al ADN y ciclo celular 17

Organización y arquitectura de las rutas de control de daño al ADN 19

Detección del daño al ADN 25

Transducción de la señal de daño al ADN a los efectores 31

Eventos posteriores a la activación de las rutas de control:

recuperación y adaptación $\quad 34$

5. La ruta de control traduccional y sus implicaciones en cáncer

MATERIALES Y MÉTODOS

1. Cultivo y manipulación celular 49

1.1 Bacterias 49

1.2 Levaduras $\quad 49$

2. Preparación de drogas y tratamientos 58

2.1 Preparación de drogas 58

2.2 Ensayos de sensibilidad a drogas $\quad 59$ 
3. Técnicas de transferencia génica 61

3.1 Preparación de células competentes de bacteria $\quad 61$

3.2 Transformación en bacterias 62

3.3 Transformación el levaduras 62

4. Técnicas de manipulación génica 64

4.1Generación de plásmidos 64

4.2 Generación de la cepa mutante $G C N 2^{c} \quad 64$

5. Obtención de extractos proteicos 67

5.1 Extractos proteicos de levadura para transferencia a $\begin{array}{ll}\text { membrana } & 67\end{array}$

6. Electroforesis y técnicas de detección de proteínas 68

6.1 Electroforesis de proteínas 68

6.2 Transferencia a membrana 68

6.3 Tinción de geles con Ponceau S 69

6.4 Inmunodetección de proteínas transferidas a $\begin{array}{ll}\text { membrana } & 69\end{array}$

7. Genómica funcional 71

7.1 Extracción y marcaje del ARN de levadura 71

7.2 Micromatrices, hibridizaciones y análisis

de las imágenes $\quad 71$

7.3 Análisis de los genes con cambios en expresión

de significancia estadística $\quad 72$

$\begin{array}{ll}\text { RESULTADOS } & 75\end{array}$

1. Caracterización de los efectos de beta-lapachona $\begin{array}{ll}\text { en levaduras } & 77\end{array}$

1.1 Efectos sobre crecimiento y viabilidad celular $\quad 77$

1.2. Efectos sobre el ciclo celular $\quad 77$ 
1.3. Sensibilidad de cepas mutantes con defectos

en las rutas de control

1.4. Papel de Mec1p y Tel1p en el mecanismo de control activado por beta-lapachona

1.5. Papel de las vías de reparación al daño al ADN en la toxicidad de beta-lapachona

1.6. Implicación del complejo XMR en la toxicidad de beta-lapachona

1.7. Relaciones epistáticas

1.8. Fosforilación de un componente del complejo XMR

2. Análisis de la implicación de topoisomerasas

3. Radicales libres

3.1. Producción de radicales libres por tratamiento con beta-lapachona

3.2. Contribución de los radicales libres a la viabilidad

3.3. Producción de radicales libres y control

de ciclo celular

3.4. Deshidrogenasas de levadura

3.5. Análisis de la producción de ROS en mutantes en actividad deshidrogenasa

\section{Caracterización del mutante $\Delta$ nde2}

4.1. Estudios de la tolerancia del mutante $\Delta n d e 2$

en distintas fuentes de carbono

4.2. Análisis de la respuesta de control del mutante $\Delta$ nde2

4.3. Fosforilación de RAD53 e Histona H2A

en el mutante $\Delta$ nde2

4.4 Sinergismos con otros agentes genotóxicos 
e implicación de NDE2

4.5. Respuesta de $\Delta n d e 2$ a otros lesionantes

4.6. Respuestas de los mecanismos de control

del mutante $\Delta$ nde2 a phleomicina

4.7. Nde2p y el sistema de reparación de DSB

Beta-lapachona y la ruta de control general de nutrientes

5.1. Genómica funcional con beta-lapachona

5.2. Beta-lapachona y la ruta de control traduccional

5.3. Análisis de la implicación de la ruta GCN

en las respuestas activadas por beta-lapachona

5.4. Respuestas de las vías de control en mutantes

en la ruta de control traduccional

5.5. Activación de la ruta de control traduccional

en mutantes con mecanismos de control defectivos

5.6. Beta-lapachona activa la ruta de control

traduccional en una forma dependiente de Nde2p

1. Beta-lapachona es citotóxica en levadura y activa un punto de control dependiente de Mre11p y Tel1p

2. Generación de radicales libres y sus efectos sobre la citotoxicidad de beta-lapachona en levadura

3. Nde2p modula la toxicidad de beta-lapachona

4. Beta-lapachona y la ruta de control traduccional

4.1. Activación de la ruta GCN por tratamiento con beta-lapachona

4.2. Implicación de la activación de la ruta GCN 
en los eventos activados por beta-lapachona

4.3. Implicación de NDE2 en estas respuestas

165

5. Modelo de acción de beta-lapachona en levadura

CONCLUSIONES

BIBLIOGRAFÍA

ANEXOS: Artículos 


\section{ÍNDICE DE FIGURAS}

Figura

página

1 Estructura molecular de beta-lapachona

2 Mecanismos de control que operan las distintas fases del ciclo celular

3 Respuestas de daño al ADN en fase

4 Detección y señalización de roturas de doble banda

5 Control traduccional de GCN4

6 Arrestos de ciclo celular en levadura

7 Generación del mutante $\mathrm{GCN}^{\mathrm{C}}$

8 Efectos de beta-lapachona sobre crecimiento y viabilidad

9 Efectos de beta-lapachona sobre el ciclo celular

10 Viabilidad en las distintas fases del ciclo celular

11 Sensibilidad de mutantes con rutas de control defectivas

83

12 Transición G1-S en mutantes $\Delta m e c 1, \Delta t e / 1$ y $\Delta m e c 1 \Delta t e / 1$

13 Fosforilación de Rad53p en mutantes $\Delta m e c 1, \Delta t e / 1$ y $\Delta$ mec1 $1 \Delta t e / 1$

14 Sensibilidad de mutantes en sistemas de reparación

88

15 Fosforilación de Histona H2A por tratamiento

89

16 Respuestas de control del mutante $X M R$

91

17 Interacciones epistáticas y funcionales entre Tel1p

18 y Xrs2p

93

19 Respuestas de mutantes en topoisomerasas

20 Modelo de acción de NQO1

99

21 Generación de radicales libres por tratamiento con beta-lapachona

22 Generación radicales libres y toxicidad de betalapachona 
23 Radicales libres y respuestas de las rutas de control

24 Sensibilidad de mutantes en actividad deshidrogenasa

25 Generación de ROS en mutantes en actividad deshidrogenasa

26 Tolerancia del mutante $\Delta n d e 2$

27 Progresión de ciclo celular del mutante $\Delta$ nde2

28 Fosforilación de Rad53p e Histona H2A en $\Delta$ nde2

29 Sinergismos

30 Respuestas de $\Delta$ nde 2 a otros lesionantes

31 Respuestas de $\Delta$ nde2 a phleomicina

32 Eficiencia de reparación del mutante $\Delta$ nde2

33 Fosforilación de elF2 $\alpha$ por tratamiento con betalapachona

34 Mutantes en la ruta GCN y beta-lapachona

35 Sensibilidad del mutante $\mathrm{GCN}^{\mathrm{C}}$

36 Modulación de las respuestas de las vías de control por la ruta $G C N$

37 Activación de la ruta GCN en mutantes de control

38 Fosforilación de elF2 $\alpha$ en el mutante $\Delta n d e 2$

39 Mecanismo de activación de E2F

40 Modelo de señalización y reparación del daño al ADN

41 Modelo propuesto del mecanismo de acción de beta-lapachona en levaduras 


\section{ÍNDICE DE TABLAS}

\section{Tabla}

página

1 Proteínas de respuesta al daño al ADN en

$$
\text { eucariotas }
$$

2 Lista de cepas de S. cerevisiae 56

3 Lista de plásmidos 63

4 Lista de anticuerpos $\quad \mathbf{7 0}$

5 Genes diferencialmente inducidos por tratamiento con beta-lapachona

6 Genes diferencialmente reprimidos por tratamiento con beta-lapachona 


\section{ABREVIATURAS}

aa

ADN

ADNc

ADP

ARN

ARNm

ARNt

ATP

$\beta$-lap

BSA

DMEM

DMSO

dNTP

DSB

dsARN

EDTA

GCN

GDP

$\mathrm{GO}$

GTP

HEPES

$\mathrm{HU}$

LB

MMS

$\mathrm{NADH}$

NCBI

PAGE

PBS

PEG

Phleo

PIKK

PMSF

PVDF

ROS

SAM

ssADN

SD

SDS

TBS
Aminoácido

Ácido desoxirribonucleico

ADN complementario

Adenosina difosfato

Ácido ribonucleico

ARN mensajero

ARN transferente

Adenosina trifosfato

Beta-lapachona

Albúmina sérica bovina

Modificación Dulbecco del Medio Eagle

Dimetil sulfóxido

Desoxynucleótido trifosfato

Rotura de doble hebra del ADN

ARN de doble cadena

Ácido etilendiaminotetraacético

Control General de Nutrientes

Guanosina difosfato

Ontología génica

Guanosina trifosfato

Ácido 2-(4-(2-Hidroxietil)-1-piperazinil)etanosulfónico

Hidroxiurea

Medio de cultivo Luria-Bertani para bacterias

Metil metano sulfonato

Nicotinamida adenina dinucleótido

Centro Nacional de Información Biotecnológica

Electroforesis en gel de poliacrilamida

Tampón salino de fosfatos

Polietilenglicol

Phleomicina

Proteína quinasa similar a la fosfatidil-inositol 3quinasa

Fluoruro de fenilmetilsulfonil

Fluoruro de polivinilideno

Especies reactivas de oxígeno

Análisis de significancia de micromatrices

ADN de simple hebra

Medio mínimo sintético definido para levaduras

Dodecil sulfato sódico

Tampón salino de Tris (hidroximetil) aminometano 
TCA Ácido tricloroacético

UORF Marco abierto de lectura corriente arriba de la región codificante

UTP Uracilo trifosfato

VIH Virus de la inmunodeficiencia humana

YPD Medio complejo de Extracto de Levadura, Peptona y Glucosa para levaduras 


\section{INTRODUCCIÓN}





\section{TERAPIA ANTITUMORAL.}

El estudio del cáncer, como muchas otras enfermedades humanas, ha aportado profundos coenocimientos sobre el comportamiento de las células normales y los tejidos, como así también sobre los procesos que llevan a la transformación celular. El clonaje del gen $R B$ (retinoblastoma) llevó a comprender cómo funciona el producto de este gen supresor de tumor, el primero descrito, en la restricción de la progresión a través del ciclo celular (Riley et al., 1994). Del mismo modo, el estudio de mutaciones en la proteína v-Src condujo al reconocimiento del rol de las proteínas tirosina quinasas en la regulación de la división celular y diferenciación (Irby $R$ and Yeatman $\mathrm{T}, 2000)$.

Pero la principal motivación de los estudios sobre las bases moleculares del cáncer es el desarrollo de nuevas terapias contra tumores para los cuales no existen tratamientos efectivos, o para los que las terapias existentes generan efectos no terapéuticos significativos. Las terapias contra el cáncer actuales - principalmente cirugía, radioterapia y quimioterapia - todas tienen desventajas. La cirugía es efectiva en muchos tumores primarios, pero las metástasis son difíciles de identificar. Aunque la radiación $\gamma$ mata muchos tumores localizados, también mata a las células normales. La mayoría de las drogas utilizadas en quimioterapia (como por ejemplo cisplatino, taxol, 5-fluorouracilo, y adriamicina) están diseñadas para matar células que se dividen, causando su efecto también sobre las células madre del intestino y de la piel, provocando diarrea y pérdida de cabello, y son inefectivas contra células con mutaciones en p53, un carácter común en algunos cánceres. 
Las investigaciones moleculares en la biología del cáncer han dado lugar ya a algunas terapias más eficaces, y se pueden anticipar más avances en los próximos años por la explotación de estos nuevos descubrimientos. Como ejemplo puede citarse que la sobreexpresión del receptor Her2 en ciertos tumores de mama puede ser atacada por un anticuerpo monoclonal anti-Her2 (Engel and Kaklamani, 2007), e inhibidores de la farnesil transferasa aportan resultados prometedores en la terapia de tumores con mutaciones que activan Ras (Appels et al., 2005). Además se están desarrollando inhibidores específicos de la actividad telomerasa o de la angiogénesis pero aún no existe claridad sobre qué tumores podrían tratarse con tales reactivos.

Los tumores causados por mutaciones en genes supresores de tumor son más difíciles de tratar debido a que resultan de la pérdida de una proteína normal. Entre los intentos de tratamiento se está estudiando la posibilidad de reintroducción del gen salvaje que codifique p53, PTEN o un inhibidor de la ciclina quinasa en un tumor que hubiera perdido estas proteínas (McNeish et al., 2004). Un desafío de tal terapia es la introducción del gen sólo en el tumor y no en las células normales, donde podría inhibir la división. Además los niveles de las proteínas expresadas a partir de los genes introducidos deberían ser cercanos a los normales para que sean efectivas.

En la actualidad, el enfoque en la búsqueda de nuevas drogas dirigidas contra el cáncer se centra en identificar agentes dirigidos de manera específica contra la célula tumoral. Hoy en día está bien establecido que la mayoría de los agentes anticancerosos inducen 
apoptosis y se conoce que mutaciones en este programa reducen la sensibilidad al tratamiento y, en el peor de los casos, la resistencia a la terapia. Los agentes que inducen apoptosis, al ser comparados con drogas citotóxicas, tienen la ventaja de ser menos mutagénicos, menos tóxicos y representarán menos riesgo de originar resistencia al tratamiento.

La mayoría de las drogas quimioterapéuticas matan a las células tumorales indirectamente por activación de apoptosis mediada por los puntos de control o "checkpoints" tras la creación de un daño no selectivo al ADN o a microtúbulos. Sin embargo, un carácter común a las células tumorales es la inestabilidad de su genoma y una alta frecuencia de mutación de genes implicados en el control de la proliferación y del ciclo celular. Entre los genes que aparecen mutados con alta frecuencia en tumores humanos se encuentran componentes que regulan el control del ciclo celular en la transición G1/S. Entre éstos destacan p53 (con mutaciones que lo inactivan o causan pérdida total en un $50 \%$ de tumores de todos los tipos), Rb (mutaciones en un $40 \%$ de tumores), p16 (40-50\%), y ciclina D1 (sobreexpresada en distintos tipos de tumores; Sherr CJ and McCormick F, 2002).

Así, estas células tumorales con mecanismos de control defectivos no serán capaces de inducir correctamente apoptosis por tratamiento quimioterapéutico convencional. De aquí que estrategias terapéuticas encaminadas en reactivar o reestablecer funciones de control del ciclo celular en células tumorales permitirían que éstas fueran capaces de inducir apoptosis. Más aún, la reactivación de las 
funciones normales de los mecanismos de control en tales células tumorales podría per se inducir apoptosis como respuesta a los daños intracelulares acumulados por éstas durante su progresión. 


\section{BETA-LAPACHONA}

La beta-lapachona (3,4-dihidro-2,2-dimetil-2H-nafto[1,2-b]pirano-5,6diona) es una droga en fase de investigación preclínica con unas propiedades que la convierten en un nuevo agente antitumoral muy prometedor ya que: 1) induce la muerte celular en un amplio espectro de células tumorales humanas y en xenotransplantes de tumores humanos en ratón (Pardee et al., 2002), 2) potencia dramáticamente la letalidad de otros antitumorales como la radiación ionizante, los agentes alquilantes y, sobre todo, el taxol en varios tipos de tumores humanos implantados en ratones (Li et al., 1999), y 3) sin duda la más relevante, induce selectivamente la apoptosis en células tumorales pero no en células normales en proliferación ( $\mathrm{Li}$ et al., 2003). Esta última propiedad de la beta-lapachona no es compartida por agentes antitumorales convencionales.

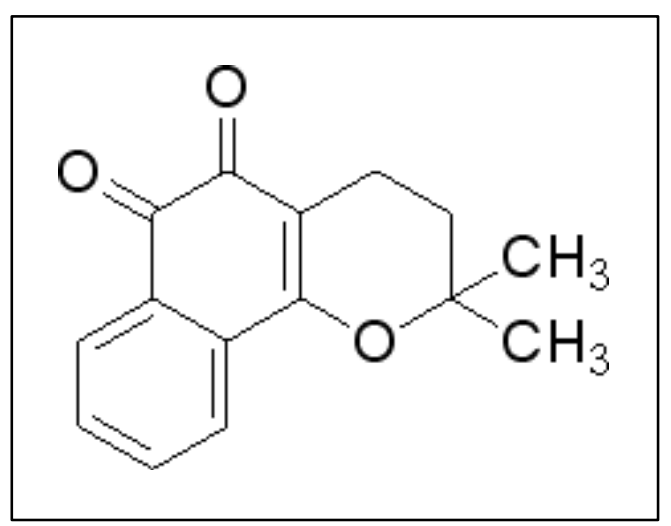

Figura 1. Estructura molecular de beta-lapachona

A pesar de estos resultados tan prometedores, el mecanismo de acción de la beta-lapachona no se conoce en profundidad. Se ha 
reportado que posee una gran variedad de actividades farmacológicas, entre otras contra tripanosomas, oncovirus, reparación del ADN, VIH, psoriasis y sepsis (Sun et al., 2006). Sin embargo, este arreglo de potenciales ha sido propuesto principalmente en base a datos in vitro.

La primera observación del efecto in vitro de beta-lapachona contra células cancerígenas fue realizada durante el estudio de la generación de radicales libres en células de sarcoma de ratón incubadas en cultivo con beta-lapachona a dosis de $40-60 \mu \mathrm{M}$ (Docampo et al., 1979). A concentraciones más relevantes farmacológicamente, se encontró que beta-lapachona por sí misma tenía muy poco efecto sobre cultivos de células humanas normales, pero era un potente sensibilizador contra células con daños en el ADN inducido por radiación o agentes alquilantes (Boothman et al., 1987).

La posibilidad de utilizar beta-lapachona como agente quimioterapéutico contra el cáncer surgió primero a causa de la observación de que inhibía a la topoisomerasa I (Li et al., 1993). La inducción de apoptosis en células tumorales en cultivo soportó posterioremente su uso como un potencial inductor de apoptosis en células cancerígenas ( $\mathrm{Li}$ et al., 1995). Ahora se conoce además que beta-lapachona es capaz de inducir muerte celular no apoptótica, o necrótica en algunas líneas celulares de cáncer, y se ha propuesto que la mitocondria podría ser una organela diana en la inducción de la muerte celular por esta droga (Li et al., 1999). 
La potencialidad de la actividad de beta-lapachona contra el cáncer fue basada en su actividad in vivo contra varios tumores. La primer prueba farmacológica in vivo de beta-lapachona fue la inhibición de infecciones oncovirales en ratones, observándose que la infección viral y la oncogénesis inducida por virus eran bloqueadas (SchaffnerSabba et al, 1984). Sin embargo, no se supo si beta-lapachona tendría actividad contra tumores ya establecidos hasta que fue probada con éxito en monoterapia, o en combinación con paclitaxol u otros agentes, sobre xenotransplantes de tumores humanos en ratones (Li et al., 1999). Resultados tan prometedores han motivado el desarrollo clínico de este agente como compuesto dirigido contra el cáncer. Además, ARQ501, una composición farmacéutica de betalapachona, ha mostrado signos alentadores de actividad antitumoral en ensayos clínicos de fases I y lb, y actualmente está en ensayos de fase II para tratamiento de cáncer de páncreas (C.Li et al., 2006; http://clinicaltrials.gov/ct/show/Nct00102700?ORDER=4).

El mecanismo de acción de beta-lapachona podría involucrar múltiples vías y es dependiente de muchos factores, incluyendo la concentración, la duración del tratamiento, o el fondo genético. Si bien se considera un agente lesionante del ADN, la evidencia disponible es muy controvertida. Beta-lapachona inhibe in vitro la actividad de las topoisomerasas I y II (Krishnan and Bastow, 2001). Sin embargo, las dosis requeridas para bloquear la actividad de topoisomerasa I/II son más elevadas que las que inducen apoptosis en tumores. La proteína codificada por el gen NQO1 $(\mathrm{NAD}(\mathrm{P}) \mathrm{H}$ : quinona oxido-reductasa) se ha propuesto como diana in vivo de la beta-lapachona, con la generación de radicales libres mediada por 
NQO1 como responsable del efecto antitumoral (Pink et al., 2000). Sin embargo, líneas celulares tumorales que carecen de NQO1, como las células HL60 y MDA-MB-468, son sensibles a la droga. Por otro lado, la línea celular NCM-460 es muy resistente a betalapachona, mientras que la línea SW480 es extremadamente sensible, y ambas expresan niveles equivalentes de NQO1 (Li et al., 2003).

Un carácter especialmente relevante de beta-lapachona es que su letalidad es totalmente independiente de la pérdida de función de p53 o de factores pro-apoptóticos (Bey EA et al., 2007). El patrón de proteólisis apoptótica generado por tratamiento con beta-lapachona es consistente con la activación de calpaína $\mu$ (Tagliarino $\mathrm{C}$ et al., 2003), mientras que otros aspectos de su citotoxicidad son únicos y parecen responder más bien a un proceso de necrosis dependiente de PARP-1 (Sun X et al., 2006). Independientemente del programa de muerte celular inducido por beta-lapachona, esta molécula es capaz de activar un mecanismo de control en células con control defectivo, induciendo de este modo señales que conducen a la muerte celular de las células tumorales.

Dadas las características farmacológicas tan relevantes de esta molécula, la identificación del mecanismo molecular preciso a través del cual beta-lapachona produce letalidad selectivamente en células tumorales sería de gran importancia ya que proporcionaría nuevas dianas moleculares para el desarrollo de estrategias terapéuticas más eficaces contra el cáncer. Las dianas identificadas tendrían un valor incalculable como factores diagnóstico/pronóstico en la 
etiología del cáncer y en su tratamiento, respectivamente; y proporcionarían información muy valiosa para aumentar los usos terapéuticos de esta molécula. 


\section{LEVADURA COMO SISTEMA MODELO PARA EL ESTUDIO DE DROGAS ANTITUMORALES.}

La levadura de gemación Saccharomyces cerevisiae es un sistema modelo de gran valor para el estudio de procesos biológicos básicos conservados entre organismos eucariotas, como las rutas de reparación del ADN y los controles de ciclo celular. S. cerevisiae es uno de los organismos eucariotas más simples. Además de su rápido crecimiento (presenta un ciclo de vida de 90 minutos) y la facilidad con que se replican cultivos y aíslan mutantes, destaca por un sencillo y versátil sistema de transformación de ADN (Gietz et al. 1995). Su genoma haploide presenta pequeño tamaño y relativamente baja complejidad, estando contenido en 16 cromosomas bien caracterizados. Por estas características, el genoma de levadura fue el primer genoma eucariota secuenciado, revelando la presencia de 6466 marcos abiertos de lectura. Por otro lado, la ausencia de patogenicidad permite su manipulación con las mínimas precauciones.

S. cerevisiae es un sistema genético que, a diferencia de la mayoría de otros microorganismos, presenta dos fases biológicas estables: haploide y diploide. La fase haploide permite generar, aislar y caracterizar mutantes con mucha facilidad, mientras que en la diploide se pueden realizar estudios de complementación. Además, el desarrollo de protocolos de introducción de ADN exógeno facilita mucho la manipulación genética de este microorganismo. Los genes asociados a prácticamente cualquier fenotipo pueden ser aislados mediante la complementación de mutantes a partir de genotecas 
genómicas o de ADNc. El ADN introducido en las células de levadura puede ser autorreplicante o integrarse en el genoma. Como la integración de moléculas de $A D N$ en el genoma ocurre casi exclusivamente por recombinación homóloga, es muy sencillo reemplazar fragmentos de ADN de secuencia conocida. De esta forma se pueden intercambiar las copias normales de genes por otras alteradas o inactivas. Así, los fenotipos asociados a la pérdida de función de los diferentes genes han permitido comprender su papel fisiológico con gran precisión.

El conocimiento de la secuencia completa de su genoma (Goffeau et al. 1996) y su constante revisión (Kumar et al. 2002) han permitido la manipulación genética de sus casi 6600 genes (Oliver, 1996), el uso extensivo de micromatrices de ADN para investigar el transcriptoma (DeRisi et al. 1997; Brown y Botstein, 1999) y estudios a escala genómica de, entre otros muchos aspectos, la expresión génica (Velculescu et al. 1997), localización de proteínas (Ross- Macdonald et al. 1999) y la organización funcional del genoma (Giaever et al. 2002) y el proteoma (Gavin et al. 2002 y 2006).

La maquinaria molecular de muchos procesos celulares se encuentra conservada tanto en levadura como en mamíferos. Esto se ilustra con el hecho de que rutinariamente se han introducido genes de mamífero en levadura para el análisis sistemático de su función. Muchos genes humanos relacionados con enfermedades tienen ortólogos (esto es, genes derivados de un ancestro común) en levadura (Ploger et al. 2000). S. cerevisiae ha mostrado ser un excelente modelo para el estudio de enfermedades humanas y rutas 
implicadas en las mismas gracias a que al menos el $31 \%$ de las proteínas codificadas en el genoma de levadura tienen un ortólogo humano, y casi el $50 \%$ de los genes involucrados en enfermedades humanas exhiben un ortólogo en levadura.

S. cervisiae se ha utilizado exitosamente en repetidas ocasiones como herramienta para la comprensión de los mecanismos de acción de drogas conocidas (Matthews and kopczynski, 2001), como así también ha mostrado ser un excelente modelo para la identificación de determinantes de sensibilidad a drogas antitumorales como cisplatino (Niedner et al, 2001), y para el descubrimiento de nuevas drogas antitumorales y posibles nuevas dianas terapéuticas (Outeiro et al., 2006). Además, la facilidad de manipulación de su genoma proporciona a este sistema modelo la flexibilidad requerida para identificar la diana de un agente quimioterápico o para descifrar las rutas que modulan la sensibilidad a un agente determinado. Por otro lado, la letalidad inducida por drogas en cepas con mutaciones en todos los genes de su genoma (Bjornsti, 2002), puede explotarse para definir defectos genéticos en células tumorales que potencien la citotoxicidad inducida por la quimioterapia. 


\section{PUNTOS DE CONTROL DE DAÑO AL ADN Y CICLO CELULAR}

Junto con la capacidad fundamental de todos los organismos de reproducirse surge el desafío de copiar fielmente sus genomas y mantenerlos en su estado primigenio durante ciclos sucesivos de división celular. Los genomas de las células eucariotas sufren continuamente daños por agentes extracelulares así como por subproductos de procesos intracelulares tales como la misma replicación del ADN. Las lesiones resultantes pueden causar inestabilidad genómica, y comprometer la viabilidad celular. Las células han desarrollado mecanismos de vigilancia denominados controles de ciclo celular o "checkpoints", que garantizan el orden de los eventos del ciclo celular para preservar la estabilidad del genoma. Entre ellos, los controles de daño al ADN previenen la segregación cromosómica cuando éste está dañado, en todas las fases del ciclo celular (G1, S y G2). Defectos en la señalización del daño al ADN impiden la capacidad de reparación de lesiones, produciendo predisposición a cáncer en seres humanos (Nyber KA, 2002).

Estos controles de daño al ADN son redes regulatorias no esenciales que controlan la capacidad de las células de arrestar la progresión del ciclo celular en respuesta a daño al ADN, permitiendo así que haya tiempo para la reparación. Sin embargo, la función de estas redes incluye otros aspectos además de la regulación del arresto de ciclo, ya que también controlan la activación transcripcional y posttraduccional de las vías de reparación del ADN (Wu X et al., 2000), cambios en la composición de la cromatina, y la localización de las proteínas de reparación del ADN en los sitios del daño (Mills KD et 
al., 1999). Así, la acción combinada de estas respuestas contribuye a incrementar la capacidad de las células de sobrevivir al daño.

Las proteínas de las rutas de control están bien conservadas entre todos los eucariotas, indicando que la arquitectura básica de estas rutas de control de daño al $A D N$ ha sido mantenida a través de la evolución. Los ortólogos humanos de proteínas de esta ruta de levaduras tienen funciones bien establecidas como supresores de tumores, indicando que los mecanismos que preservan la integridad genómica son similares a aquellos defectivos en tumores humanos (Hartwell LH et al., 1994).

Diversas mutaciones en algunos componentes de estas rutas de control están presentes en personas con síndromes asociados con la predisposición a cáncer, tales como Ataxia Telangiectasia (Painter and Young, 1980). Los pacientes con este síndrome sufren numerosos problemas que se suman a la alta frecuencia de aparición de tumores, lo cual enfatiza la importancia de estos puntos de control en la fisiología humana. Asímismo, se ha demostrado que varios genes de estas rutas son esenciales para la supervivencia celular y del organismo (Takai $\mathrm{H}$ et al., 2000). Este hecho extiende la relevancia de las mismas, y establece una conexión entre defectos genéticos en componentes de las rutas de control y las principales patologías que desafían la supervivencia del hombre, tales como cáncer, deficiencia inmune y desórdenes degenerativos. 


\section{1- ORGANIZACIÓN Y ARQUITECTURA DE LAS RUTAS DE CONTROL DE DAÑO AL ADN.}

En la levadura de gemación $S$. cerevisiae, la activación del mecanismo de control de daño al ADN resulta en arresto del ciclo celular durante las fases $\mathrm{G} 1$ o $\mathrm{G} 2$ en respuesta al ADN dañado (Lydall and Weinert, 1996). También ocurre una disminución en la velocidad de replicación del ADN y de la progresión del ciclo celular cuando el daño aparece durante la fase $S$ (Lowndes and Murguía, 2000). Este último punto de control se conoce como "punto de control de fase S". También el control de replicación funciona durante la fase S para arrestar el ciclo celular y evitar la aparición de orígenes tardíos de replicación cuando la replicación se halla bloqueada (Santocanale et al., 1998 ; Figura 2)

Al igual que otras vías de transducción de señales, la ruta de control de daño al ADN puede describirse como una cascada de señalización que consiste de sensores, transductores y efectores de la señal. Los sensores detectan anomalías estructurales en el ADN generando la señal de daño. Los transductores reciben y amplifican esta señal transmitiéndola a los efectores. Los efectores incluyen componentes de la maquinaria de reparación del ADN así como reguladores transcripcionales y del ciclo celular, siendo éstos los mediadores de la respuesta global al daño en el ADN. La organización de los componentes depende en gran parte del contexto, ya que ciertas moléculas tienen múltiples funciones en estas vías de transducción de la señal. 


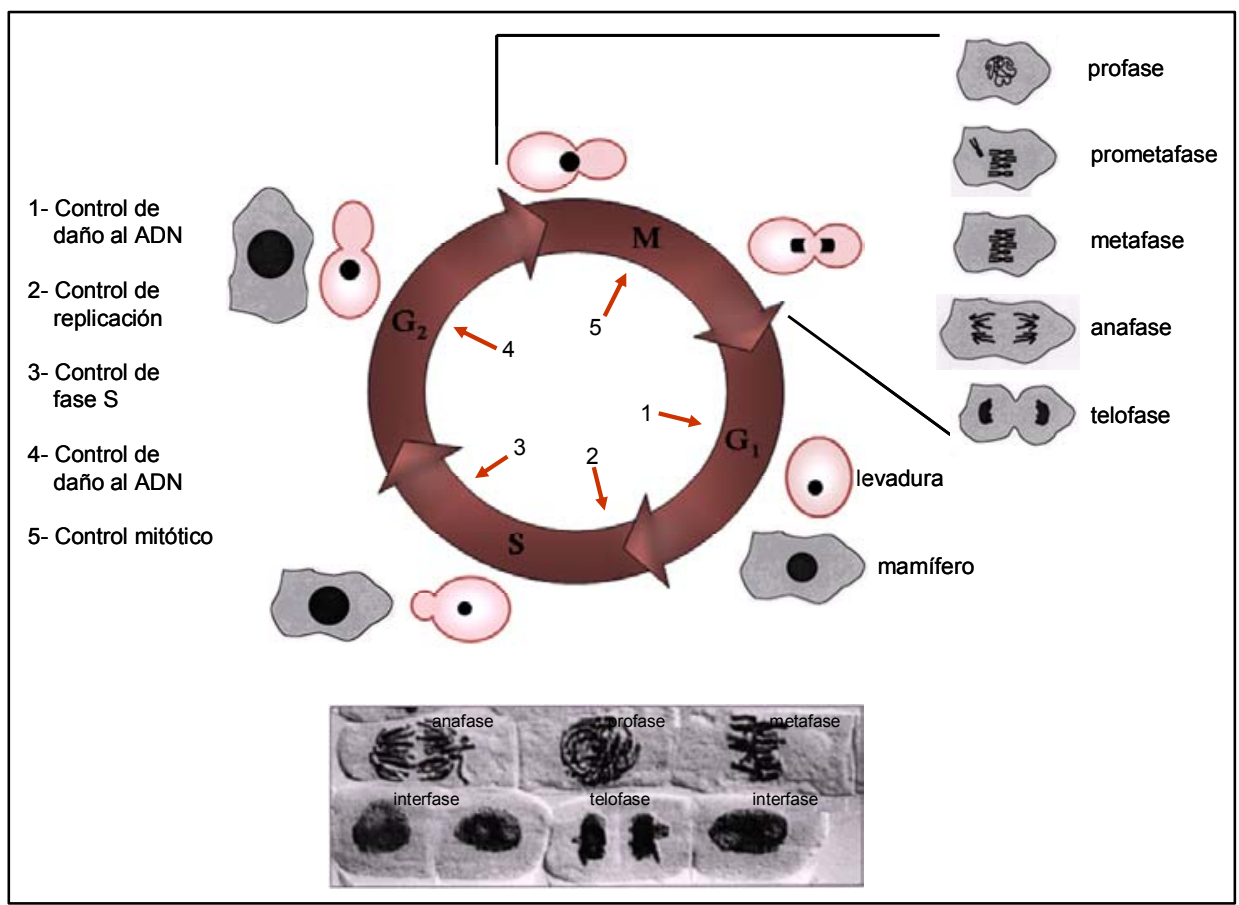

Figura 2. Equema representativo de los puntos de control que operan en eucariotas durante las distintas fases del ciclo celular.

Los controles de daño al ADN en G1 y G2 incluyen varias proteínas que funcionan coordinadamente como complejos multiproteicos. Se considera que estos complejos son los más cercanos a los verdaderos sensores del daño, cuya identidad aún no es conocida. La mayoría de estos complejos fueron identificados por estudios genéticos de amplio espectro realizados en levadura, donde defectos en los controles de daño al ADN causan hipersensibilidad a agentes genotóxicos. 
Existen varias teorías acerca de cuáles podrían ser las señales primarias que indiquen anomalías estructurales en el cromosoma o zonas con ADN no replicado. Sin embargo, hay un acuerdo general en la idea de que las proteínas de las rutas de control se activan o reclutan en los sitios con lesiones a través de su interacción con diferentes complejos ADN-proteína. De éstos, el más estudiado y caracterizado es el compuesto por los filamentos de proteína RPA (proteína de replicación A) en torno a zonas de ADN de simple hebra (ssADN; Branzei and Foiani, 2005). De todos modos, no está todavía claro si estos filamentos de RPA representan directamente la señal primaria o si simplemente son requeridos para conseguir una activación de las respuestas de control.

En levadura, el complejo "RFC-like" (Rad24-Rfc2-5) y el complejo "PCNA-like" (Rad17-Mec3-Ddc1) son esenciales para promover una respuesta al daño correcta, y se piensa que actúan en los primeros pasos de reconocimiento del daño en las fases $\mathrm{G} 1$ y G2, y también, aunque en menor extensión, durante la fase $S$ (Branzei and Foiani, 2006). Rad9p también funciona en esta ruta en cooperación con Mrc1p para promover la activación de las vías de control y la estabilidad del replisoma en respuesta a perturbaciones en la replicación (Alcasabas et al., 2001).

El punto de control de fase $S$ también requiere Rad9p, y a los complejos Rad24 y Rad17. Sgs1p es también parte del control de fase $S$ en una rama paralela a la de Rad24, pero no funciona en los controles de daño al ADN de G1 o G2 (Frei and Gasser, 2000). El control de replicación es independiente de Rad9p y de los complejos 
Rad24 y Rad17, e incluye a Rfc5p, Dpb11p, Drc1p, Pol2p y probablemente a otras proteínas que sensan el bloqueo en la replicación (Wang and Elledge, 1999). Ortólogos de las proteínas mencionadas anteriormente han sido identificados en muchas especies, incluyendo humanos. (Tabla 1, Figura 3)

El regulador central de estas vías en la levadura de gemación $S$. cerevisiae es Mec1p. Mec1p pertenece a una familia de proteina quinasas conocidas como PIKKs (phosphatydil-inositol 3-kinase like protein kinases; proteínas quinasas similares a la fosfatidil-inositol 3quinasa). Al igual que otros componentes de los controles de daño al $A D N$, Mec1p forma parte de un complejo multiproteico con Lcd1p que es reclutado en los sitios de daño en el ADN (Rouse and Jackson, 2002). Mec1p es parcialmente redundante en su función con otra PIKK llamada Tel1p (Nakada et al., 2003). Los ortólogos humanos de Mec1p y Lcd1p son ATR y ATRIP respectivamente. El ortólogo humano de Tel1p es ATM, y está principalmente implicado en detectar y responder a roturas de doble hebra (DSB, del inglés double strand breaks), mientras que ATR responde a una mayor variedad de lesiones, especialmente durante la replicación. La mutación de ATM en humanos da lugar al síndrome de Ataxia Telangiectasia, un síndrome de predisposición a cáncer, caracterizado por hipersensibilidad a genotoxinas que producen rotura de doble hebra (Abraham, 2001). 


\begin{tabular}{|c|c|c|c|}
\hline \multicolumn{4}{|c|}{ Proteínas de respuesta al daño al $\mathrm{ADN}$} \\
\hline Clase Funcional & S. Cerevisiae & S. Pombe & Mamíferos \\
\hline $\begin{array}{l}\text { Proteínas } \\
\text { "PCN-like" }\end{array}$ & $\begin{array}{l}\text { Rad17p } \\
\operatorname{Ddc1p} \\
\operatorname{Mec} 3 p\end{array}$ & $\begin{array}{l}\text { Rad1 } \\
\text { Rad9 } \\
\text { Hus1 }\end{array}$ & $\begin{array}{l}\text { hRAD1 } \\
\text { hRAD9 } \\
\text { hHUS1 }\end{array}$ \\
\hline $\begin{array}{l}\text { Proteínas } \\
\text { "RFC-like" }\end{array}$ & $\begin{array}{l}\operatorname{Rad} 24 p \\
\text { RFC2-5 }\end{array}$ & $\begin{array}{l}\text { Rad17 } \\
\text { RFC3 }\end{array}$ & $\begin{array}{l}\text { hRAD17 } \\
\text { RFC2-5 }\end{array}$ \\
\hline $\begin{array}{l}\text { Proteínas } \\
\text { BRCT }\end{array}$ & $\begin{array}{l}\operatorname{Rad} 9 p \\
\operatorname{Dpb} 11 \mathrm{p}\end{array}$ & $\begin{array}{l}\text { Crb2/Rhp9 } \\
\text { Cut5 }\end{array}$ & BRCA1?, 53BP1? \\
\hline $\begin{array}{l}\text { Proteínas } \\
\text { PIKK }\end{array}$ & $\begin{array}{l}\text { Meclp } \\
\text { Tellp }\end{array}$ & $\begin{array}{l}\operatorname{Rad} 3 \\
\text { Tel1 }\end{array}$ & $\begin{array}{l}\text { ATR } \\
\text { ATM }\end{array}$ \\
\hline $\begin{array}{l}\text { Subunidades } \\
\text { PIKK }\end{array}$ & Lcd1p/Ddc2p/Pie1p & $\operatorname{Rad} 26$ & ATRIP/hRAD26 \\
\hline $\begin{array}{l}\text { Kinasas } \\
\text { efectoras }\end{array}$ & $\begin{array}{l}\text { Chk1p } \\
\text { Rad53p }\end{array}$ & $\begin{array}{l}\text { Chk1 } \\
\text { Cds1 }\end{array}$ & $\begin{array}{l}\text { hCHK1 } \\
\text { hCHK2 }\end{array}$ \\
\hline
\end{tabular}

TABLA 1: Proteínas de respuesta al daño al ADN en eucariotas.

En respuesta a daño al ADN, varias proteínas se fosforilan en una forma dependiente de Mec1p/Tel1p. Estas incluyen a Rd53p y Chk1p, que son por sí mismas proteínas quinasas. Se considera que estas proteínas son las transductoras de la señal de daño al ADN. Rad53p y Chk1p regulan por fosforilación la actividad de efectores de la respuesta al daño (Branzei and Foiani, 2006). Los ortólogos humanos de Rad53p y Chk1p son respectivamente hCHK2 y hCHK1. Es interesante que hayan sido descriptas mutaciones en hCHK2 en cánceres de mama y en el síndrome de predisposición al cáncer de Li-Fraumeni (Varley and Haber, 2003). 


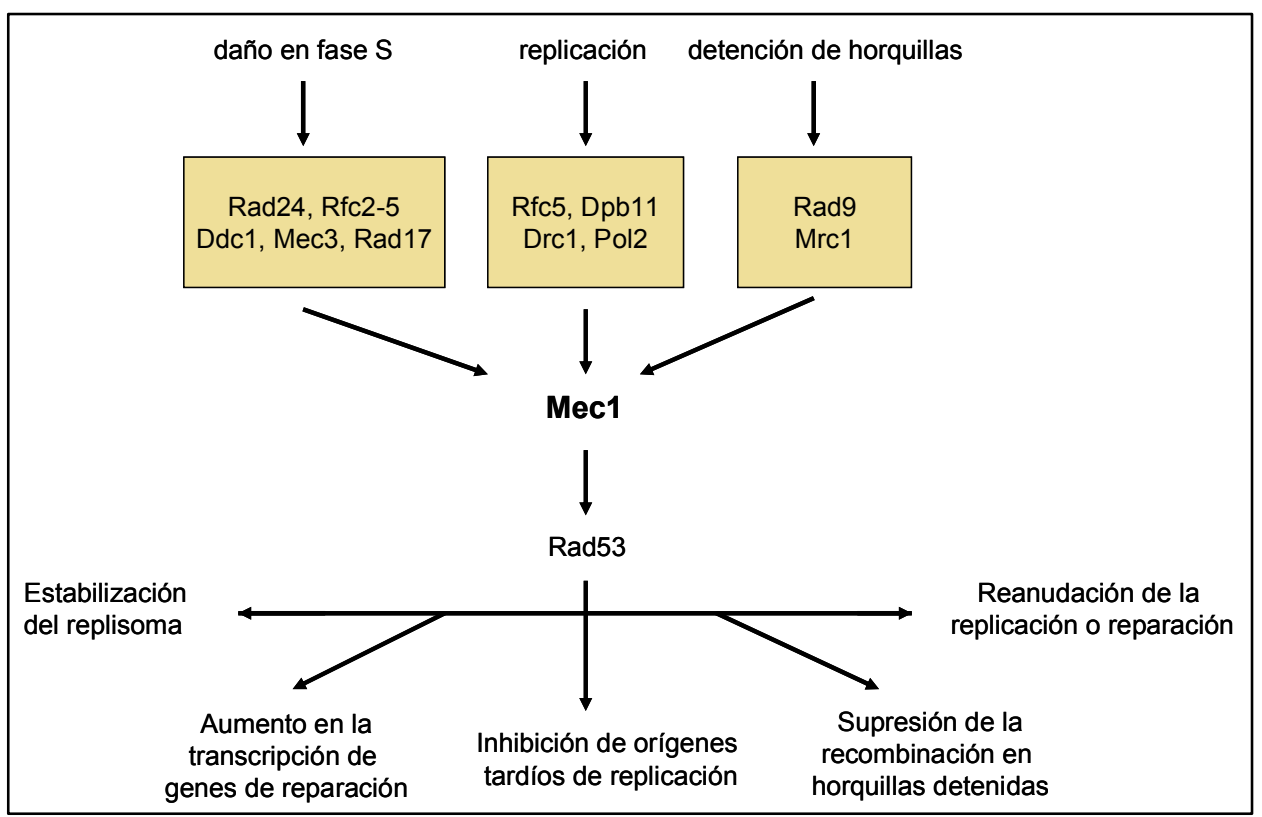

Figura 3. Respuestas de daño al $A D N$ en fase $S$ en levadura de gemación. Representación esquemática de los sensores, las vías que conducen a la activación de los puntos de control y los procesos regulados por la ruta de control activada. (Modificado a partir de Branzei y Foiani, 2006) 


\section{2- DETECCIÓN DEL DAÑO AL ADN}

Los complejos de las rutas de control anteriormente descritos son capaces de translocarse y asociarse a los sitios con daños en el ADN. Una vez aparecida una estructura aberrante, el complejo Rad24 dirige al complejo Rad17 sobre los sitios de daño (Kondo T et al., 2001). La carga del complejo Rad17 sobre las lesiones requiere el complejo Rad24, pero no el Mec1-Lcd1. De forma similar, la unión de Lcd1p al ADN asistiría la correcta carga de Mec1p independientemente de los complejos Rad24 y Rad17 (Rouse and Jackson, 2002).

Experimentos in vitro demuestran que el complejo Mec1-Lcd1 se une al ADN (Rouse and Jackson, 2002), por lo tanto este complejo podría considerarse como un sensor de daño al ADN bona-fide. Resulta interesante que los ortólogos humanos de Mec1p y Lcd1p, ATR y ATRIP, exhiban características similares.

Una vez reclutado en los sitios de daño, Mec1p fosforila y activa a la quinasa Rad53p. La activación de Rad53p por Mec1p requiere los complejos Rad24 y Rad17 (de la Torre-Ruiz et al., 1998). Sin embargo éstos no se requieren para cargar Mec1p en sitios de daño ni para la fosforilación de algunos sustratos como la histona H2A (Downs et al., 2000) o el mismo Lcd1p (Paciotti V et al., 2000). Así, estos complejos Rad24 y Rad17 podrían asistir el reclutamiento de otras dianas de Mec1p para una fosforilación eficiente y podrían requerirse para mantener a Mec1p en una forma activa. Alternativamente, estos complejos podrían sólo reclutarse para un 
subgrupo de lesiones más difíciles de reparar, aunque no hay evidencias que permitan discernir entre estas tres posibles acciones.

Los agentes que dañan el ADN producen una amplia variedad de lesiones. Resulta interesante que todas ellas disparan una eficiente respuesta de daño al ADN y la translocación de los complejos de control en los sitios de daño. Por lo tanto debería existir un "adaptador" para el reconocimiento del daño que reclute las proteínas de estas rutas en las lesiones. Alternativamente, podría existir un grupo de factores que procesara las lesiones hasta una estructura común que pudiera ser reconocida por estos complejos.

Sin importar la verdadera naturaleza del sensor/adaptador del daño al $A D N$, la evidencia disponible sugiere que, después de un daño al $A D N$, se genera una estructura intermedia que es reconocida por los complejos de la ruta de control. Esta estructura no es actualmente conocida probablemente a causa de su naturaleza transitoria. Un buen candidato podría ser una estructura de ADN de simple hebra (ssADN) por distintas razones: 1) el ADN de simple hebra es generado durante diferentes procesos de reparación; 2) el ssADN se encuentra normalmente cubierto en la célula por la proteína Rpa, y mutantes que carecen de dicha proteína exhiben controles de daño al ADN defectivos; y 3) los complejos Mec1-Lcd1 y RPA pueden ser purificados a partir de extractos de células por medio de sSADN (Alani et al., 1992).

Estudios de inmunofluorescencia en mamíferos han revelado que las proteínas de las rutas de control se localizan en sitios discretos o focos dentro del núcleo luego de un daño al ADN. Estas incluyen 
ATR, ATRIP, hRAD17 (Zou et al., 2002), el complejo MRE11-RAD50NBS1 (Bartek and Lukas, 2007), hCHK2 (Melchionna R et al., 2000), BRCA1 (Scully $R$ et al., 1997) y algunos factores de reparación tales como proteínas del sistema de reparación por escisión de nucleótidos y las proteínas RAD51 y RAD52 implicadas en recombinación homóloga (Haaf $\mathrm{T}$ et al., 1995). No es clara la naturaleza exacta de estos focos, pero la evidencia sugiere que corresponden a los sitios de daño al ADN. Utilizando técnicas que permiten la generación de daño al ADN por radiación en partes discretas del núcleo, se ha reportado que las proteínas antes mencionadas sólo se acumulan en las zonas irradiadas. Estas interacciones en los sitios de daño parecen ser dinámicas y no irreversibles, ya que los complejos son intercambiados entre los focos en forma dependiente de tiempo. Este carácter es esencial para una función coordinada entre los complejos de las rutas de control y reparación.

La detección del daño al ADN durante la fase-S parece ser realizada principalmente por los componentes de la misma maquinaria de replicación del ADN. Estos incluyen Pol2p, Rfc5p, Dpb11p, y Drc1p. Además, el control de fase $S$ que detiene la progresión del ciclo celular durante esta fase involucra dos ramas parcialmente redundantes: una dependiente de los complejos Rad24/Rad17, y otra que requiere Sgs1p (Myung and Kolodner, 2002). Generalmente se acepta que el procesamiento de lesiones primarias por la maquinaria de replicación genera estructuras que podrían ser detectadas por las proteínas de control. Alternativamente, componentes de la maquinaria de replicación podrían enviar una señal cuando 
encuentran lesiones en el ADN. Como resultado del procesamiento del daño por la maquinaria de replicación/control, podría aparecer un alto número de intermediarios de replicación y recombinación, produciéndose un estrés replicativo que interfiere con la duplicación del ADN y genera reordenamientos genómicos. Para prevenir estos efectos, es necesaria la activación de las vías de reparación por recombinación. De hecho, mutantes de levadura en Mec1p y Tel1p acumulan mayores niveles de reordenamientos genómicos que otros mutantes con controles defectivos.

Las lesiones por roturas en la doble hebra (DSB) son reconocidas en mamíferos por el complejo multifuncional MRE11-RAD50-NBS1 (MRN; Bartek and Lukas, 2007). Las evidencias que apoyan al complejo MRN como sensor de DSB incluyen: 1) el reconocimiento directo del ADN por la subunidad RAD50; 2) el hecho de que NBS1 es requerido para recultar ATM a los sitios con DSB; 3) la naturaleza hipomórfica del mutante RAD50 que estimula constitutivamente la señalización por ATM; 4) el rápido ensamblaje de NBS1 en los sitios de DSB; y 5) el hecho de que el reclutamiento inicial del complejo MRN en los sitios de DSB es independiente de cualquier otra proteína de respuesta al daño en el ADN (Figura 4). La interacción inicial de MRN con la lesión de DSB es transitoria (Lukas C et al., 2003), y sirve para reclutar la quinasa ATM a través de su interacción con el dominio C-terminal de NBS1. Tras la formación del complejo MRN-ATM en los sitios de daño, se disparan dos eventos que culminan en el reordenamiento local del ADN y de la cromatina que rodea al sitio dañado. Estos eventos son esenciales para la reparación y para iniciar las señales de control. 
Primero, ATM fosforila la cola C-terminal de la histona $\mathrm{H} 2 \mathrm{~A}$, lo cual a su vez sirve como señal de unión para la proteína MDC1, con funciones de mediador/adaptador. MDC1 combina dos características importantes: se une a la histona $\mathrm{H} 2 \mathrm{~A}$ fosforilada (Stucki $\mathrm{M}$ et al., 2005) e interacciona físicamente con la subunidad NBS1 del complejo MRN (Lee AC et al., 2005). Además de MDC1, se conocen otras proteínas que interaccionan con la cromatina en las cercanías del DSB, como 53BP1, BRCA1, el complejo MRN e incluso ATM. El aumento local de concentración de ATM es importante para estimular la fosforilación de la quinasa CHK2.

Segundo, MRN y ATM son esenciales para iniciar la resección del DSB y generar la formación de $\operatorname{ssADN}$, la estructura intermedia crítica para la reparación por recombinación homóloga y para la señalización dependiente de ATR (Adams KE et al., 2006) 


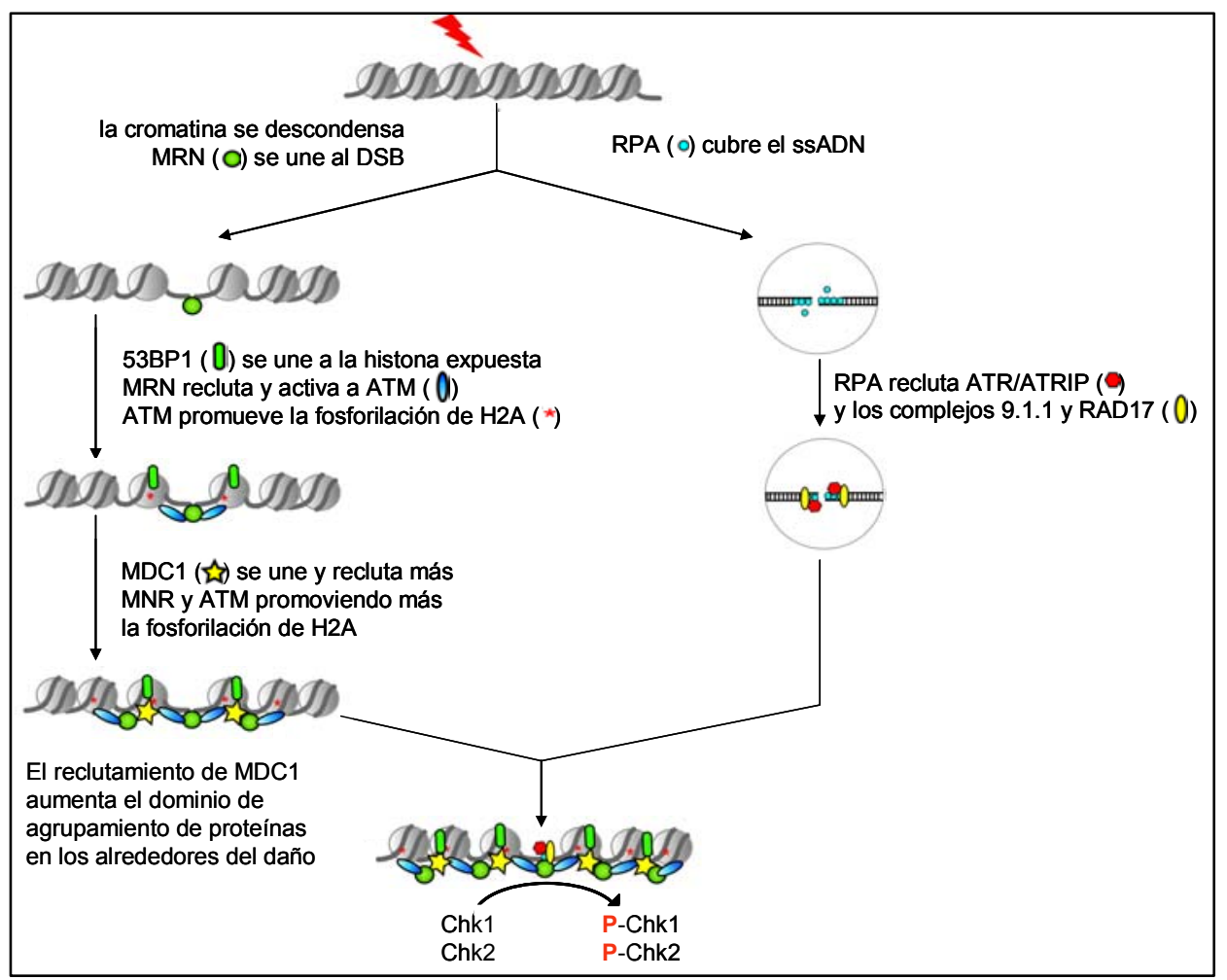

Figura 4. Modelo de detección y señalización de roturas de doble banda en mamíferos (Adaptado de Su TT, 2006). 


\subsection{TRANSDUCCIÓN DE LA SEÑAL DE DAÑO AL ADN A LOS EFECTORES.}

Una vez generada la señal de daño al ADN por las proteínas de las rutas de control, ésta se transduce a través de una cascada de fosforilación que es común a todos los controles de daño al ADN sin importar el estadio del ciclo celular. En levadura están involucradas cuatro proteína quinasas: Mec1p, Rad53p, Dun1p y Chk1p (Nyber et al., 2002).

Mec1p es el regulador central de esta cascada de proteína quinasas. Mec1p está implicada en la detección del daño al ADN, y también funciona como un transductor controlando el estado de fosforilación de un grupo de proteínas respuesta al daño. Entre éstas se incluyen algunos componentes de la ruta de control como Rad53p, Rad9p y Lcd1p. La razón de estos eventos de fosforilación podría ser el reclutamiento de sustratos que actúen por debajo de la ruta de control con el fin de que sean fosforilados eficientemente. Así, la activación de Rad53p por Mec1p requiere la interacción de Rad53p con Rad9p, que actúa como adaptador. Esta interacción, que es inducible por daño al ADN, ocurre después de la fosforilación de Rad9p por Mec1p (Gilbert et al., 2001). Otra diana próxima a Mec1p es la histona H2A (Downs et al., 2000). En este caso, la fosforilación de H2A por Mec1p induce una alteración de la cromatina en la vecindad de la lesión, con el fin de facilitar la reparación.

Rad53p y Dun1p son también proteína quinasas activadas por daño al ADN o por una parada en la replicación, y funcionan con 
posterioridad a Mec1p. Una vez que está activa, la serina/treonina quinasa Rad53p se autofosforila en ausencia de otras proteínas (Branzei and Foiani, 2006). Así, la formación de un complejo con Mec1p es requerida sólo para la activación inicial de la quinasa Rad53p. Rad53p activa luego transduce la señal y activa a la quinasa Dun1p. No existe demasiada información sobre los efectores cuya función se ve modulada por estas quinasas, pero en el caso de Rad53p éstos incluyen al regulador transcripcional Swi6p, que controla la expresión de genes de ciclina en la transición G1/S (Sidorova and Breeden, 1997), la quinasa Cdc5p, implicada en la salida de mitosis (Smits et al., 2000), y la subunidad beta del complejo pola/primasa, requerido para la iniciación de la síntesis del ADN (Pellicioli et al, 1999). Otros posibles efectores de Rad53p son Rnr3p, Nup1p, Nup2p y Nup60p, dado que se ha demostrado que estas proteínas son fosforiladas tras tratamiento con MMS en sitios consenso de fosforilación de esta quinasa (Smolka et al., 2007).

Dun1p define una rama por debajo de Rad53p que está involucrada en la transcripción y reparación en respuesta a daño al ADN. Su actividad se requiere para la expresión del gen $R N R$ mediante la regulación de la función del represor transcripcional Ctr1p (Zhou and Elledge, 1993). Los genes $R N R$ codifican subunidades de la ribonucleótido reductasa, responsable de mantener en balance los niveles de dNTPs cuando son requeridos para la reparación o la replicación del $A D N$. Además, la actividad ribonucleótido reductasa es regulada posttranscripicionalmente por el inhibidor Sml1p (Branzei and Foiani, 2006). Recientemente se ha demostrado que Dun1p fosforila a Sml1p, promoviendo su degradación (Zhao X et al., 2001). 
Así pues, Dun1p parece ser el paso final en la vía de Rad53p y Mec1p que regula la disponibilidad de dNTPs.

Tal como se mencionó anteriormente, todas estas quinasas presentan ortólogos en humanos (Tabla 1). Estas muestran roles equivalentes en las funciones de control a sus contrapartes de levadura. Así, mutaciones en ATR sensibilizan a las células de mamíferos a todas las formas de daño al ADN (Wright et al., 1998). Las funciones de ATR se superponen parcialmente con las de la proteína quinasa ATM, el ortólogo humano de Tel1p de levadura. La evidencia disponible encaja con un modelo en el cual ATM controla principalmente las respuestas a radiación ionizante, y ATR responde a otros tipos de daño. Sin embargo este modelo demanda mucho más soporte experimental.

ATR y ATM controlan las subsecuentes respuestas celulares al daño al ADN regulando la función de las quinasas hCHK1 y hCHK2, los ortólogos humanos de Chk1p y Rad53p de levadura respectivamente. hCHK2 es fosforilado por daño al ADN en una manera dependiente de ATR/ATM. La actividad de la quinasa hCHK1 no aumenta en respuesta al daño al ADN o a bloqueos replicativos. Sin embargo, es fosforilada tras radiación ionizante (Liu et al., 2000). Ratones mutantes en hCHK1 mueren en estadios tempranos durante la embriogénesis, de manera similar que los mutantes en ATR. Así, el hecho de que ratones mutantes en ATR y hCHK1 muestren fenotipos similares, y que ATR controle la fosforilación de hCHK1, sugieren que hCHK1 es un efector clave en la vía de ATR. 


\subsection{EVENTOS POSTERIORES A LA ACTIVACIÓN DE LAS RUTAS DE CONTROL: RECUPERACIÓN Y ADAPTACIÓN.}

La respuesta de los mecanismos de control a la señal primigenia es amplificada a una respuesta global que incluye una disminución en la progresión del ciclo celular, reparación del ADN, o estabilización de las horquillas de replicación. En levaduras, la quinasa Mec1p juega un rol crucial mediando la progresión de ciclo en respuesta a un daño o a problemas replicativos, principalmente a través de la inducción de la cascada de fosforilaciones que se describió previamente. Así, la activación de la ruta de control estimula la transcripción de diferentes factores de reparación y ajusta los mecanismos que promueven la estabilización de las horquillas de replicación y/o la reanudación de la replicación.

Tras tratamiento genotóxico, Rad53p junto con Mec1p son requeridos para fosforilar Dun1p, una proteína quinasa que controla varios genes inducibles por daño al $A D N$, y $\operatorname{Cdc5p}$, una quinasa "polo-like" que ha sido implicada en la regulación de la mitosis. El mecanismo empleado por Dun1p para inducir la transcripción de genes de reparación es probablemente muy diverso y no está comprendido en su totalidad pero, como se ha mencionado, involucra el aumento en los niveles de dNTPs y la degradación de Sml1p, un inhibidor de la ribonucleótido reductasa.

Cuando las horquillas de replicación encuentran un daño, éstas se detienen y se activa el control de replicación. Esta activación es particularmente importante para estabilizar el replisoma y las 
horquillas detenidas, inhibiendo el disparo de los orígenes tardíos de replicación y conteniendo la actividad de las enzimas de recombinación en estos puntos. En ausencia de control de replicación, como en el caso de mutantes rad53, el replisoma se disocia y las horquillas detenidas degeneran acumulando zonas con intervalos o "gaps" y moléculas hemireplicadas (Branzei and Foiani, 2006).

Una vez removido el bloqueo en la replicación, se piensa que las horquillas estabilizadas por Rad53 reanudan la replicación, y existe evidencia que sugiere que componentes del mecanismo de control de replicación estarían altamente implicados en la recuperación de estas horquillas.

Junto a su función en mediar la integridad de las horquillas de replicación y en reanudar la replicación, la maquinaria de control parece ser importante en la reparación por recombinación homóloga de DSBs en G2 a través de la quinasa dependiente de ciclina Cdk1p. Además, la fosforilación de la histona H2A es sumamente importante para una eficiente reparación de DSBs, quizás porque promueva el reclutamiento de diferentes factores de las vías de control y reparación.

En respuesta a un daño al ADN, la fosforilación de Rad53p y Chk1p dependiente de Mec1p promueve la reparación del ADN a través del arresto de ciclo previo a la entrada en mitosis, previniendo la segregación de cromátidas dañadas. La recuperación del arresto de ciclo ocurre cuando se ha completado el proceso de reparación y 
cesa la activación del mecanismo de control. Pero cuando los intentos de reparación del ADN fallan, la célula se "adapta" en presencia del daño y reanuda el ciclo celular (Sandell and Zakian, 1993). Se supone que este proceso de adaptación provee a la célula la oportunidad de reparar el daño en el ciclo celular subsiguiente. La inactivación de Rad53p sería un prerrequisito para la adaptación, requiriéndose para esta respuesta la defosforilación de Rad53p por las fosfatasas Ptc2p y Ptc3p, tras la activación de estas últimas por la quinasa CK2p (Guillemain G et al., 2007). 


\section{LA RUTA DE CONTROL TRADUCCIONAL $Y$ SUS IMPLICACIONES EN CÁNCER.}

La proliferación celular se regula a través de un delicado balance entre la expresión de genes que promueven o inhiben el crecimiento. Esta regulación ocurre a múltiples niveles, como la transcripción, la poliadenilación del $A R N$, el tráfico núcleo-citoplasmático del $A R N$, la traducción de los ARNm y la estabilidad de los mismos. Aunque la regulación transcripcional es crucial para la proliferación celular, el control de la expresión génica depende también de la traducción selectiva de los ARNm. El control traduccional proporciona a la célula una herramienta muy sofisticada para modular la producción de proteínas clave en un modo independiente del núcleo celular. En este sentido, cada vez existen más datos que sugieren que alteraciones en esta regulación contribuyen a la pérdida del control del ciclo celular y a la aparición de tumores (Clemens, 2004).

El control de la traducción ocurre fundamentalmente a nivel de la iniciación de la síntesis de proteínas. Dos fases en el proceso de iniciación de la traducción parecen estar implicados en la transformación celular: 1) La unión del ARNt iniciador a la subunidad menor del ribosoma , mediado por el factor de iniciación elF2 y 2) La unión de la subunidad menor del ribosoma al extremo $5^{\prime}$ del ARNm mediado por elF4E y sus factores asociados. Ambas fases de iniciación de la síntesis de proteínas parecen ser relevantes en la regulación del crecimiento celular, ya que tanto elF2 como elF4E se encuentran a menudo sobre-expresados en carcinomas de pecho, 
tiroides y linfomas no Hogdkins así como en otros tumores (Rosenwald, 2004).

El papel de elF4E y alguno de sus factores asociados en la iniciación y progresión tumoral está bien establecido. Se conoce por ejemplo que la sobre-expresión de elF4E induce la transformación de células NIH-3T3 (Lazaris-Karatzas et al., 1990). La implicación de elF2 en la tumorogénesis, aunque menos estudiada, también está bien fundamentada. elF2 se regula negativamente por fosforilación de su subunidad $\alpha$ en la serina 51 . Esta fosforilación ocurre también en respuesta a la privación de factores de crecimiento, nutrientes, diferentes situaciones de stress (osmótico, oxidativo, altas temperaturas, etc) e infecciones virales (Clemens, 2001). La fosforilación resulta en una disminución de la actividad del factor elF2 y en la subsecuente reducción en la síntesis de proteínas. Las evidencias disponibles que asignan un papel a la fosforilación de elF2 en la oncogénesis son las siguientes: 1) la expresión de un inhibidor de la fosforilación de elF2 o el mutante no fosforilable de elF2 S51A inhiben la apoptosis (Srivastava et al., 1998), 2) la expresión del mutante no fosforilable de elF2 S51A induce un fenotipo transformado (Srivastava et al., 1998) y 3) la citotoxicidad de algunos agentes antitumorales en fase experimental se media a través de la fosforilación de elF2 $\alpha$ (Aktas et al., 1998). En eucariotas superiores, el estado de fosforilación de elF2 $\alpha$ se controla por al menos cuatro serina/treonina proteína quinasas: HRI, GCN2, PKR y PERK. De todas ellas, probablemente la más relevante en relación con la transformación maligna es la proteína quinasa inducible por interferón PKR. Así, se han detectado reordenamientos genéticos en 
el locus de PKR para un tipo de leucemias linfocíticas murinas. Por otro lado, la expresión de mutantes dominantes negativos de PKR produce un fenotipo transformado en fibroblastos murinos, y, la expresión de PKR induce apoptosis o estimula la apoptosis inducida por otros agentes (Jagus et al., 1999). Estas evidencias, junto con el hecho de que el tratamiento con interferon- $\gamma$. induce la actividad de PKR, han permitido proponer que PKR funciona como un gen supresor de tumor (Jagus et al., 1999).

Las rutas de control de la traducción están conservadas en todos los organismos eucariotas, entre ellos la levadura Saccharomyces cerevisiae. Al igual que en mamíferos, $S$. cerevisiae regula la iniciación de la síntesis de proteínas a través del factor elF4E, codificado por el gen $C D C 33$, y de la fosforilación de elF2 $\alpha$ (Sui2p en levadura), siendo este último el mecanismo regulador más relevante. En levadura, la fosforilación de elF2 controla un programa de expresión génica que adapta a la célula en respuesta al ayuno de nutrientes. A diferencia de mamíferos, $S$. cerevisiae sólo contiene una quinasa de elF2 $\alpha$, codificada por el gen GCN2. Gcn2p controla la traducción selectiva de un factor de transcripción denominado Gcn4p (Hinnebusch, 2005).

La traducción de GCN4 es controlada por una ruta reguladora llamada ruta de control general de nutrientes (GCN, de General Control of Nutrients), que se activa por el ayuno de aminoácidos o purinas (Hinnebusch 1997), limitación de glucosa o crecimiento en etanol (Yang et al. 2000), alta salinidad (Goossens et al. 2001), tratamiento con el agente alquilante metil metanosulfonato (Natarajan 
et al. 2001) y tratamiento con rapamicina (Valenzuela et al. 2001). En respuesta a la escasez de nutrientes, $S$. cerevisiae activa la proteina quinasa Gcn2p, que fosforila la subunidad $\alpha$ de elF2 en su serina 51 (Hinnebusch, 2005). elF2 es responsable de llevar el metionil-ARNt iniciador cargado (Met-ARNti ${ }^{\mathrm{Met}}$ ) a la subunidad pequeña (40S) del ribosoma en el primer paso de la iniciación de la traducción. Este ARNt cargado se une al ribosoma en forma de un complejo ternario que contiene el propio Met-ARNti ${ }^{\text {Met }}$ y GTP y luego se libera en forma de complejo binario elF2-GDP. El factor elF2B es el encargado de reciclar el elF2-GDP de nuevo en elF2-GTP. La fosforilación de elF2 $\alpha$ transforma a elF2-GDP de sustrato a inhibidor de elF2B, lo que impide la formación del complejo ternario (Figura 5). Esta reducción de la cantidad de complejo ternario no es responsable de una inhibición sustancial de la síntesis proteica, pero sí del aumento de la traducción de GCN4 (Hinnebusch, 1997). elF2B está formado por cinco subunidades, codificadas por cuatro genes esenciales y uno no esencial: GCN3. Gcn3p es la subunidad reguladora, así que un mutante $\Delta g c n 3$ es incapaz de activar la traducción de GCN4 en condiciones de ayuno ya que elF2B se hace resistente a la inhibición por por elF2 $\alpha$ fosforilado (Bushman et al. 1993).

La regulación traduccional de GCN4 se consigue a través de cuatro marcos abiertos de lectura localizados en la región 5'- no traducida del ARNm de GCN4 (uORFs, de untranslated Open Reading Frames), que lo hacen extremadamente sensible a los niveles de elF2. Cuando no existe limitación de nutrientes, los niveles de elF2 activo son elevados y las uORFs bloquean la traducción de GCN4. En células con ayuno de aminoácidos se produce un acúmulo de 
ARNt descargados que activan a Gcn2p. La fosforilación de elF2 en su subunidad $\alpha$ por Gcn2p, disminuye los niveles de elF2 activo que alivian la inhibición de las uORFs, favoreciéndose la traducción selectiva de GCN4 a la vez que se produce un bloqueo general de la traducción (Hinnebusch and Natarajan, 2002). Así, los altos niveles de la proteína Gcn4p activan la expresión de genes que codifican proteínas de las rutas de biosíntesis de aminoácidos.

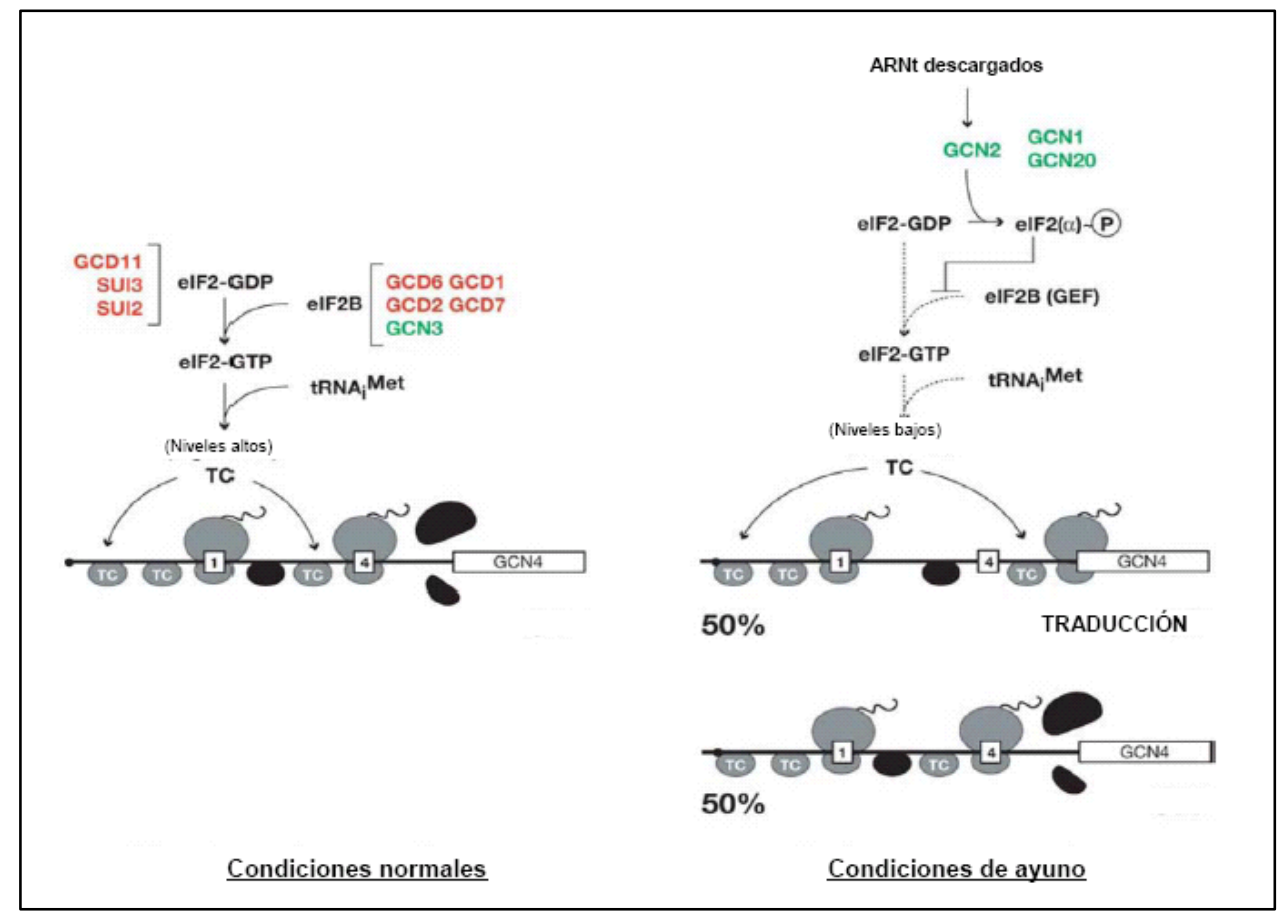

Figura 5. Modelo para el control traduccional de GCN4 mediante la fosforilación de elF2 $\alpha$ por Gcn2p (Modificado a partir de Hinnebusch, 2005) 
Existen ciertas formas de daño al ADN que son capaces de activar la ruta de control general de nutrientes aun en ausencia de ayuno de aminoácidos (Natarajan $\mathrm{K}$ et al., 2001). Recientes hallazgos en nuestro laboratorio indican que la quinasa Gcn2p contribuye al mecanismo de control de daño al ADN en S. cerevisiae (MenachoMárquez et al., 2007), y resultados similares se han obtenido en estudios de ciclo celular en levadura de fisión tras radiación ultravioleta (Tvegård T et al., 2007). En células de mamíferos, las quinasas GCN2 y PERK actúan cooperativamente regulando la fosforilación de elF2 $\alpha$ en condiciones de estrés de retículo endoplásmico (Hamanaka $R$ et al., 2005). Este aumento en la fosforilación de elF2 $\alpha$ se ha asociado con la activación de p53 y el concomitante arresto de ciclo (Zhang F et al., 2006). Así, el papel de las rutas de control traduccional en la regulación de los controles de ciclo parece estar conservado en la evolución. 


\section{OBJETIVOS}



1- Caracterización de las respuestas celulares activadas por el tratamiento con beta-lapachona en la levadura S. cerevisiae.

2- Identificación del mecanismo de control de ciclo activado por betalapachona.

3- Identificación de las dianas moleculares responsables de estos efectos. 



\section{MATERIALES Y MÉTODOS}





\section{CULTIVO Y MANIPULACIÓN CELULAR}

\subsection{Bacterias}

Para el cultivo y manipulación de bacterias se siguieron métodos estándar (Sambrook and Russell, 2001). El medio de cultivo utilizado ha sido:

Medio LB: (Luria Bertani)

Extracto de levadura $\quad 0,5 \%$

Triptona-Peptona $\quad 1 \%$

Cloruro sódico $\quad 1 \%$

Bacto-Agar (si es preciso) $\quad 2 \%$

En caso de necesitarlo suplementamos el medio con Ampicilina (AppliChem) a una concentración final de $100 \mu \mathrm{gr} / \mathrm{ml}$.

\subsection{Levaduras}

Las cepas de levadura utilizadas en la presente tesis doctoral se muestran en la Tabla 2. El cultivo y manipulación de levaduras se llevó a cabo siguiendo métodos estándar (Prinz W, 2003). Los medios de cultivo utilizados han sido:

Medio YPD: (Yeast extract - Peptone - Dextrose, medio complejo)

Extracto de levadura $\quad 1 \%$

Peptona 2\%

Glucosa (dextrosa) 2\% 
En los casos en que la fuente de carbono fuera otra diferente a glucosa, ésta se ha reemplazado por la cantidad correspondiente $(2 \%)$ de galactosa, rafinosa o etanol.

Medio SD: (Synthetic Defined, medio mínimo)

Yeast Nitrogen Base sin aminoácidos (Difco) 0,7\%

Glucosa

$2 \%$

Ácido Succínico (ajustado a pH 5,5 con Tris) 0,59\%

Para el crecimiento de cepas auxótrofas suplementamos el medio con las siguientes concentraciones de aminoácidos y bases nitrogenadas:

Aminoácidos (excepto Histidina) $100 \mu \mathrm{gr} / \mathrm{ml}$

Histidina y bases nitrogenadas $30 \mu \mathrm{gr} / \mathrm{ml}$

En ambos casos se añadió Bacto-Agar (Difco) al 2\% para la preparación de medios sólidos.

\section{ENSAYOS DE CRECIMIENTO EN MEDIO SÓLIDO ("GOTEOS")}

Realizamos diluciones decimales seriadas de cultivos líquidos de distintas cepas de levadura y transferimos aproximadamente $3 \mu \mathrm{l}$ de cada dilución, con la ayuda de un replicador (Sigma), a placas de medio sólido con las condiciones diferenciales a estudiar. Posteriormente incubamos las placas entre 2 y 5 días. En el análisis del crecimiento tuvimos en cuenta tanto la mayor dilución a la cual aún se observa crecimiento como el tamaño de colonia. 


\section{ENSAYOS DE CRECIMIENTO EN MEDIO LÍQUIDO}

La capacidad de crecimiento de cultivos de levadura en medio líquido se cuantificó a lo largo del tiempo midiendo la densidad óptica a 660 $\mathrm{nm}$ de dichos cultivos (Burke et al. 2000).

Los cultivos realizados en microplacas se registraron mediante un analizador Bioscreen C (Thermo Labsystems). Medimos la densidad óptica con un filtro de banda ancha (420-580 nm) para reducir la contribución del medio a la lectura de absorbancia. La temperatura de crecimiento fue $28,5^{\circ} \mathrm{C}$ y los cultivos fueron sometidos a agitación vigorosa durante los 20 segundos previos a la lectura de absorbancia. Esta lectura se llevó a cabo cada 20 minutos durante las 24, 48 ó 72 horas que duró el experimento.

En todos los casos se utilizaron cultivos de levadura en fase exponencial de crecimiento (absorbancia a $660 \mathrm{~nm}$ entre 0,5 y 1 ), los cuales se diluyeron veinte veces en cada una de las condiciones analizadas. Con el propósito de simplificar las gráficas, las curvas de crecimiento con distintas dosis de droga fueron representadas como porcentaje de crecimiento en función de la dosis, calculando la relación de absorbancia a cada dosis respecto del control sin tratar. Los cálculos de IC50 se realizaron utilizando la función "Pharmacology" del programa Sigma Plot.

\section{ENSAYOS DE VIABILIDAD}

Para determinar el porcentaje de células viables en un cultivo líquido de levaduras, cuantificamos la densidad celular mediante la absorbancia a $660 \mathrm{~nm}$, realizamos diluciones seriadas hasta tener una densidad de 1000 células por $\mathrm{ml}$ y plaqueamos $0,2 \mathrm{ml}$ en placas 
de YPD. Dos días después cuantificamos el número de colonias visibles.

\section{ENSAYOS DE SINCRONIZACIÓN CELULAR.}

- Sincronización con Factor $\alpha$.

Las células MAT $\alpha$ se arrestan en fase $\mathrm{G} 1$ de su ciclo celular en respuesta a la feromona de apareamiento Factor $\alpha$ (Sigma). Para realizar los ensayos de sincronización diluimos un cultivo en fase exponencial de crecimiento hasta una densidad óptica a $660 \mathrm{~nm}$ de 0,15-0,2. Posteriormente añadimos Factor $\alpha$ a una concentración de $4 \mu \mathrm{gr} / \mathrm{ml}$. Para monitorizar el arresto en fase G1 del ciclo, cada 15 minutos (pasada la primer hora y media de tratamiento) se tomó una muestra de cultivo y se cuantificó el número de células arrestadas (células normales sin yema y células con morfología de pera denominada shmoo). Cuando el número de células sin yema y shmoo alcanzó el 95\% como mínimo se consideró arrestado el cultivo y se llevó a cabo el tratamiento correspondiente.

\section{- Sincronización con Hidroxiurea.}

Las células de levadura se arrestan en fase $S$ de su ciclo celular por tratamiento con hidroxiurea (Sigma) debido a la inhibición del enzima ribonuclétido reductasa (Szekeres et al., 1997). Para realizar la sincronización en fase $S$, diluimos un cultivo en fase exponencial hasta una densidad óptica a $660 \mathrm{~nm}$ de 0,2 y añadimos hidroxiurea hasta una concentración de 0,2M. Para monitorizar el arresto se tomó muestra de cultivo y se cuantificó el número de células arrestadas (arresto visualizado como dos células de igual tamaño 
unidas por un único núcleo). Cuando el número de células arrestadas fue mayor al 95\% se consideró arrestado el cultivo.

- Sincronización con Nocodazol.

El nocodazol es un fármaco anti-mitótico que inhibe la polimerización de unidades libres de tubulina al unirse al residuo de arginina de la subunidad beta-tubulina, produciendo en levadura un arresto en la fase G2 del ciclo celular (Wang and Burke, 1995).

Para realizar la sincronización en fase $\mathrm{G} 2$, diluimos un cultivo en fase exponencial hasta una densidad óptica a $660 \mathrm{~nm}$ de 0,2 y añadimos $2 \mu \mathrm{g} / \mathrm{ml}$ de nocodazol (Sigma). Para monitorizar el arresto (transcurrida la primer hora y media de tratamiento) se tomó muestra de cultivo y se cuantificó el número de células arrestadas (arresto visualizado como dos células unidas, de igual tamaño). Cuando el número de células arrestadas fue mayor o igual al $90 \%$ se consideró arrestado el cultivo.

- Liberación del arresto.

Para cuantificar la reentrada de las células en el ciclo celular, el cultivo arrestado se lavó con suero salino $(\mathrm{NaCl}$ al $0,9 \%$ en agua destilada) dos veces y se resuspendió en el medio de cultivo correspondiente sin la droga utilizada para el arresto. A diferentes tiempos se tomó $1 \mathrm{ml}$ de cultivo que se fijó con $75 \mu \mathrm{L}$ de formaldehído. En el microscopio se cuantificó el número de células sin y con yema que presentaba el cultivo. 


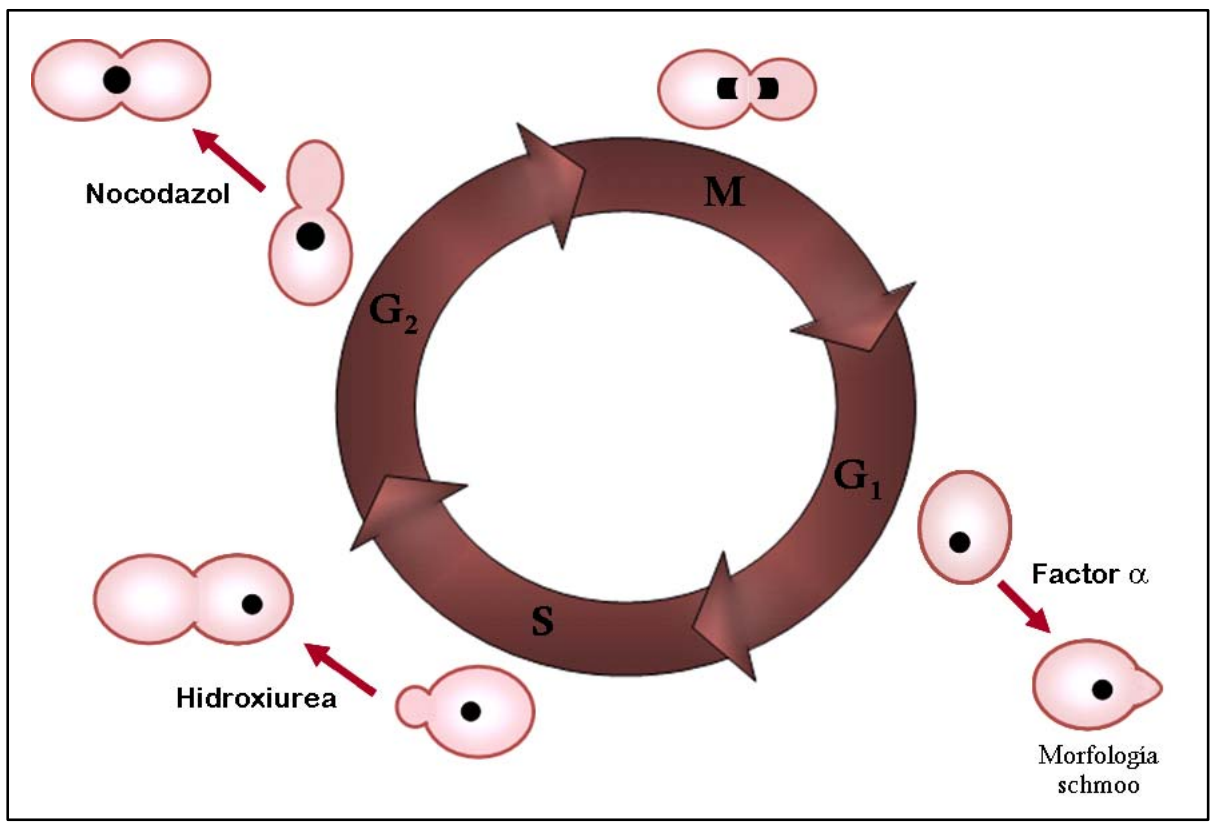

Figura 6. Representación esquemática del ciclo celular de levadura y los distintos arrestos.

\section{MEDICIÓN DE ESPECIES REACTIVAS DE OXIGENO}

La concentración de radicales libres intracelulares se detectó a través del método de la dihidrorrodamina 123 (Madeo et al. 1999). Las células de levadura en fase de crecimiento exponencial fueron centrifugadas y lavadas dos veces con agua para eliminar restos de medio de cultivo. Posteriormente las células se resuspendieron en 1 $\mathrm{ml}$ de agua destilada a la cual se agregó $5 \mu \mathrm{g}$ de dihidrorrodamina (SIGMA) a partir de una solución de partida preparada a $2,5 \mathrm{mg} / \mathrm{ml}$ en etanol. Al tiempo de la adición de la rodamina también se agregó el tratamiento oportuno. La generación de radicales libres fue 
monitorizada analizando los espectros de fluorescencia entre 500 y $550 \mathrm{~nm}$ en fluorímetro Perkin Elmer, LS50B.

\section{ENSAYOS DE REPARACIÓN DE ROTURAS DE DOBLE BANDA EN EL ADN POR UNIÓN DE EXTREMOS}

La capacidad de las células de levadura de reparar roturas de doble banda en el ADN fue valorada de acuerdo al método descrito por Schiestl y Gietz (1989). En este tipo de ensayo la endonucleasa de restricción HindIII fue utilizada para generar roturas de doble banda dentro de una región del plásmido YCplac33, el cual no presenta homología con secuencias cromosomales. Muestras de plásmido sin digerir y de plásmido completamente digerido fueron utilizadas para transformar cepas de levadura, y el número de transformantes obtenido se cuantificó por contaje de las colonias capaces de crecer en medio selectivo. Para normalizar posibles diferencias en las eficiencias de transformación entre distintas cepas de levadura, las transformaciones con plásmido digerido y superenrollado fueron llevadas a cabo siempre en paralelo realizándose al menos 8 repeticiones de cada ensayo. Así la eficiencia de transformación utilizando plásmido linearizado normalizada con la correspondiente a plásmido sin cortar provee una estimación cuantitativa de la capacidad de reparación de daños de doble banda en el ADN de diferentes cepas de levadura. 
TABLA 2. Lista de cepas de Saccharomyces cerevisiae utilizadas

\begin{tabular}{|c|c|c|}
\hline Nombre & Genotipo relevante & Referencia \\
\hline W303.1a & $\begin{array}{l}\text { MATa leu2-3,112 his3-11 ura3-1 } \\
\text { ade2-1trp1-1 can1-100 }\end{array}$ & $\begin{array}{l}\text { De la Torre-Ruiz } \\
\text { et al., } 1998\end{array}$ \\
\hline mecl-1 & W303.1a, mecl-1 & \\
\hline$\Delta t e l 1$ & W303.1a, tell::URA3 & \\
\hline$\Delta r a d 9$ & W303.1a, $\operatorname{rad} 9:: H I S 3$ & \\
\hline$\Delta r a d 24$ & W303.1a, $\operatorname{rad} 24: \because U R A 3$ & \\
\hline rad53.11 & W303.1a, rad53-11 & \\
\hline$\Delta r a d 17$ & W303.1a, $\operatorname{rad} 17: \because U R A 3$ & \\
\hline$\Delta m e c 3$ & W303.1a, mec $3:: T R P 1$ & \\
\hline smll & W303.1a, smll-1 & $\begin{array}{l}\text { D'Amours D and } \\
\text { Jackson SP, } 2001\end{array}$ \\
\hline$\Delta m e c l$ smll & sml1-1, mec1::TRP1 & \\
\hline$\Delta t e l 1$ smll & sml1-1, tell::HIS3 & \\
\hline $\begin{array}{l}\Delta m e c 1 \Delta t e l 1 \\
\text { smll }\end{array}$ & sml1-1, mec1::TRP1 tell::HIS3 & \\
\hline$\Delta x r s 2$ & W303.1a, $x r s 2:: L E U 2$ & \\
\hline$\Delta m r e 11$ & W303.1a, mre11::HIS3 & \\
\hline$\Delta r a d 50$ & W303.1a, rad50::TRP1 & \\
\hline$\Delta x m r$ & 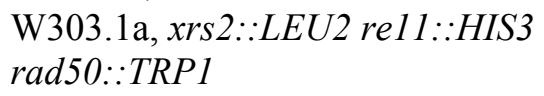 & \\
\hline$\Delta \operatorname{rad} 52$ & $\begin{array}{l}\text { W303.1a, rad52::loxP-kanMX- } \\
\text { loxP }\end{array}$ & $\begin{array}{l}\text { Grenon M et al., } \\
2001\end{array}$ \\
\hline$\Delta r a d 52 \Delta k u 80$ & $\begin{array}{l}\text { rad52::loxP-kanMX-loxP } \\
\text { ku80::URA3 }\end{array}$ & \\
\hline$\Delta k u 80$ & W303.1a, ku80::URA3 & \\
\hline$\Delta r a d 14$ & W303.1a, rad14::URA3 & \\
\hline$\Delta r a d 23$ & W303.1a, rad23::URA3 & \\
\hline $\begin{array}{l}\Delta x r s 2 \Delta m e c 1 \\
\text { smll }\end{array}$ & sml1-1, mec1::TRP1 xrs $2: \because L E U 2$ & $\begin{array}{l}\text { D'Amours D and } \\
\text { Jackson SP, } 2001\end{array}$ \\
\hline$\Delta x r s 2 \Delta$ tell smll & sml1-1, tel1 ::HIS3 $x r s 2: \because L E U 2$ & \\
\hline$\Delta x r s 2 \Delta t e l 1$ & sm1-1, xrs $2: \because$ LEU2 tel1 $\because: H I S 3$ & \\
\hline$\Delta m e c 1$ smll & mec1::TRP1 & \\
\hline sml1 XRS2-HA & sml1-1 pYPGE15-XRS2-HA & $\begin{array}{l}\text { Menacho- } \\
\text { Márquez et al., } \\
2006\end{array}$ \\
\hline$\Delta m e c 1 \mathrm{smll}$ & sml1-1, mec1::TRP1 & \\
\hline$X R S 2-H A$ & pYPGE15-XRS2-HA & \\
\hline
\end{tabular}




\begin{tabular}{|c|c|c|}
\hline$\Delta$ tell smll & sml1-1, tell::HIS3 pYPGE15- & \\
\hline$X R S 2-H A$ & $X R S 2-H A$ & \\
\hline BY4741 & $\begin{array}{l}\text { MATa, leu } 2 \Delta 0, \text { his } 3 \Delta 0, \text { met } 15 \Delta 0 \text {, } \\
\text { ura } 3 \Delta 0\end{array}$ & EUROSCARF \\
\hline$\Delta$ topl & BY4741, top $1:: K A N M X 4$ & \\
\hline$\Delta$ top3 & BY4741, top $3:: K A N M X 4$ & \\
\hline top2-1 & W303.1a, top2-1 & $\begin{array}{l}\text { Brill SJ et al., } \\
1988\end{array}$ \\
\hline$\Delta n d e 1$ & BY4741, nde1::KANMX4 & EUROSCARF \\
\hline$\Delta n d e 2$ & BY4741, nde21::KAN2MX4 & \\
\hline soye2 & BY4741, oye $2:: K A N M X 4$ & \\
\hline soye3 & BY4741, oye $:: K A N M X 4$ & \\
\hline$\Delta$ aifl & BY4741, aif $1: K A N M X 4$ & \\
\hline$\Delta c b r 1$ & BY4741, cbr1::KANMX4 & \\
\hline$\Delta m c r l$ & BY4741, mer $1: \because K A N M X 4$ & \\
\hline$\Delta l p d 1$ & BY4741, lpd1::KANMX4 & \\
\hline$\Delta k u 80$ & BY4741, ku80::KANMX4 & \\
\hline$\Delta g c n 1$ & BY4741, gcn $1:: K A N M X 4$ & \\
\hline$\Delta g c n 2$ & BY4741, gcn $2:: K A N M X 4$ & \\
\hline$\Delta g c n 3$ & BY4741, gcn $3:: K A N M X 4$ & \\
\hline$\Delta g c n 4$ & BY4741, gcn $4:: K A N M X 4$ & \\
\hline$\Delta g c n 20$ & BY4741, gcn 20::KANMX4 & \\
\hline$G C N 2 c$ & BY4741, GCN2c-M719V-E1537G & $\begin{array}{l}\text { Menacho- } \\
\text { Márquez et al., } \\
2007\end{array}$ \\
\hline
\end{tabular}




\section{PREPARACIÓN DE DROGAS Y TRATAMIENTOS}

\subsection{Preparación de drogas}

Beta-lapachona (3,4-dihidro-2,2-dimetil-2H-nafto[1,2-b]pirano-5,6diona; SIGMA) se disolvió a una concentración de $10 \mathrm{mg} / \mathrm{ml}$ (equivalente a $41 \mathrm{mM}$ ) en DMSO, separada en alícuotas y conservada a $-80^{\circ} \mathrm{C}$ hasta su utilización. En todos los tratamientos esta solución de partida fue diluida en el medio de cultivo a la concentración deseada. La concentración final de DMSO nunca fue superior al $0,1 \%$.

MMS (SIGMA) es un poderoso mutágeno del ADN que transfiere grupos metilo a las bases nitrogenadas (Chang $M$ et al., 2002). En todos los casos este compuesto fue diluido en YPD a una concentración final de 0,1\%(v/v).

Phleomicina (de Streptomyces verticillos; SIGMA) es un glicopéptido radiomimético, estructuralmente relacionado al antibiótico bleomicina. Phleomicina bloquea la entrada en fase-S del ciclo celular y produce daños en el ADN (He C et al., 1996). Este compuesto fue disuelto en agua a una concentración de $20 \mathrm{mg} / \mathrm{ml}$ y conservado a $-80^{\circ} \mathrm{C}$ hasta su utilización.

Hidroxiurea es un inhibidor específico de la síntesis de ADN y un agente antineoplásico específico de fase-S (Szekeres T et al., 1997). El mecanismo de acción de hidroxiurea involucra la inhibición del enzima ribonucleótido reductasa, impidiendo la síntesis de 
desoxirribonucleótidos a partir de ribonucleótidos. En todos los casos la cantidad de hidroxiurea necesaria se pesó y agregó directamente al medio de cultivo.

Nocodazol (o metil [5-(2-tienil-carbonil)-1H-benzimidazol-2-yl]carbamato) es una droga anticáncer que interfiere con la función de los microtúbulos en la mitosis, probablemente porque su unión directa a tubulina causa cambios conformacionales en esta proteína. En nuestros estudios el nocodazol fue disuelto en DMSO a una concentración de $10 \mathrm{mg} / \mathrm{ml}$ y almacenado a $-20^{\circ} \mathrm{C}$ hasta su utilización. En todos los casos fue agregado directamente al medio de crecimiento a la dosis indicada.

El dicumarol (3,3'-metilen bis(4-hidroxicumarina)) es un anticoagulante que interfiere con la vitamina $K$, y que además es bioquímicamente utilizado como inhibidor de reductasas (Edwards $Y$ et al., 1980; Cullen J et al., 2003) . Este compuesto fue preparado en agua a una concentración de $5 \mathrm{mM}$ con el agregado de una alícuota de $\mathrm{NaOH}$ para favorecer su disolución. Una vez disuelto, se conservó a $-20^{\circ} \mathrm{C}$ durante no más de una semana.

\subsection{Ensayos de sensibilidad a drogas}

Los tratamientos con beta-lapachona se realizaron por exposición directa de los cultivos a la concentración deseada de la droga, llevando como control un volumen idéntico del mismo cultivo tratado con la cantidad equivalente de DMSO. Tanto en los ensayos de 
viabilidad como en los de ciclo celular, los tratamientos se realizaron durante una hora.

Los tratamientos con radiación ultravioleta de células en placa se llevaron a cabo exponiendo las mismas a una radiación de $254 \mathrm{~nm}$ $\left(50 \mathrm{~J} / \mathrm{m}^{2}\right)$ durante 10 segundos (UV Stratalinker 1880, Stratagene). 


\section{TÉCNICAS DE TRANSFERENCIA GÉNICA}

\subsection{Preparación de células competentes de bacteria}

En todos los casos, las células bacterianas empleadas en los ensayos de esta tesis correspondieron a la cepa de Escherichia coli $X L 1$ blue. Para la preparación de células competentes utilizamos el método de los cationes divalentes (Hanahan D, 1986) que otorga una eficiencia de unos $10^{3}-10^{4}$ transformantes por nanogramo de plásmido. Para ello enfriamos unos minutos en hielo un cultivo de $300 \mathrm{ml}$ de bacterias en fase exponencial. Centrifugamos $10 \mathrm{~min}$. a $5000 \mathrm{rpm}$ en centrífuga refrigerada $\left(4^{\circ} \mathrm{C}\right)$, y resuspendimos las células en $60 \mathrm{ml}$ de medio RF1 frío. Dejamos $30 \mathrm{~min}$. en hielo y volvimos a centrifugar $10 \mathrm{~min}$. a $5000 \mathrm{rpm}$. Resuspendimos de nuevo las células, con ayuda de un vórtex, en $10 \mathrm{ml}$ de medio RF2 frío. Dejamos en hielo $15 \mathrm{~min}$. y distribuimos posteriormente en alícuotas de $50 \mu \mathrm{L}$ en microtubos estériles. Congelamos las alícuotas rápidamente y conservamos a $-80^{\circ} \mathrm{C}$ hasta su uso.

\section{Medio RF1:}

$\begin{array}{ll}\mathrm{RbCl} & 0,1 \mathrm{M} \\ \mathrm{MnCl}_{2} \cdot \mathrm{H}_{2} \mathrm{O} & 50 \mathrm{mM} \\ \mathrm{CaCl}_{2} \cdot \mathrm{H}_{2} \mathrm{O} & 10 \mathrm{mM} \\ \text { Glicerol } & 15 \% \\ \text { Acetato potásico } & 30 \mathrm{mM}(\mathrm{pH} \mathrm{7,5} \text { con acético })\end{array}$

Mezclar y ajustar a pH 5,8 con ácido acético 0,2 M. 


\section{Medio RF2:}

$\mathrm{RbCl} \quad 10 \mathrm{mM}$

$\mathrm{CaCl}_{2} \quad 75 \mathrm{mM}$

Glicerol $\quad 15 \%$

MOPS $\quad 10 \mathrm{mM}(\mathrm{pH} \mathrm{6,8}$ con $\mathrm{NaOH})$

Mezclar y ajustar a pH 6,8 con $\mathrm{NaOH} 1 \mathrm{M}$.

\subsection{Transformaciones en bacteria}

Para las transformaciones de bacteria utilizamos un protocolo sencillo estándar de transformación por choque térmico (Hanahan $D$, 1986). Se mezclaron $3 \mu \mathrm{L}$ del ADN de interés con $50 \mu \mathrm{L}$ de bacterias competentes en glicerol 15\%. Después de incubar 30 minutos en hielo, la mezcla se calentó a $42^{\circ} \mathrm{C}$ durante 50 segundos y se volvió a poner en hielo 1 minuto. Tras 1 hora recuperándose en LB líquido se sembraron en LB-agar con antibiótico.

\subsection{Transformaciones en levadura}

Para la transformación de levadura se recurrió al método del litio (Gietz R et al. 1995). Las células en fase exponencial con una densidad óptica cercana a 1 (medida como absorbancia a 660nm) se centrifugaron y lavaron dos veces con agua estéril. Posteriormente se trataron con acetato de litio $100 \mathrm{mM}$. Después se mezclaron $50 \mu \mathrm{L}$ de estas células con 1-5 $\mu \mathrm{L}$ del ADN a introducir en la célula en una solución conteniendo acetato de litio $100 \mathrm{mM}$, Polietilenglicol (PEG) 4000 al $40 \%$, y 2 mg/ml de ADN monocatenario. La mezcla se incubó 
30 minutos a $30^{\circ} \mathrm{C}$ y luego se le aplicó un choque térmico de $42^{\circ} \mathrm{C}$ durante otros 30 minutos. Pasado ese tiempo se sembró en el medio selectivo correspondiente.

Los plásmidos utilizados tanto en la transformación de bacterias como en la de levaduras se encuentran listados y descritos en la Tabla 3.

Tabla 3. Plásmidos utilizados.

\begin{tabular}{lll}
\hline Nombre & Descripción & Referencia \\
\hline pYPGE15 & $\begin{array}{l}\text { Vector de expression en } \\
\text { levadura diseñado para } \\
\text { clonación direccional de }\end{array}$ & Brunelli JP, Pall \\
& $\begin{array}{l}\text { ADNc. } \\
\text { Construcción diseñada para }\end{array}$ & Menacho- \\
pYPGE15- & $\begin{array}{l}\text { la expresión de Xrs2p } \\
\text { XRS2-HA }\end{array}$ & Márquez M, \\
& $\begin{array}{l}\text { fusionada al epítope HA } \\
\text { P180 }\end{array}$ & Murguía JR. \\
& $\begin{array}{l}\text { UTR) no traducida (5'- } \\
\text { fusionada a lacZ en YCp50 }\end{array}$ & Yang, Wek et al. \\
YCplac33 & $\begin{array}{l}\text { Vector centromérico derivado } \\
\text { del pUC19 }\end{array}$ & Gietz RD, Sugino \\
p1052 & $\begin{array}{l}\text { Plásmido que contiene el } \\
\text { alelo GCN2 M719V-E1537G }\end{array}$ & Ramirez et al. \\
& & \\
\hline & &
\end{tabular}




\section{TÉCNICAS DE MANIPULACIÓN GÉNICA}

\subsection{Generación de plásmidos}

Para generar el plásmido pYPGE15-XRS2-HA hemos clonado el fragmento kpnl-Sall del plásmido YCpT-XRS2-HA (gentilmente cedido por el Dr. Katsunori Sugimoto). Dicho fragmento, que contiene el gen XRS2 marcado con el epítope HA en su extremo C-terminal, fue introducido en el vector pYPGE15 (Bruneli and Pall, 1993) linearizado con las mismas enzimas.

El estado de la construcción se chequeó por análisis de restricción utilizando métodos estándares y se comprobó la expresión de la proteína marcada con el tamaño apropiado. Paralelamente se comprobó que la construcción complementara los fenotipos de sensibilidad al daño al ADN del mutante nulo $\Delta x r s 2$.

\subsection{Generación de la cepa mutante $\mathrm{GCN}^{\mathrm{c}}$}

Hinnebusch y colaboradores han generado recientemente una colección de mutantes constitutivos de la proteína quinasa Gcn2p (Ramírez et al., 1992). Cuando se sobreexpresan, estos mutantes son letales en levadura, y su letalidad depende de la iniciación de la síntesis de proteínas ya que se rescata en un mutante no fosforilable de elF2 .

Con el objeto de construir una cepa mutante de la quinasa Gcn2p que presente una actividad constitutivamente elevada en el fondo 
genético utilizado en esta tesis, aislamos el fragmento Xbal-Sall de 6,6 Kpb, a partir de un plásmido gentilmente cedido por el $\mathrm{Dr}$. Hinnebusch, que porta la secuencia completa del gen $G C N 2 c-M 719 \mathrm{~V}$ $E 1537 G$. Esta secuencia presenta dos cambios aminoacídicos: una valina por una metionina en la posición 719 y una glicina por un glutamato en la 1537 (Figura 7). La secuencia de interés fue purificada por técnicas estándares de laboratorio y utlizada para integrar el alelo hiperactivo en un mutante $\Delta g c n 2$.

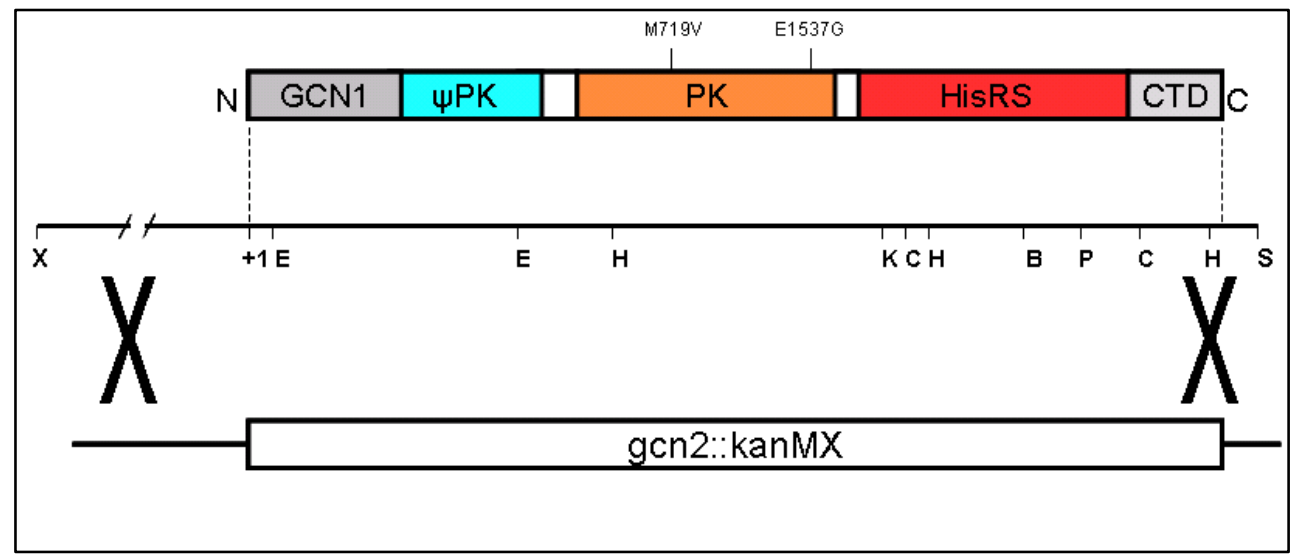

Figura 7. Representación esquemática de la estrategia de reemplazo alélico para generar el mutante $\mathrm{GCN}^{c}$. En la parte superior se marcan las sustituciones de aminoácidos que rinden el alelo hiperactivo. Abreviaturas: GCN1, dominio de unión a Gcn1p; $\varphi \mathrm{PK}$, dominio pseudoquinasa de función desconocida; PK, dominio con actividad quinasa; HisRS, sitio de unión a tARNs; CTD, dominio de dimerización y unión a ribosoma; X, Xbal; E, EcoRI; H, HindlII; K, Kpnl; C, Bcll; B, BamHI; P, Pvul; S, Sall. 
Posteriormente los integrantes fueron seleccionados en medio mínimo suplementado con 5-metil triptófano con el objeto de favorecer el crecimiento del mutante con la ruta de control traduccional constitutivamente activa (Niederberger et al., 1986). Así, las cepas con el alelo GCN2c fueron chequeados por su defecto de crecimiento, su capacidad de crecer en presencia de 5-metil triptófano, los altos niveles de expresión de la construcción GCN4::LacZ tras ser transformados con el plásmido p180, y por un incremento en la fosforilación del factor eucariótico de iniciación de la traducción elF2 en su subunidad alfa con respecto a la cepa silvestre BY4741. 


\section{OBTENCIÓN DE EXTRACTOS PROTEICOS}

\subsection{Extractos proteicos de levadura para transferencia a membrana}

Para obtener extractos proteicos de levadura que luego se someterían a electroforesis e inmunodetección se siguió el método del ácido tricloroacético (TCA) (Wright et al. 1989). Para ello, cultivos en fase exponencial, sometidos o no a los tratamientos a estudiar, se centrifugaron $y$, una vez eliminado el sobrenadante, se resuspendieron en ácido tricloroacético al $20 \%$. Las células se rompieron mediante la adición de bolas de vidrio de $0,5 \mathrm{~mm}$ de diámetro y posterior agitación con vórtex. El extracto se centrifugó de nuevo y se resuspendió en un volumen igual de tampón de carga de proteínas $2 \mathrm{X}$ (tris- $\mathrm{HCl} 62,5 \mathrm{mM} \mathrm{pH} \mathrm{8,7,} \mathrm{SDS} 2 \%, \beta$-mercaptoetanol $5 \%$, glicerol $10 \%$ y azul de bromofenol $0,01 \%$ ). La muestra se hirvió durante 5 minutos, se volvió a centrifugar y se conservó el sobrenadante (Laemmli 1970).

En el caso de preparación de extractos proteicos para la posterior inmunodetección de la forma fosforilada de elF $2 \alpha$, las fracciones de cultivo en fase exponencial se centrifugaron y resuspendieron inmediatamente en tampón de carga de proteínas $2 X$. Las muestras se hirvieron durante 10 minutos y se congelaron a -80 grados hasta su utilización. 


\section{ELECTROFORESIS Y TÉCNICAS DE DETECCIÓN DE PROTEÍNAS}

\subsection{Electroforesis de proteínas}

La separación de proteínas por electroforesis se llevó a cabo en condiciones desnaturalizantes en geles discontinuos de poliacrilamida y SDS (SDS-PAGE), utilizando el sistema MiniProtean 3 (BioRad). Estos geles constan de una zona superior de concentración (acrilamida:bisacrilamida $30: 0,8$ al $6 \%$, tris- $\mathrm{HCl} 125$ $\mathrm{mM} \mathrm{pH} 6,8$, SDS 0,1\%) y una zona inferior de resolución (acrilamida:bisacrilamida 30:0,8 al 7-15\% según el tamaño de las proteínas a separar, tris- $\mathrm{HCl} 375 \mathrm{mM} \mathrm{pH} \mathrm{8,8,} \mathrm{SDS} \mathrm{0,1 \% ).} \mathrm{Cuando} \mathrm{la}$ técnica se empleó para posterior inmnodetección de Rad53p o histona $\mathrm{H} 2 \mathrm{~A}$, las relaciones archilamida:bisacrilamida fueron 80:1 y 29:1 respectivamente. En todos los casos, la electroforesis se realizó a diferencia de potencial constante de $120 \mathrm{~V}$ en tampón de electroforesis SDS-PAGE 1X (glicina $192 \mathrm{mM}$, trizma base $25 \mathrm{mM}$ y SDS $0,1 \%)$, y se utilizaron marcadores preteñidos de peso molecular: Kaleidoscope (6,9-201 kDa, BioRad), Precision Plus Dual color (6,9-201 kDa, BioRad) y Page Ruler (11-170 kDa, Fermentas).

\subsection{Transferencia a membrana}

Para la transferencia a membrana se utilizó el set Mini-Trans Blot (BioRad) y tampón de transferencia (tampón de electroforesis SDSPAGE 1X, metanol 20\%). La transferencia se realizó a intensidad constante de 170-190 mA durante 45-70 minutos con refrigeración. 
En todos los casos la transferencia se llevó a cabo utilizando membranas de nitrocelulosa (Protran, Schleicher \& Schüell), la cuales fueron previamente embebidas en el mismo tampón utilizado para la transferencia.

\subsection{Tinción de membranas con Ponceau S}

Esta técnica se utilizó para comprobar la eficiencia de transferencia a membrana y como control interno de carga (Korotzer et al. 1961). Se sumergieron las membranas en la solución colorante (Ponceau $\mathrm{S}$ (Sigma) al $0,1 \%$, ácido acético al $5 \%$ ) durante unos minutos con agitación. El exceso de colorante se retiró con agua destilada.

\subsection{Inmunodetección de proteínas transferidas a membrana}

Las membranas se bloquearon en agitación durante un mínimo de dos horas con leche desnatada (Regilait) al 0,5-2\%, dependiendo de la especificidad del anticuerpo usado, disuelta en tampón TBS (50 $\mathrm{mM}$ Tris- $\mathrm{HCl} \mathrm{pH} 7,6 ; 3$ mM KCl y $200 \mathrm{mM} \mathrm{NaCl}$ ) con Tween 0,05$0,1 \%$, en función también del anticuerpo (Johnson et al. 1984). La inmunodetección (Harlow and Lane 1988) comenzó con la incubación de la membrana con el anticuerpo primario correspondiente (Tabla 4), diluido en TBS-Tween (TBS-T), con agitación durante toda la noche a $4^{\circ} \mathrm{C}$.

Después de la incubación con el anticuerpo primario, la membrana se sometió a tres lavados de 10 minutos cada uno en TBS-T-Leche con agitación a temperatura ambiente. Posteriormente la membrana 
se incubó durante 30-60 minutos a temperatura ambiente y en agitación con el correspondiente anticuerpo secundario (anti-lgG de conejo o ratón según el anticuerpo primario usado, conjugado a peroxidasa, BioRad) diluido 1:20000 en TBS-T-Leche. El exceso de anticuerpo se retiró con tres lavados de 10 minutos cada uno con TBS-T. La detección se realizó usando un sistema de quimioluminiscencia (ECL Plus Western Blotting Detection System, Amersham Biosciences) según recomendaciones del fabricante. La señal se analizó utilizando películas de rayos X (Biomax Light-1, Kodak).

TABLA 4: Lista de anticuerpos utilizados.

\begin{tabular}{|c|c|c|}
\hline Nombre & Descripción & Origen \\
\hline Anti Rad53p & Reconoce la quinasa Rad53p & $\begin{array}{l}\text { De la Torre- } \\
\text { Ruiz et al., } \\
1998)\end{array}$ \\
\hline Anti-HA & $\begin{array}{l}\text { Monoclonal de ratón (12CA5) que } \\
\text { reconoce el epítope HA } \\
\text { (hemaglutinina del virus de la } \\
\text { influenza) }\end{array}$ & ROCHE \\
\hline Anti Fosfo-H2A & $\begin{array}{l}\text { Reconoce la serina } 129 \text { fosforilada } \\
\text { de la histona } \mathrm{H} 2 \mathrm{~A}\end{array}$ & Abcam \\
\hline Anti $\mathrm{H} 2 \mathrm{~A}$ & Reconoce histona $\mathrm{H} 2 \mathrm{~A}$ & Abcam \\
\hline $\begin{array}{ll}\text { Anti } & \text { Fosfo- } \\
\text { elF2 } \alpha & \end{array}$ & $\begin{array}{l}\text { Reconoce la serina } 51 \text { fosforilada } \\
\text { de la subunidad } \alpha \text { del factor } \\
\text { eucariótico de iniciación } 2 \text { (elF2) }\end{array}$ & $\begin{array}{l}\text { Cell Signaling } \\
\text { Technology }\end{array}$ \\
\hline $\begin{array}{l}\text { Anti IgG de } \\
\text { conejo }\end{array}$ & $\begin{array}{l}\text { Anticuerpo conjugado a peroxidasa } \\
\text { de rábano }\end{array}$ & BioRad \\
\hline $\begin{array}{l}\text { Anti IgG de } \\
\text { ratón }\end{array}$ & $\begin{array}{l}\text { Anticuerpo conjudado a peroxidasa } \\
\text { de rábano }\end{array}$ & Abcam \\
\hline
\end{tabular}




\section{GENÓMICA FUNCIONAL}

\subsection{Extracción y marcaje del ARN de levadura}

Los cultivos de levadura fueron crecidos hasta fase exponencial y tratados durante una hora con DMSO o $4 \mu \mathrm{g} / \mathrm{ml}$ de beta-lapachona, y las células fueron colectadas por centrifugación e inmediatamente congeladas a -80 grados.

El ARN total se extrajo por métodos estándares y para las hibridizaciones se marcaron por método indirecto, por incorporación de 5-(3-aminoalil)-2-deoxi-UTP (aa-dUTP) en ADNc de monocadena mediante transcripción reversa. Para cada reacción se utilizó ARN Poli(A) (500 ng), usando tanto oligo-dT como nonámeros randomizados para primar la reacción de la transcriptasa reversa. La síntesis de la monocadena de ADNc se llevó a cabo durante 3 horas a 42 grados con transcriptasa reversa Superscript II (Invitrogen), y el ADNc fue purificado con columnas Qiaquick (Qiagen). EI acoplamiento del aa-ADNc al fluoróforo Cye éster se llevó a cabo en oscuridad utilizando Cy3 o Cy5 CyDye NHS-ester (Amersham) y el ADNc marcado se purificó por columnas Qiaquick. El correcto marcaje se comprobó mediante análisis en geles de agarosa.

\subsection{Micromatrices, hibridizaciones y análisis de las imágenes}

Las micromatrices fueron cedidas por el Dr. Joaquín Ariño del Institut de Biotecnología i Biomedicina, Universidad Autónoma de Barcelona, y los datos fueron depositados en NCBIs Gene Expresión Ómnibus 
(GEO, http://www.ncbi.nlm.nih.gov/geo/) y pueden consultarse a través del número de acceso GSE8111.

La hibridización de las micromatrices se realizó manualmente utilizando cámaras de hibridización Telechem, siguiendo las intrucciones del proveedor. De manera resumida, la prehibridización fue de 30 minutos en presencia de $0,1 \%$ SDS y $0,1 \mathrm{mg} / \mathrm{ml}$ de BSA, y la hibridización se realizó durante toda la noche a 50 grados en presencia de $0,1 \%$ SDS y $0,1 \mathrm{mg} / \mathrm{ml}$ de ADN de esperma de salmón. Las matrices fueron lavadas a 42 grados y secadas en centrífuga de mesa (5 minutos a $600 \mathrm{~g}$ ).

La imagen de las micromatrices se registró a través de un scanner (Axon Instruments) a una resolución de $10 \mu \mathrm{m}$. Las imágenes se analizaron y normalizaron usando el programa GenePix de Axon Instruments. Sólo se seleccionaron los puntos con intensidad (sustraída la señal base) mayor que dos veces la media de base en al menos un canal. La normalización y el análisis de los datos se llevó a cabo utilizando programas Acuity (Axon Instruments) y/o SAM (Tusher et al., 2001). En cualquier caso, un gen se consideró diferencialmente regulado cuando su expresión fue al menos 1,5 veces mayor o menor que en el control (FDR $<6 \%)$.

\subsection{Análisis de los genes con cambios en expresión de significancia estadística.}

Los grupos de genes que muestran inducción o represión tras el análisis realizado según el apartado anterior, se analizaron a través 
del uso de las bases de datos Gene Ontology y FatiGo plus de Babelomics (Al-Shahrour et al., 2006) con el objeto de detectar categorías funcionales de procesos biológicos sujetos a cambios por el tratamiento utilizado.

Para detectar grupos de genes bajo control de factores de transcripción comunes se ha utilizado la base de datos Yeastract

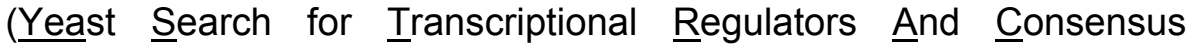
Tracking; Texeira et al.,2006). 



\section{RESULTADOS}





\section{Caracterización de los efectos de beta-lapachona en levaduras.}

\subsection{Efectos sobre crecimiento y viabilidad celular.}

Previos reportes en la bibliografía indican que beta-lapachona induce muerte celular y retraso en la progresión normal del ciclo celular en células tumorales (Li et al., 2003). Con el propósito de conocer si el tratamiento con beta-lapachona activa respuestas similares en levadura, evaluamos el crecimiento y la viabilidad de cultivos de levaduras en fase exponencial tratados con diferentes dosis de la droga. Beta-lapachona inhibió el crecimiento de cultivos de levadura del tipo silvestre (o WT, del inglés Wild Type; Figura 8A) y disminuyó la supervivencia celular (Figura 8B) en una forma dependiente de dosis y tiempo.

\subsection{Efectos sobre el ciclo celular.}

Con el objeto de ver los efectos de beta-lapachona sobre la progresión del ciclo celular en levaduras, examinamos la activación de las rutas de control de ciclo durante la transición G1/S en células sincronizadas con factor-alfa, tratadas con beta-lapachona, y liberadas en medio sin droga. Las células reasumían la progresión del ciclo celular con un significante retraso de 30 minutos en comparación con los controles sin tratar (Figura 9A). Cuando las células sincronizadas con factor-alfa se liberaban en medio en presencia de droga, éstas no reiniciaban la progresión del ciclo celular incluso tras dos horas de la liberación del arresto (Figura 9C). 

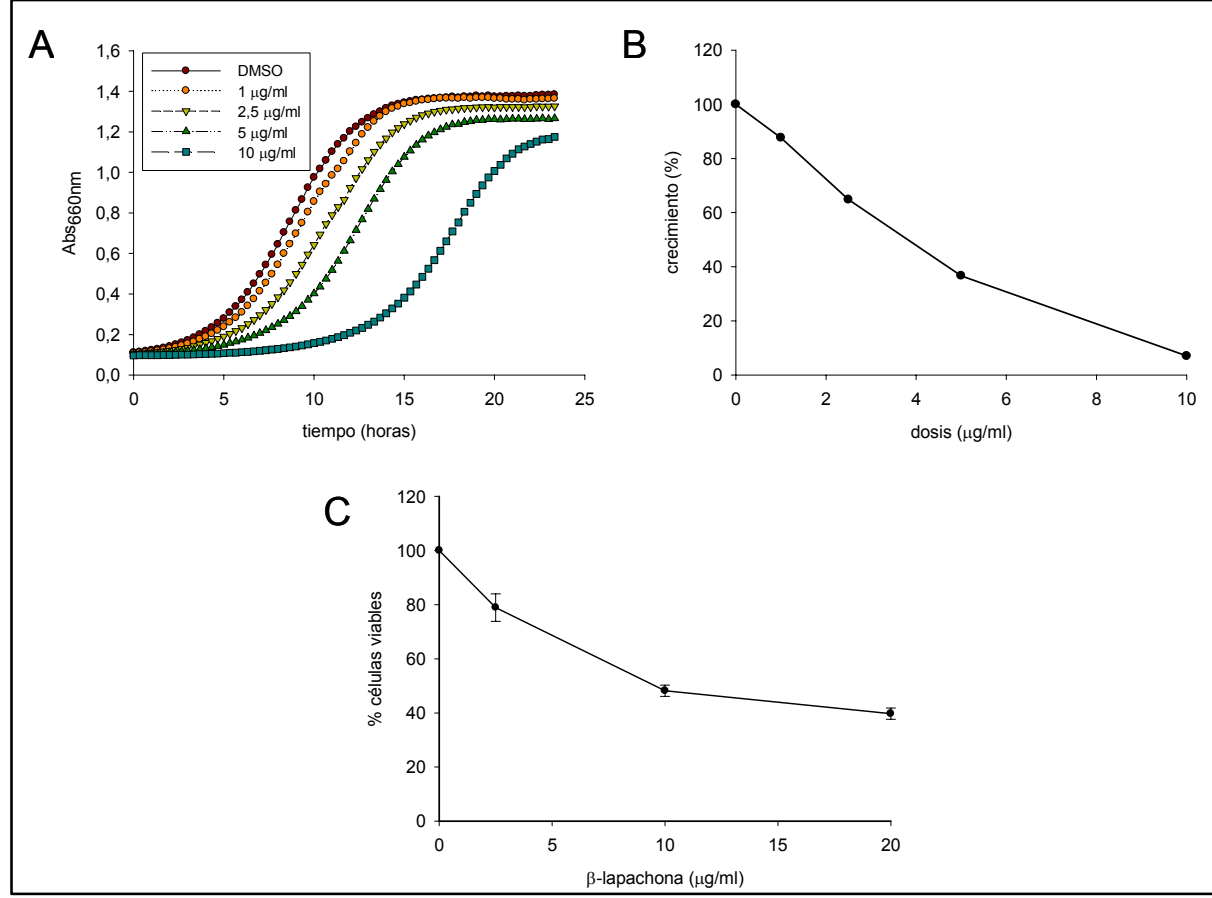

Figura 8: A, curvas de crecimiento en microplacas (medido por Abs660 nm) de la cepa $W T$ en presencia de distintas dosis de beta-lapachona. B, representación gráfica del porcentaje de crecimiento de la cepa a las distintas dosis de beta-lapachona según la información de la figura A. C, pérdida de la viabilidad de cultivos expuestos a diferentes dosis de betalapachona

Posteriormente investigamos la activación de los mecanismos de control durante la transición G2/M por beta-lapachona. Para esto tratamos células $W T$ arrestadas con nocodazol, que luego liberamos en medio sin droga para monitorizar la progresión del ciclo celular tras el tratamiento. Observamos que beta-lapachona no inducía ningún tipo de retraso detectable en la progresión normal del ciclo 
(Figura 9B) ya que la cinética de desaparición de células con yemas grandes en cultivos tratados con la droga era similar a la de los controles. Como prueba de la activación de este tipo mecanismo de control utilizamos un tratamiento con MMS en las mismas condiciones (Figura 9D).

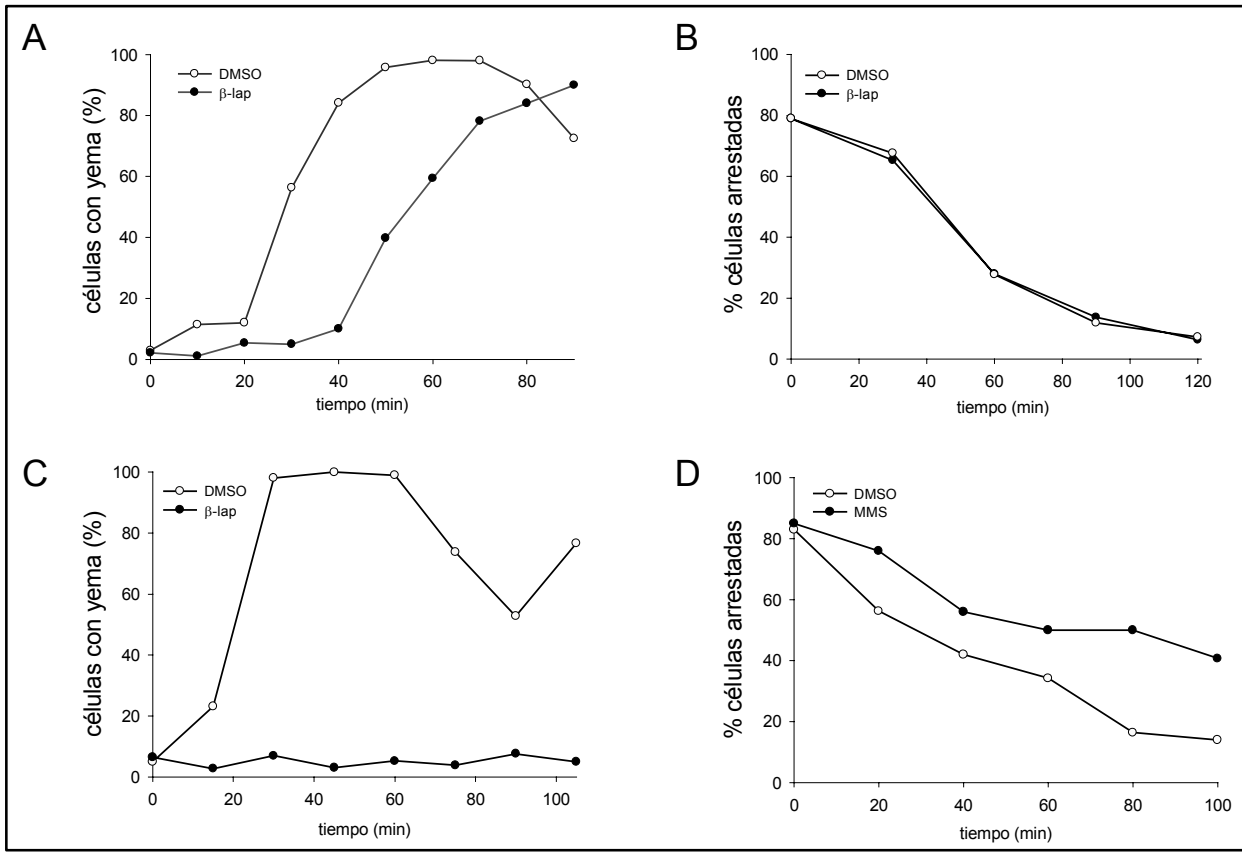

Figura 9: $\mathrm{A}$, análisis de la transición $\mathrm{G} 1 / \mathrm{S}$ en cultivos de células $W T$ tras una hora de tratamiento con $10 \mu \mathrm{g} / \mathrm{ml}$ de beta-lapachona. B, análisis de la transición G2/M de células $W T$ tras una hora de tratamiento con $10 \mu \mathrm{g} / \mathrm{ml}$ de beta-lapachona. $\mathrm{C}$, análisis de la entrada en fase $\mathrm{S}$ de células arrestadas en G1 y liberadas en medio en presencia de $10 \mu \mathrm{g} / \mathrm{ml}$ de beta-lapachona. D, activación del mecanismo de control de G2/M con MMS 0,1\%. 
Con objeto de evaluar si la toxicidad de la droga era específica de alguna fase del ciclo, analizamos la viabilidad celular tras tratamiento con la droga en estudio en cultivos asincrónicos y en células arrestadas en G1 (factor alfa), S (HU) y G2 (nocodazol). En estas condiciones pudimos observar que las células eran más sensibles al tratamiento cuando se hallaban en las fases $\mathrm{G} 1$ o S, observándose un rescate significativo en la toxicidad en células arrestadas en G2 (Figura 10).

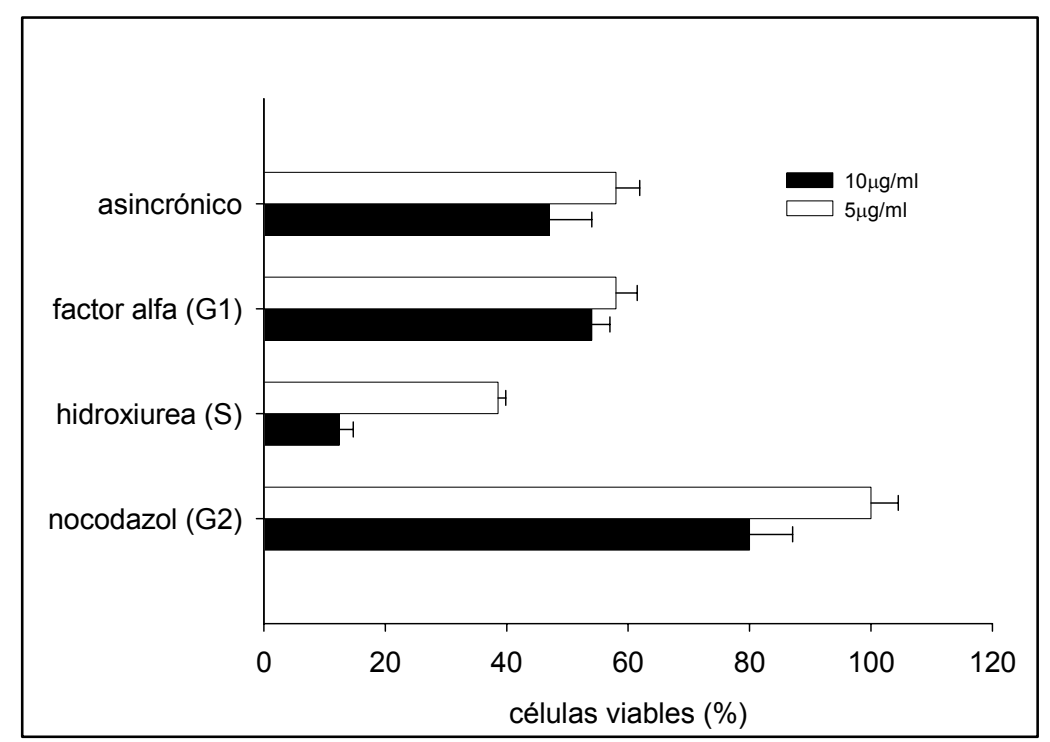

Figura 10: Viabilidad de cultivos celulares de células $W T$ arrestados en distintas fases del ciclo celular y tratados durante una hora con $5 \circ 10 \mu \mathrm{g} / \mathrm{ml}$ de beta-lapachona. 
Estos resultados indican que beta-lapachona es citotóxica en levaduras y que produce un retraso en transición G1/S del ciclo celular. Dado que beta-lapachona dispara respuestas similares en levaduras y en células tumorales, estos hallazgos validan la utilización de nuestro sistema modelo para llevar a cabo un análisis molecular de la citotoxicidad de beta-lapachona. 


\subsection{Sensibilidad de cepas mutantes con defectos en las rutas de control.}

Para caracterizar las bases moleculares de la citotoxicidad de betalapachona, analizamos el comportamiento de cepas mutantes que presentan mecanismos de control de daño al ADN defectivos. Para ello realizamos diluciones seriales de estas cepas (mec1-1, $\Delta t e l 1$, $\Delta r a d 9, \Delta r a d 24, \Delta r a d 17, \Delta m e c 3$ y rad53-11) y las inoculamos por goteo en placas con beta-lapachona. De los mutantes analizados, sólo mec1-1 y $\Delta t e l 1$ mostraron mayor sensibilidad a beta-lapachona (Figura 11A).

Posteriormente analizamos las interacciones entre Mec1p y Tel1p examinando la sensibilidad de las cepas mutantes $\Delta m e c 1, \Delta t e l 1 y$ $\Delta m e c 1 \Delta t e / 1$. Este experimento se realizó en un fondo genético $\Delta s m / 1$ ya que la mutación de $S M L 1$ suprime la letalidad de $\Delta m e c 1$. En este fondo genético ninguno de los mutantes simples mostró mayor sensibilidad a beta-lapachona (Figura 11B). Sin embargo, la combinación de las dos mutaciones aumentó significantemente la sensibilidad a la droga (Figura 11B)

Para confirmar estos resultados observamos el estado de fosforilación de Rad53p en cultivos no sincronizados de las mismas cepas mutantes tras exposición a beta-lapachona. Bajo estas condiciones, detectamos modificación de Rad53p en WT y en el mutante $\Delta t e l 1$, pero no en las cepas $\Delta m e c 1$ y $\Delta m e c 1 \Delta t e l 1$ (Figura 11C), indicando estos resultados que en células creciendo exponencialmente $M E C 1$ es requerido tanto para la supervivencia 
como para la fosforilación de Rad53p tras tratamiento con betalapachona, mientras que TEL1 posee una función que se superpone, al menos en parte, con la de MEC1.

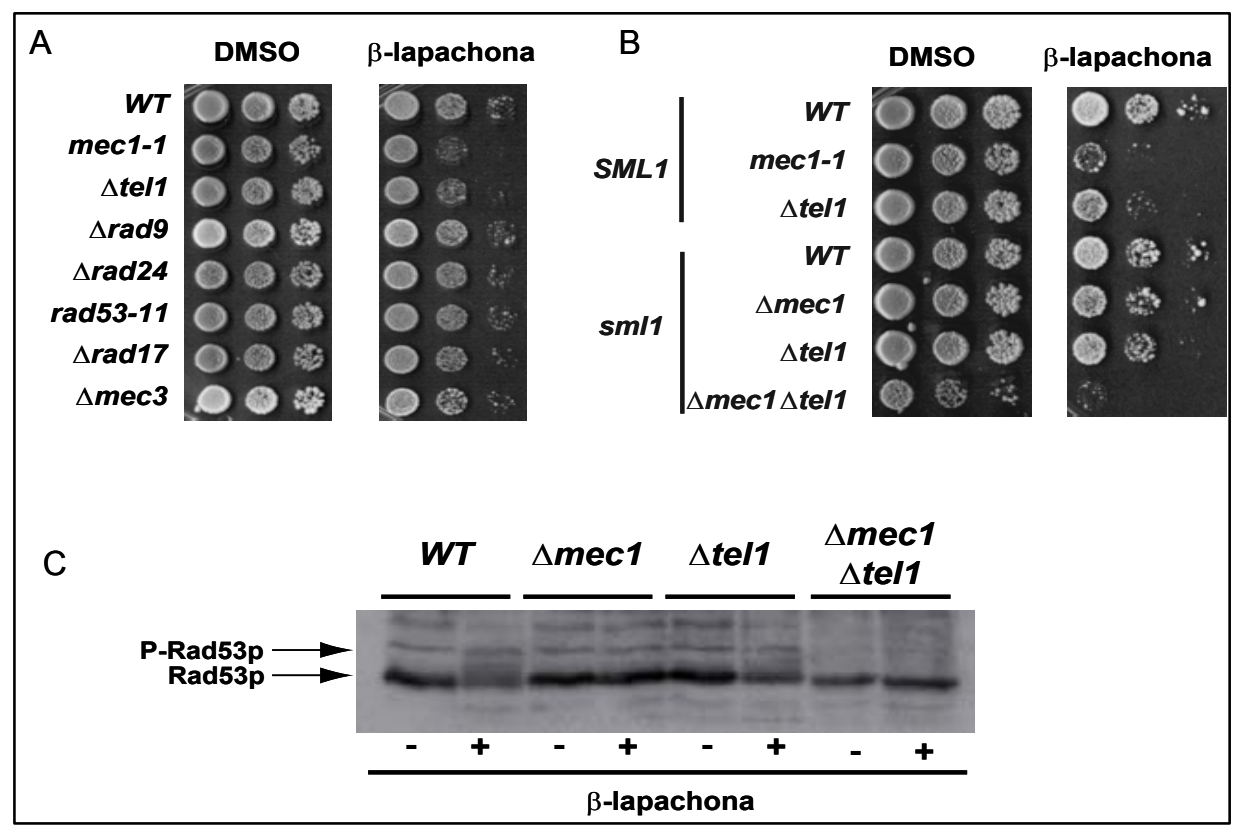

Figura 11: A, crecimiento de cepas $W T$ y mutantes en los mecanismos de control en placas de YPD con $10 \mu \mathrm{g} / \mathrm{ml}$ de beta-lapachona. B, crecimiento de $W T$, mec1.1 y $\Delta t e l 1$ (fondo genético $S M L 1$ ) y $W T, \Delta m e c 1, \Delta t e l 1$ y

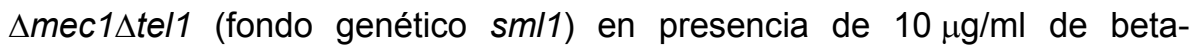
lapachona. C, fosforilación de Rad53p tras exposición a una hora de tratamiento con $10 \mu \mathrm{g} / \mathrm{ml}$ de droga. 


\subsection{Papel de Mec1p y Tel1p en el mecanismo de control activado por beta-lapachona.}

Basados en los resultados anteriores, exploramos el rol de Mec1p y Tel1p en el control de G1 activado por beta-lapachona. Para esto, tratamos cultivos de las cepas $\Delta m e c 1, \Delta t e / 1$ y $\Delta m e c 1 \Delta t e / 1$ sincronizados con factor-alfa, con beta-lapachona o MMS durante una hora, y los liberamos del arresto en ausencia completa de droga. Resultó interesante que no se observaran diferencias significantes entre las cinéticas de progresión de ciclo del mutante $\Delta m e c 1$ y la cepa $W T$ tratadas con beta-lapachona (Figura 12). Sin embargo se pudo observar que el mutante $\Delta t e / 1$ reiniciaba la progresión del ciclo celular más rápidamente que el $W T$ tras tratamiento con betalapachona, pero no tras tratamiento con MMS (Figura 12). La progresión del ciclo celular del doble mutante $\Delta m e c 1 \Delta t e / 1$, que en condiciones normales es por sí misma mucho más lenta que la correspondiente al $W T$, no se afectó significativamente por el tratamiento (Figura 12). Por lo tanto se requiere Tel1p para la activación del punto de control de G1 inducido por el tratamiento con beta-lapachona. 

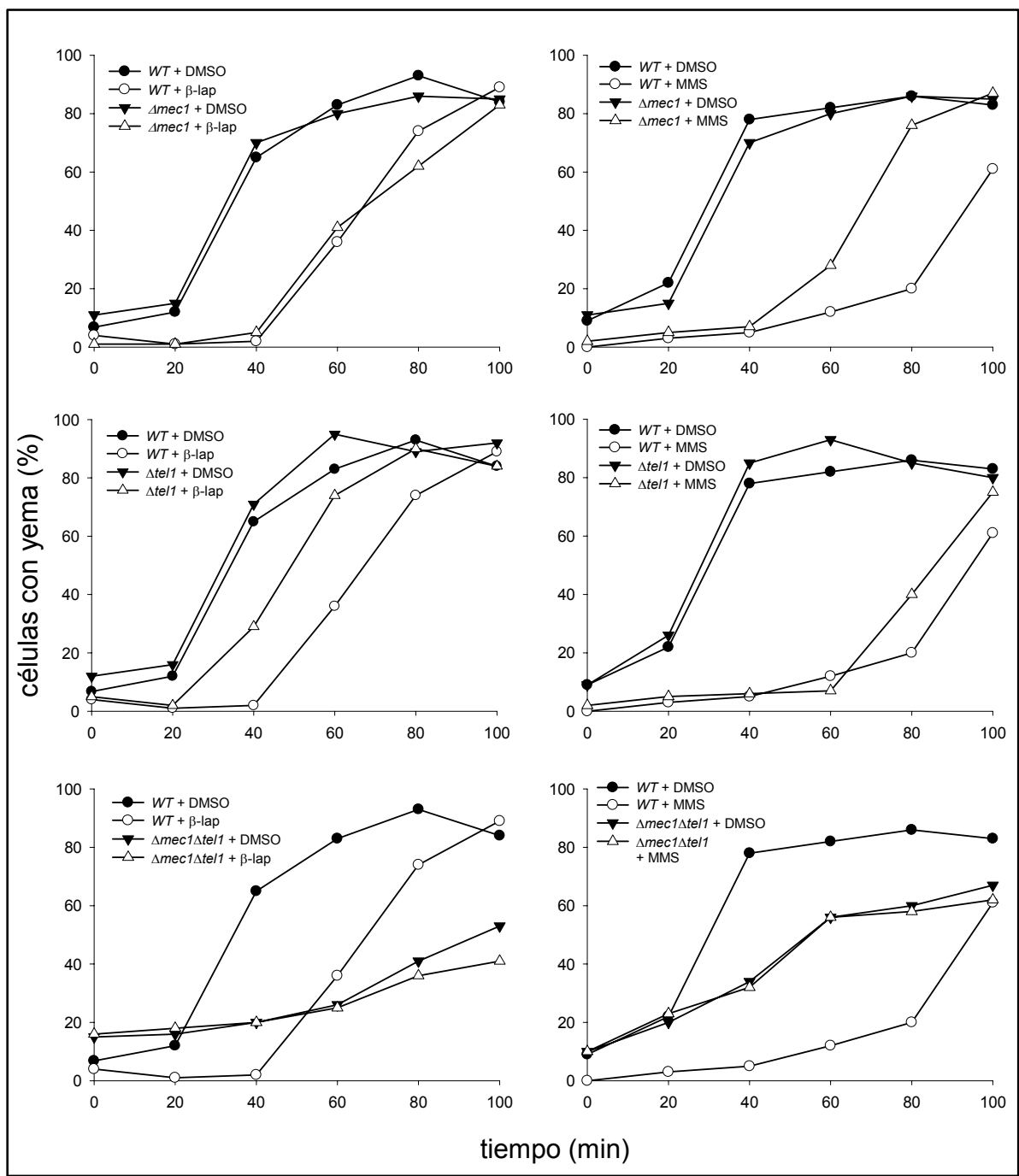

Figura 12: Análisis de la transición G1/S en células $W T, \Delta m e c 1, \Delta t e l 1$ y $\Delta$ mec1stel1 tras tratamiento de una hora con $10 \mu \mathrm{g} / \mathrm{ml}$ de beta-lapachona. En todos los casos se llevó MMS 0,1\% como control. 
Posteriormente, analizamos el grado de fosforilación de Rad53p inducido por beta-lapachona en cultivos sincronizados en $\mathrm{G} 1$ de los mutantes $\Delta m e c 1, \Delta t e l 1$ y $\Delta m e c 1 \Delta t e l 1$. La fosforilación de Rad53 se presentó visible en células $\Delta m e c 1$ arrestadas en G1 (Figura 13), aunque en un grado mucho menor que en células $W T$. En el mutante $\Delta t e / 1$ pudo detectarse una clara fosforilación de Rad53p, aunque con niveles de fosforilación claramente más bajos que en células WT (Figura 13). Como era de esperar, la mutación de MEC1 pero no la de TEL1 evitó la fosforilación de Rad53p inducida por MMS (Figura 13). Estos datos indican que en $\mathrm{G} 1$, tanto Mec1p como Tel1p median las respuestas de control activadas por beta-lapachona, pero de alguna manera el rol de Tel1p parece ser más relevante.

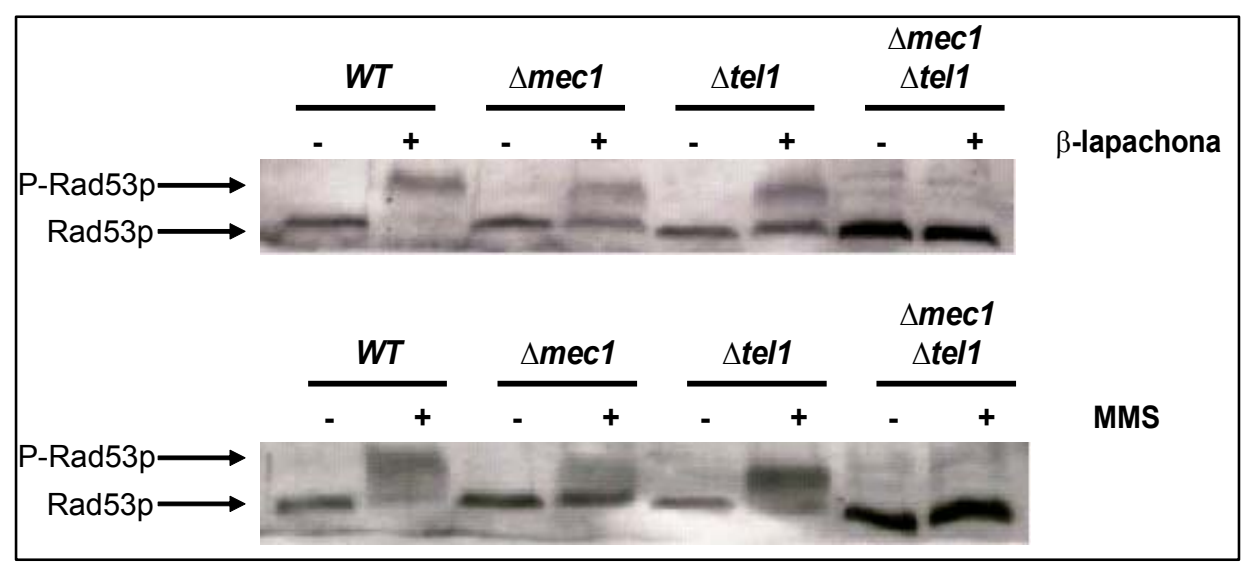

Figura 13: Análisis por inmunodetección del estado de fosforilación de Rad53p en cultivos de células en células $W T, \Delta m e c 1, \Delta t e / 1$ y $\Delta m e c 1 \Delta t e / 1$ arrestadas en $\mathrm{G} 1$ y tratadas durante una hora con $10 \mu \mathrm{g} / \mathrm{ml}$ de betalapachona. En todos los casos se llevó MMS 0,1\% como control. 


\subsection{Papel de las vías de reparación al daño al $A D N$ en la toxicidad de beta-lapachona.}

Una interpretación de los resultados anteriores sería que betalapachona genera de algún modo lesiones en el ADN que activan las respuestas de control de ciclo observadas. Si este fuera el caso, cepas con defectos en una o algunas de las vías de reparación de daño al ADN deberían exhibir sensibilidad a beta-lapachona. Para comprobar esta hipótesis, examinamos la sensibilidad de varios mutantes en los sistemas de reparación de daño al ADN tras exposición a la droga. Las cepas de levadura defectivas en sistemas de reparación de roturas de doble banda (DSB), tales como los mutantes en miembros del complejo XMR (referidos como mutantes xmr. $\Delta x r s 2, \Delta m r e 11, \Delta r a d 50)$ y los mutantes $\Delta$ rad52 y $\Delta$ rad52 $\Delta k u 80$, mostraron una significativa sensibilidad al tratamiento (Figura 14). El hecho de que mutantes defectivos en el sistema de reparación por escisión de nucleótidos ( $\Delta \mathrm{rad} 14$ y $\Delta \mathrm{rad} 23$ ) exhibieran poca o ninguna sensibilidad a la droga (Figura 14) sugiere que la letalidad inducida por beta-lapachona es al menos parcialmente consecuencia de la generación de DSB.

Para luego confirmar este hallazgo, examinamos el estado de fosforilación de la histona $\mathrm{H} 2 \mathrm{~A}$ en su residuo ser129 en células tratadas con beta-lapachona. Está bien establecido que la generación de DSB induce la fosforilación específica de histona H2A en la posición serina129 (Downs et al., 2000). Este evento de fosforilación es crítico para una reparación eficiente de DSB y ocurre en las proximidades de la lesión, siendo así un marcador bioquímico 
conveniente para detectar la generación de los mismos (Redon et al., 2003).

En acuerdo con los datos anteriores, observamos que betalapachona aumentaba los niveles de fosforilación de histona H2A ser129 tanto en células WT no sincronizadas, como en células WT arrestadas en G1 (Figura 15). Además la fosforilación de histona $\mathrm{H} 2 \mathrm{~A}$ en células arrestadas en $\mathrm{G} 1$ resultó ser dependiente de Mec1p y Tel1p (Figura 15). Por lo tanto estos resultados indican que el tratamiento con beta-lapachona está produciendo DSB in vivo.

\begin{tabular}{|c|c|c|c|c|c|}
\hline & DMSO & $\beta$-lapachona & & & \\
\hline$W T$ & 003 & $50 \div$ & & DMSO & $\beta$-lapachona \\
\hline $\begin{array}{r}\Delta x r s 2 \\
m r e 11\end{array}$ & $0.0 \mathrm{k}$ & 0 & & คी: & \\
\hline $\begin{array}{r}\Delta m r e 11 \\
\Delta r a d 50\end{array}$ & $0 \leqslant \%$ & 0 & $\begin{array}{r}W \mathrm{WI} \\
\Delta \mathrm{k} 8 \mathrm{O}\end{array}$ & 00 & 00 \\
\hline$\Delta r a d 50$ & 004 & cis & $\begin{array}{r}\Delta K u 80 \\
\Delta \operatorname{rad} 52 \Delta k u 80\end{array}$ & (a) $: 8$ & \\
\hline $\begin{array}{r}\Delta x m r \\
\Delta r a d 52\end{array}$ & 0 궁 & 0 & $\Delta r a d 52$ & (1) s & \\
\hline$\Delta \operatorname{rad} 52 \Delta k u 80$ & $\therefore \therefore$ & 8 & $\Delta r a d 14$ & 000 & $00 \%$ \\
\hline$\Delta k u 80$ & $00 \%$ & 00 & $\Delta r a d 23$ & 100 & $00 \%$ \\
\hline
\end{tabular}

Figura 14: Crecimiento de cepas $W T$ y mutantes en distintos sistemas de reparación del daño al ADN en placas de YPD con $10 \mu \mathrm{g} / \mathrm{ml}$ de betalapachona. 


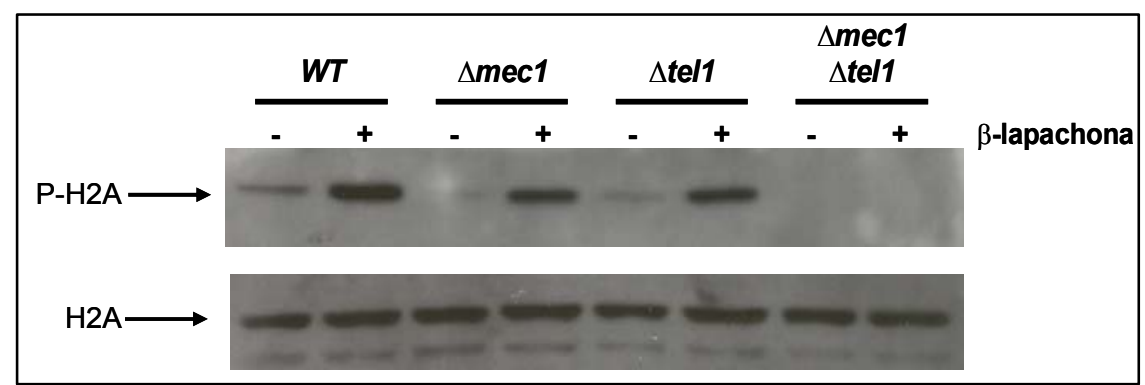

Figura 15: Inmunodetección de la forma fosforilada en ser129 de histona $\mathrm{H} 2 \mathrm{~A}$ (arriba) e histona $\mathrm{H} 2 \mathrm{~A}$ total (abajo) en células $W T, \Delta m e c 1, \Delta t e / 1$ y $\Delta m e c 1 \Delta t e / 1$ arrestadas en $\mathrm{G} 1$ y tratadas durante de una hora con $10 \mu \mathrm{g} / \mathrm{ml}$ de beta-lapachona. 


\subsection{Implicación del complejo XMR en la toxicidad de beta- lapachona.}

Recientemente se ha descrito que el complejo XMR, además de estar implicado en la reparación de DSB, es también parte de un mecanismo de control que responde a este tipo de daño (D'Amours and Jackson, 2001). Para diferenciar entre el papel de este complejo en la activación del control o en la reparación de DSB, cepas mutantes $\Delta m r e 11$ y $x m r$ sincronizadas en $\mathrm{G} 1$ fueron tratadas con beta-lapachona o MMS durante una hora y luego liberadas del arresto en ausencia de drogas. Beta-lapachona no indujo retraso en la progresión a través de G1/S en los mutantes $\Delta m r e 11$ y $\Delta x m r$ (Figura 16A). Resultados esencialmente idénticos fueron obtenidos para los mutantes $\Delta x r s 2$ y $\Delta$ rad50 (Figura 16B). Estos comportamientos no se deben a la existencia de un defecto en los mecanismos de control en los mutantes del complejo XMR ya que el tratamiento con MMS produjo un retraso en la progresión del ciclo celular en todos los mutantes del mismo grado que en células WT (Figura 16A).

De igual modo, la fosforilación de Rad53p inducida por betalapachona se vio severamente comprometida en los mutantes $x m r$ tanto en cultivo asincrónico, como en cultivos arrestados en fase G1 (Figura 16C). Por lo tanto, la activación del mecanismo de control y la fosforilación de Rad53p en respuesta a tratamiento con betalapachona requieren un complejo XMR funcional. 


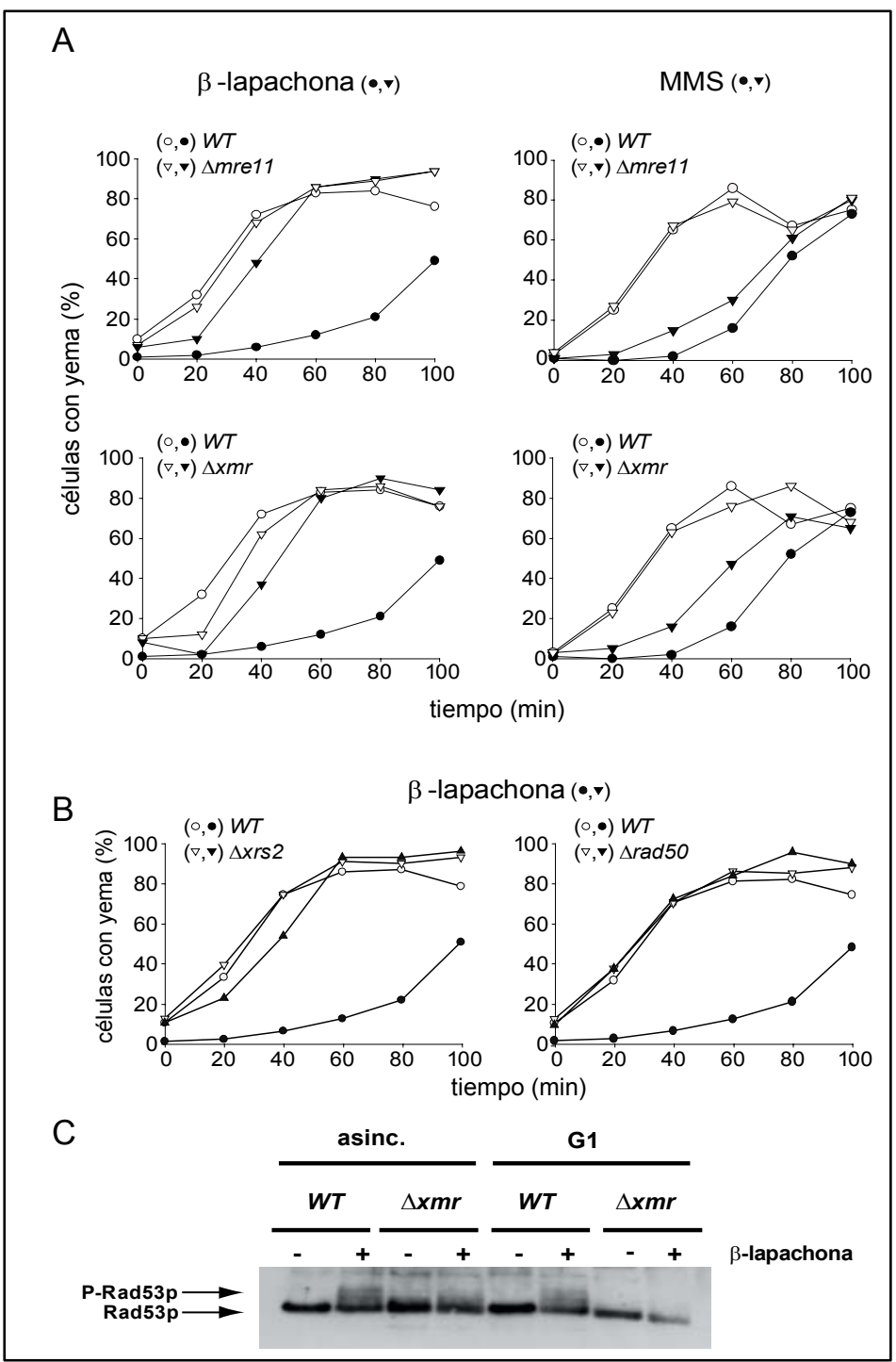

Figura 16: $\mathrm{A}$, análisis de la transición $\mathrm{G} 1 / \mathrm{S}$ en células $W T$ y mutantes del complejo XMR tras tratamiento con $10 \mu \mathrm{g} / \mathrm{ml}$ de beta-lapachona. En todos los casos se llevó MMS $0,1 \%$ como control. $B$, transición $G 1 / S$ en células $W T$ y mutantes $\Delta x r s 2$ y $\Delta$ rad50. C, análisis por inmunodetección del estado de fosforilación de Rad53p en células $W T$ y en el triple mutante $\Delta x m r$ tras tratamiento de una hora con beta-lapachona en cultivos asincrónicos y arrestados en $\mathrm{G} 1$. 


\subsection{Relaciones epistáticas.}

Con el fin de explorar las relaciones epistáticas entre MEC1, TEL1 y miembros del complejo $X M R$, examinamos la sensibilidad a betalapachona de cepas deficientes en MEC1, TEL1 y XRS2 como mutantes simples o combinaciones de mutantes. Resultó interesante que la mutación de XRS2 incrementara la sensibilidad a betalapachona del mutante $\Delta m e c 1$ en el mismo grado que una mutación $\Delta t e l 1$ (Figura 17A). Por otra parte, la mutación $\Delta x r s 2$ no afectaba significantemente la sensibilidad del mutante simple $\Delta t e / 1$ o del doble mutante $\Delta m e c 1 \Delta t e / 1$.

Confirmamos estos resultados analizando el estado de fosforilación de la histona H2A en las mismas cepas tras la exposición a betalapachona. En acuerdo con los resultados de sensibilidad, la mutación de XRS2 evitaba la fosforilación de H2A en el mutante $\Delta m e c 1$ pero no en el $\Delta t e l 1$ (Figura 17B). Estos resultados están de acuerdo con una relación epistática de las mutaciones $\Delta x r s 2$ y $\Delta t e / 1$ respecto a la sensibilidad a beta-lapachona. 


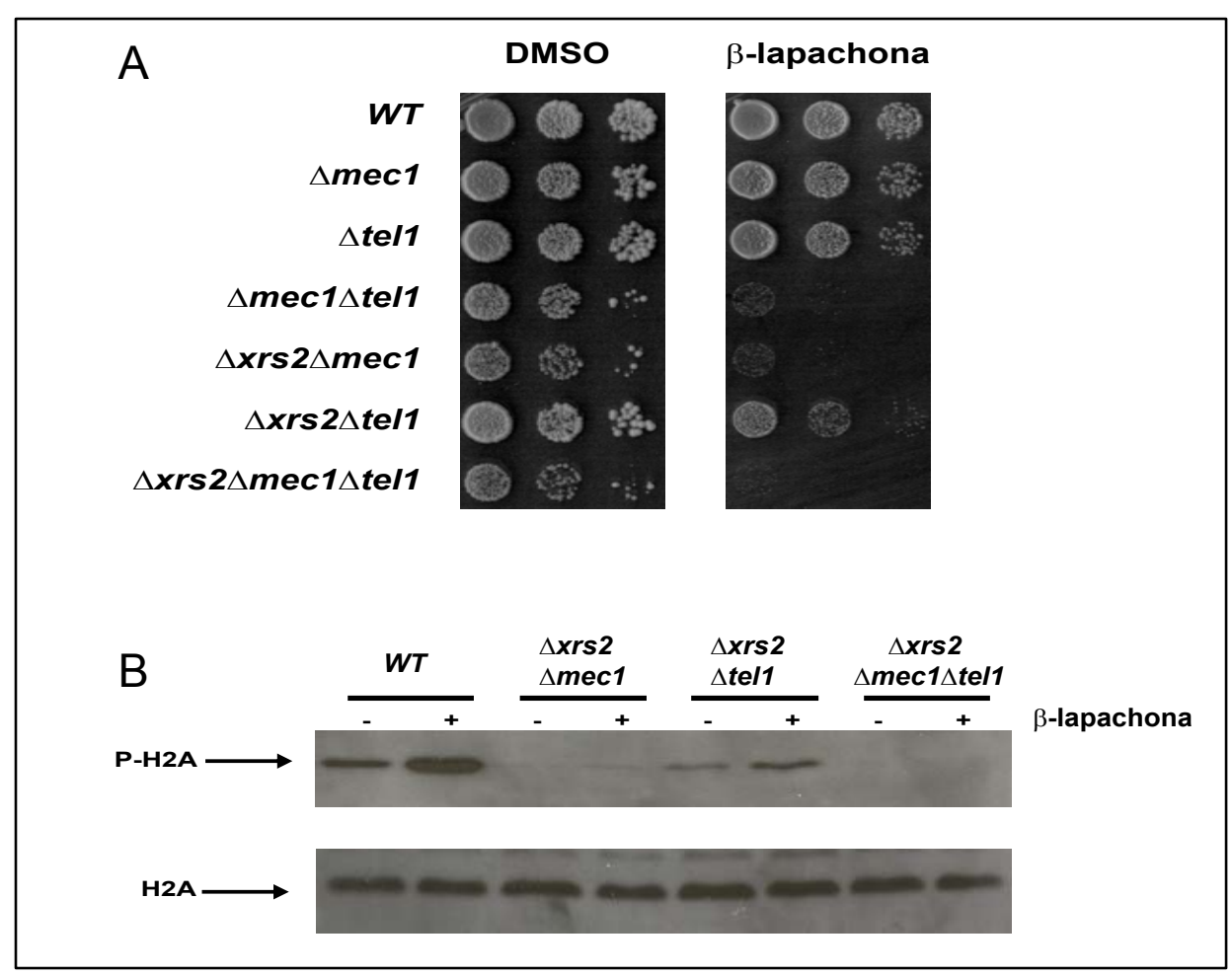

Figura 17: Interacciones epistáticas y funcionales entre Tel1p y Xrs2p. A, crecimiento de cepas deficientes en MEC1, TEL1 y XRS2 como mutantes simples o combinación de mutantes en placas de YPD conteniendo 10 $\mu \mathrm{g} / \mathrm{ml}$ de beta-lapachona. $\mathrm{B}$, inmunodetección de la fosforilación de histona $\mathrm{H} 2 \mathrm{~A}$ en cepas deficientes en MEC1, TEL1 y XRS2 como combinación de mutantes, arrestadas en $\mathrm{G} 1 \mathrm{y}$ tratadas con beta-lapachona. 


\subsection{Fosforilación de un componente del complejo XMR.}

Los componentes del complejo XMR pueden fosforilarse de una forma dependiente de Tel1p durante daño al ADN (D'Amours and Jackson, 2001). Así, los resultados anteriores nos impulsaron a analizar si el tratamiento con beta-lapachona incrementaba el estado de fosforilación de Xrs2p, y de ser así, si esta fosforilación era dependiente de Mec1p y/o Tel1p en G1. Para esto, sincronizamos en G1 células $W T, \Delta m e c 1$ y $\Delta t e / 1$ expresando una versión marcada con un epítope HA de Xrs2p, y las tratamos con beta-lapachona. En estas condiciones, la exposición a beta-lapachona aumentó los niveles de fosforilación de Xrs2p en un modo dependiente de tiempo en cepas $W T$ (Figura 18). Además, la fosforilación de Xrs2p inducida por beta-lapachona era principalmente dependiente de Tel1p, dado que los niveles de fosforilación eran más afectados por la mutación de TEL1 que por la de MEC1 (Figura 18).

En conjunto, estos datos indican que el tratamiento con betalapachona retarda la progresión del ciclo celular en la transición G1/S a través de la activación de un mecanismo de control constituido por el complejo XMR y Tel1p. 


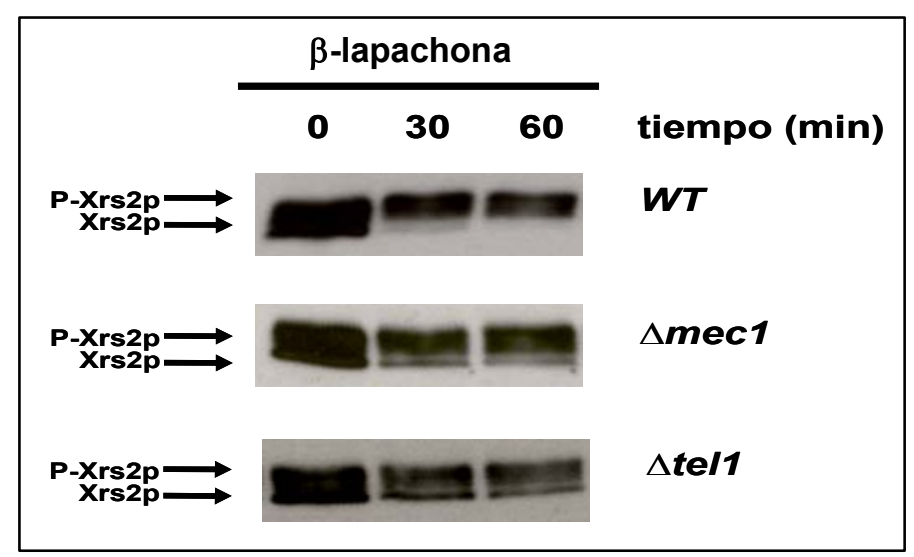

Figura 18: Inmunodetección de los niveles de Xrs2p marcada con el epítope $\mathrm{HA}$ en células $W T, \Delta m e c 1$ y $\Delta t e l 1$ arrestadas en $\mathrm{G} 1$ y tratadas con $10 \mu \mathrm{g} / \mathrm{ml}$ de beta-lapachona. Las formas fosforilada y $\sin$ fosforilar de Xrs2pHA se indican por las flechas. 
Resultados 


\section{Análisis de la implicación de topoisomerasas.}

En un intento de identificar la diana molecular que podría activar el control dependiente de Mre11p-Tel1p por beta-lapachona en levaduras, exploramos la implicación de las ADN topoisomerasas. Las ADN topoisomerasas son buenos candidatos ya que existen reportes que indican que son inhibidas in vitro por esta droga ( $\mathrm{Li}$ et al., 1993). Para evaluar esta hipótesis, examinamos las respuestas celulares a beta-lapachona de varios mutantes en ADN topoisomerasas.

Los mutantes de levadura $\Delta t o p 1$ y $\Delta t o p 3$ no mostraron evidencias de rescate o hipersensibilidad a la droga por ensayos de crecimiento en placa (Figura 19A). Además el tratamiento con beta-lapachona incrementó la fosforilación de Rad53p (Figura 19B) y el retraso en la progresión de ciclo celular (Figura 19C) de forma similar en células $W T$, en $\Delta$ top1 y en $\Delta t o p 3$.

También evaluamos la implicación de Top2p en la toxicidad de betalapachona usando el mutante termosensible top2-1 ya que TOP2 es un gen esencial. Para esto, estudiamos la viabilidad del mutante frente al tratamiento en condiciones permisivas y restrictivas de temperatura. Así, beta-lapachona resultó ser citotóxica para el mutane top2-1 en cualquier condición de temperatura (Figura 19D), no pudiéndose observar diferencias significativas en viabilidad entre este mutante y el $W T$. 
Aunque no se puede excluir totalmente a Top2p ya que la topoisomerasa Top2 $p$ termosensible podría aún ser capaz de mediar algún efecto de la droga, nuestros datos sugieren que las topoisomerasas Top1p, Top2p y Top3p no serían las dianas principales para activar el mecanismo de control de Mre11p-Tel1 $p$ por beta-lapachona. 


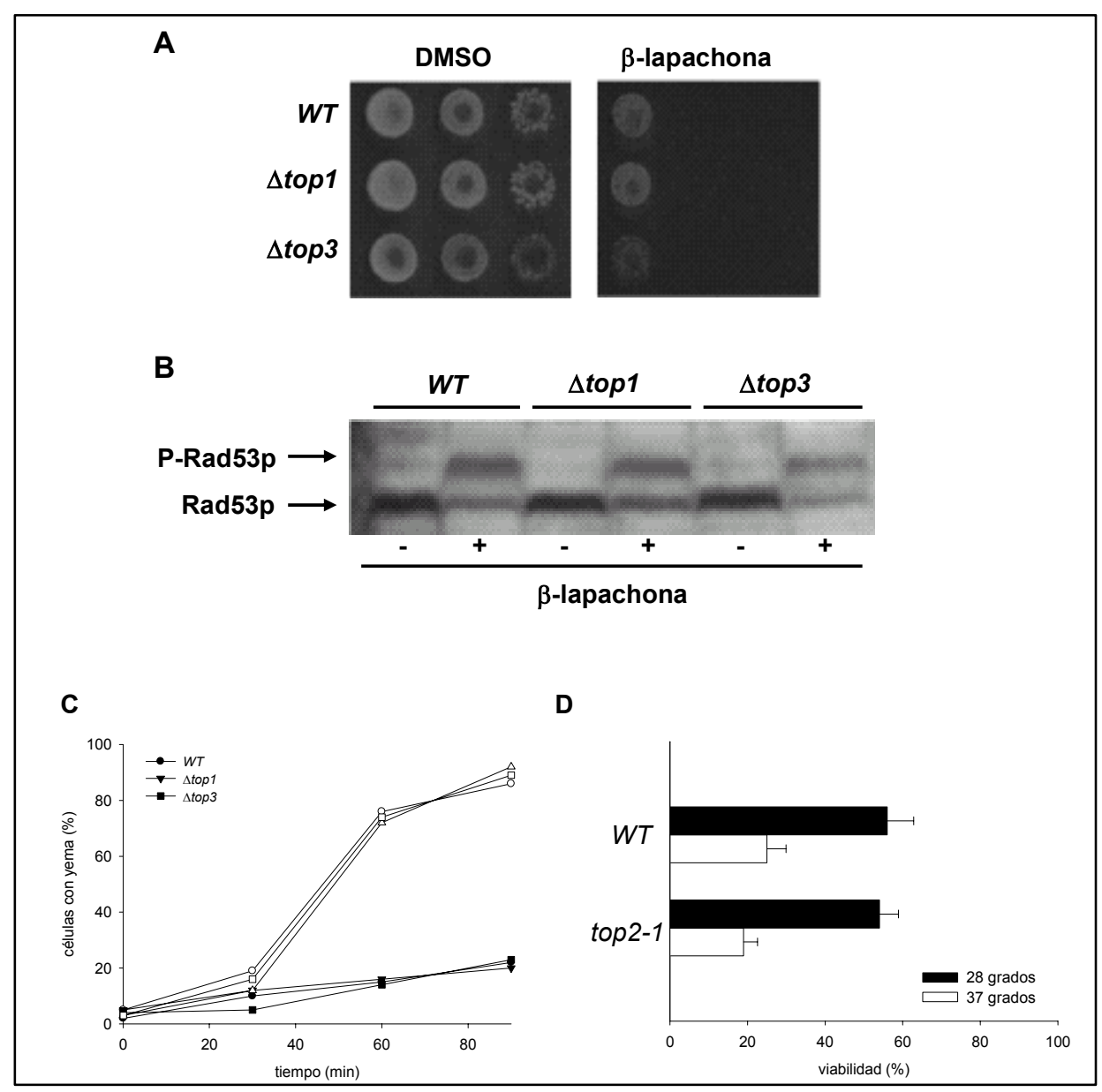

Figura 19: A, crecimiento de las cepas $W T, \Delta t o p 1$ y $\Delta t o p 3$ en placas de YPD en presencia de $10 \mu \mathrm{g} / \mathrm{ml}$ de beta-lapachona. B, inmunodetección del estado de fosforilación de Rad53p tras una hora de tratamiento con betalapachona. $\mathrm{C}$, retraso en la transición $\mathrm{G} 1 / \mathrm{S}$ tras tratamiento de una hora con $10 \mu \mathrm{g} / \mathrm{ml}$ de beta-lapachona en las cepas $W T, \Delta t o p 1$ y $\Delta t o p 3$. D, estudio de la viabilidad del mutante top2-1 en condiciones de crecimiento permisivas y restrictivas. 
Resultados 


\section{Radicales libres.}

\subsection{Producción de radicales libres por tratamiento con beta- lapachona.}

Está descrito en la literatura que el principal determinante de la citotoxicidad de beta-lapachona en células tumorales es la $\mathrm{NAD}(\mathrm{P}) \mathrm{H}$ deshidrogenasa NQO1 (Pink et al., 2000). La reducción de betalapachona por NQO1 conduce a un ciclo fútil entre las formas quinona e hidroquinona, con una pérdida concomitante de la forma reducida $\mathrm{NAD}(\mathrm{P}) \mathrm{H}$ que finalmente induce muerte celular (Figura 20). Se ha propuesto que la reducción de beta-lapachona por NQO1 es inestable, y la forma reducida revierte espontáneamente a la oxidada con generación de especies reactivas de oxígeno (ROS; Pink et al., 2000). Un inhibidor descrito de NQO1 es el dicumarol, ya que compite con el $\mathrm{NAD}(\mathrm{P}) \mathrm{H}$ por su unión a $\mathrm{NQO1}$, previniendo la reducción de quinonas.

La producción de ROS por tratamiento con beta-lapchona podría inducir daño en el ADN y resultar en la formación de DSB con la posterior activación del control dependiente de Mre11p-Tel1p. Con el objeto de evaluar si beta-lapachona inducía la generación de radicales (ROS) en levadura procedimos a medir la producción de los mismos en células $W T$ tras tratamiento con nuestra droga en estudio y con $\mathrm{H}_{2} \mathrm{O}_{2}$. El tratamiento de las células con beta-lapachona indujo la generación de ROS en levaduras (Figura 21), la cual era eficientemente bloqueada por el agregado del inhibidor de la deshidrogenada NQO1, dicumarol. 


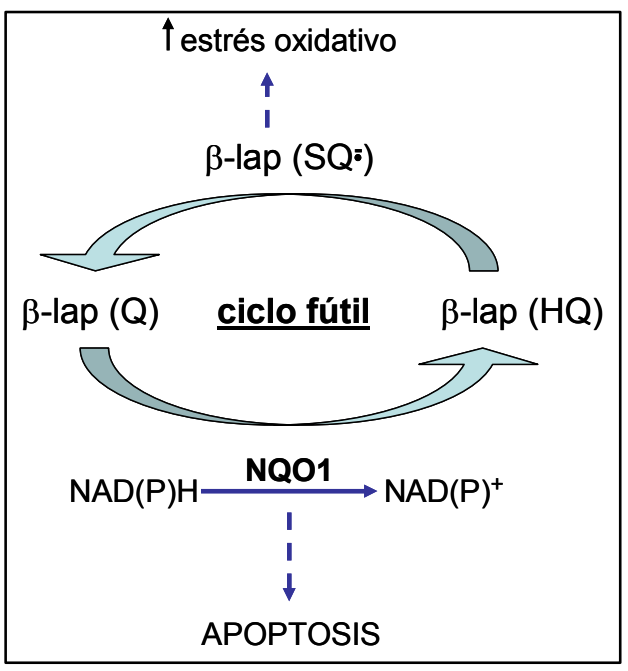

Figura 20: Modelo de citotoxicidad de beta-lapachona en células que expresan NQ01. La forma 1,2-naftoquinona $\beta$-lap (Q) es reducida a hidroquinona $\beta$-lap $(\mathrm{HQ})$ consumiéndose una molécula de NADH por reacción. La forma hidroquinona es inestable y se oxida espontáneamente al estado original a través de un intermediario semiquinona $\beta$-lap (SQ) capaz de generar estrés oxidativo, rindiendo un ciclo fútil. (Adaptado de Pink et al., 2000)

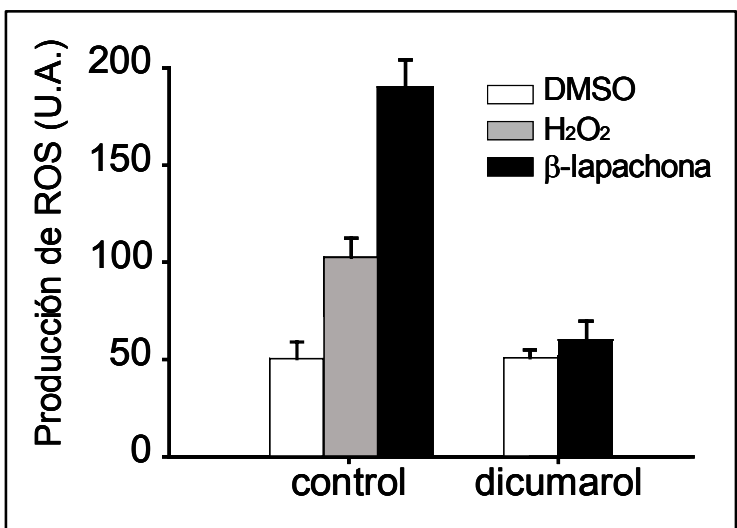

Figura 21: Medidas de la producción de ROS en células $W T$ tras tratamiento con beta-lapachona y $\mathrm{H}_{2} \mathrm{O}_{2}$ durante 30 minutos en presencia y ausencia de dicumarol $(50 \mu \mathrm{M})$ 


\subsection{Contribución de los radicales libres a la viabilidad.}

Con el objeto de comprobar si la generación de ROS por tratamiento con beta-lapachona está involucrada en la citotoxicidad de la droga, evaluamos el efecto de esta droga sobre el crecimiento y la viabilidad en condiciones que previenen la generación de radicales. Para esto tratamos cultivos de levadura en crecimiento exponencial con betalapachona en presencia y ausencia del agente dicumarol. Como se observa en la Figura 22, el tratamiento con la droga afectó tanto al crecimiento como a la viabilidad, aún en condiciones en las que no hay producción de ROS. Estos datos indican que la producción de ROS no es necesaria para la toxicidad de la droga.

\subsection{Producción de radicales libres y control de ciclo celular.}

Con el fin de saber si el aumento en la producción de ROS mediado por beta-lapachona contribuía a disparar los mecanismos de control de G1/S inducidos por el tratamiento con la droga, analizamos la progresión del ciclo celular de células $W T$ sincronizadas en G1 en presencia y ausencia del agente dicumarol. En estas condiciones el dicumarol rescató sólo parcialmente la normal progresión de ciclo en células $W T$ tras tratamiento con beta-lapachona (Figura 23A).

De forma similar, analizamos los niveles de fosforilación de histona $\mathrm{H} 2 \mathrm{~A}$ tras tratamiento en presencia y ausencia de dicumarol. En este caso, el agregado de dicumarol no afectó el estado de fosforilación de Histona $\mathrm{H} 2 \mathrm{~A}$ en células $W T$ tratadas con beta-lapachona ya sea 
en cultivos asincrónicos como en células sincronizadas en G1 (Figura 23B).

En conjunto, estos datos indican que beta-lapachona induce ROS en levadura, pero éstos no son relevantes para ninguna de las respuestas celulares que induce la droga.

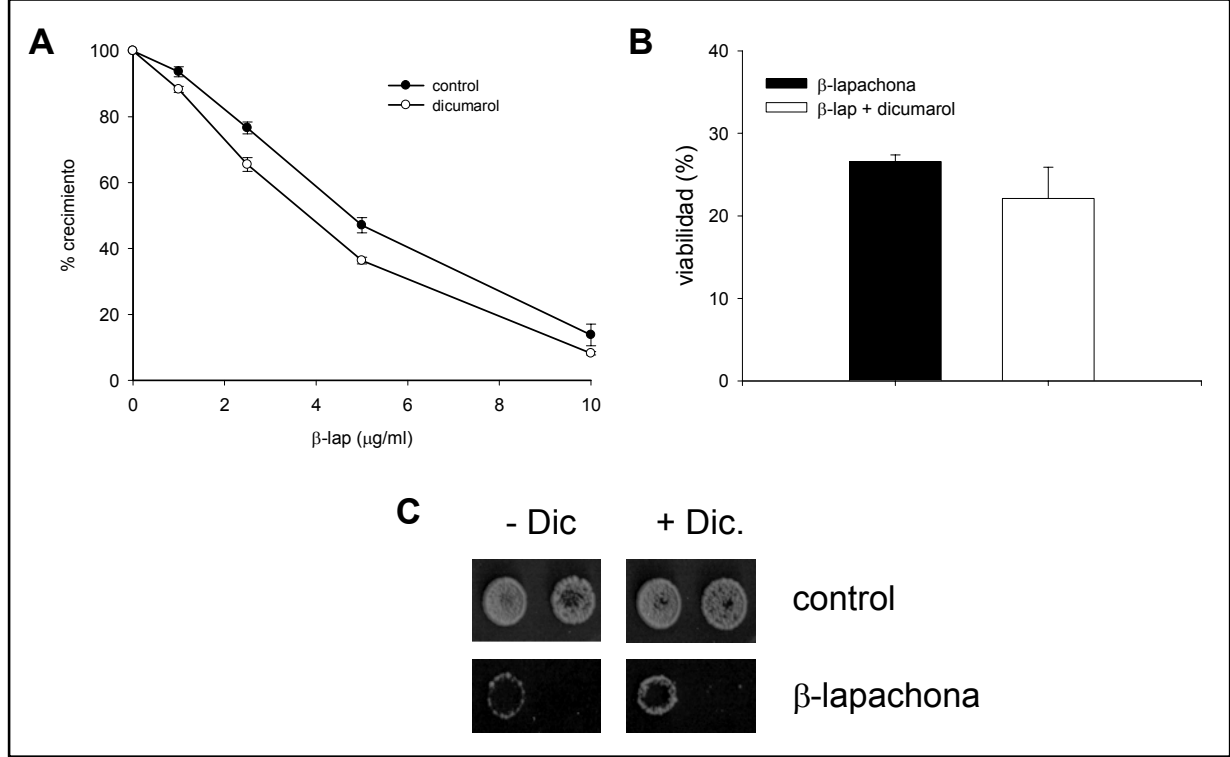

Figura 22: $A$, representación del porcentaje de crecimiento de cultivos de células $W T$ en medio conteniendo distintas dosis de beta-lapachona en presencia y ausencia de dicumarol $(50 \mu \mathrm{M})$. B, análisis de viabilidad de cultivos de células $W T$ tras una hora de tratamiento con $10 \mu \mathrm{g} / \mathrm{ml}$ de betalapachona en presencia y ausencia de dicumarol. C, crecimiento de la cepa $W T$ en placa de YPD conteniendo $10 \mu \mathrm{g} / \mathrm{ml}$ de beta-lapachona en presencia y ausencia de dicumarol. 


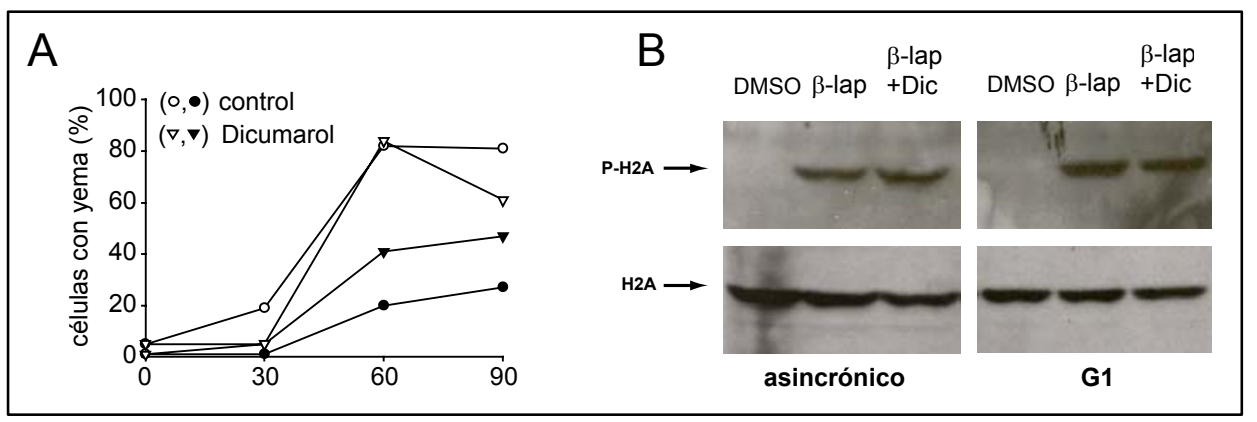

Figura 23: $\mathrm{A}$, análisis de la transición $\mathrm{G} 1 / \mathrm{S}$ de la cepa $W T$ tras tratamiento durante una hora con $10 \mu \mathrm{g} / \mathrm{ml}$ de beta-lapachona en presencia y ausencia de dicumarol $(50 \mu \mathrm{M})$. B, inmunodetección de la forma fosforilada de histona $\mathrm{H} 2 \mathrm{~A}$ tras tratamiento con $10 \mu \mathrm{g} / \mathrm{ml}$ de beta-lapachona en presencia y ausencia de dicumarol, en cultivo asincrónico y cultivo de células arrestadas en G1.

\subsection{Deshidrogenasas de levadura.}

Está descrito en la literatura que NQO1 media la toxicidad de betalapachona en múltiples líneas tumorales, y que la toxicidad se ve significantemente aumentada en líneas que expresan NQO1, mientras que células que carecen de este enzima muestran mayor resistencia a cortas exposiciones a la droga (Planchon et al., 2001).

NQO1 cataliza una reducción vía dos electrones de varias quinonas, como por ejemplo menadiona, utilizando tanto NADH como NADPH como donores de electrones. En un intento de encontrar una actividad deshidrogenasa en levadura que pudiera mediar la toxicidad de beta-lapachona, analizamos la toxicidad de la droga en 
cepas mutantes en NADH deshidrogenasas. Del análisis de crecimiento de las cepas mutantes, sólo el mutante $\Delta$ nde 2 mostró mayor resistencia al tratamiento con beta-lapachona tanto en análisis de crecimiento en medio líquido como por goteo (Figura 24).

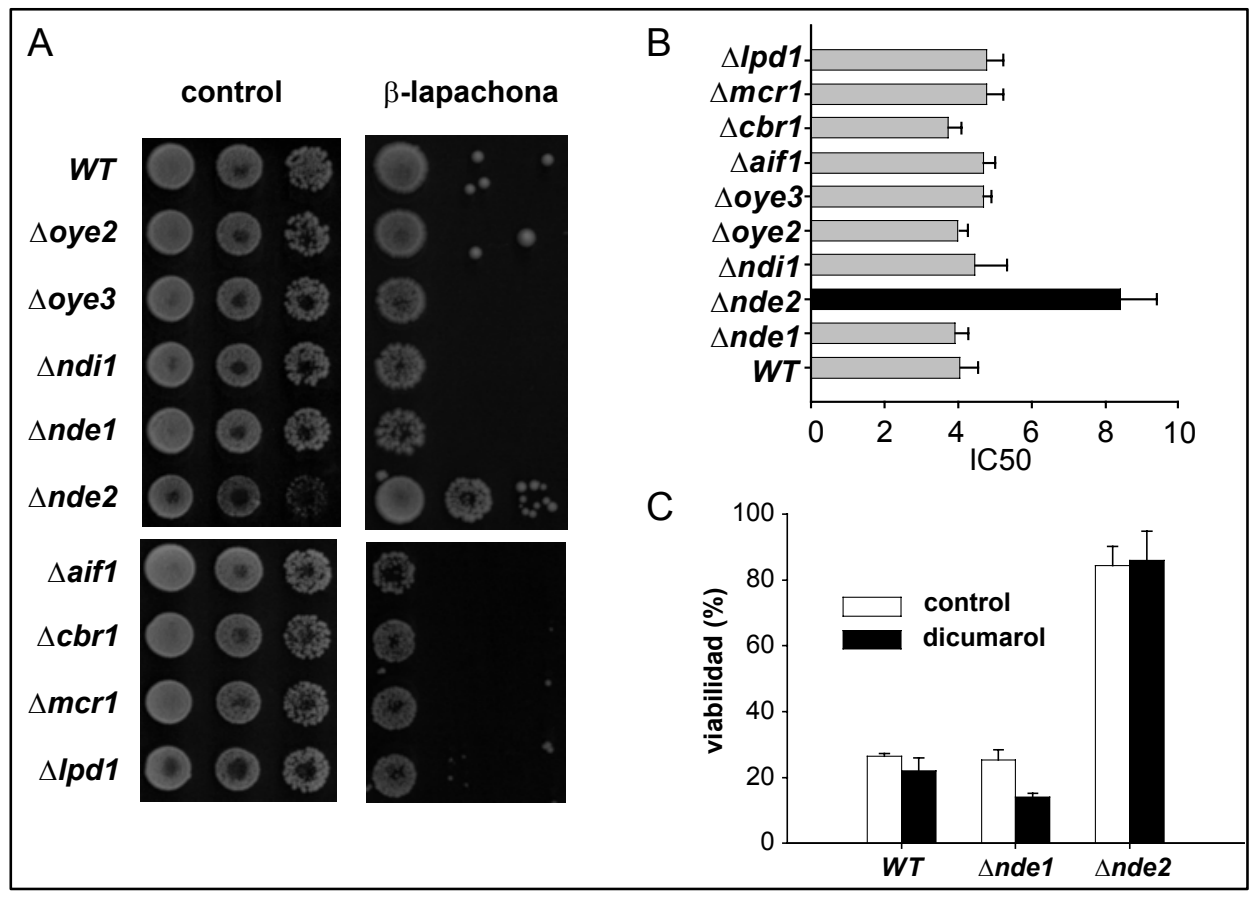

Figura 24: $\mathrm{A}$, crecimiento de mutantes en actividad deshidrogenasa en placas de YPD conteniendo $10 \mu \mathrm{g} / \mathrm{ml}$ de beta-lapachona. B, representación gráfica de los valores de IC50. C, estudio de la viabilidad de células WT, y mutantes $\Delta$ nde 1 y $\Delta$ nde 2 tras tratamiento de una hora con $10 \mu \mathrm{g} / \mathrm{ml}$ betalapachona en presencia y ausencia de dicumarol. 


\subsection{Análisis de la producción de ROS en mutantes en actividad deshidrogenasa.}

Con el propósito de descartar que la resistencia del mutante en la actividad deshidrogenasa $\Delta n d e 2$ sea debida a la falta de generación de radicales libres tras tratamiento con beta-lapachona, evaluamos la producción de estas especies reactivas de oxígeno en dicha cepa y en otros mutantes en actividad deshidrogenasa, en presencia y ausencia de dicumarol. Del análisis de los datos obtenidos podemos afirmar que el mutante $\Delta$ nde 2 produce niveles de ROS similares a los de células $W T$, mientras que el único mutante que muestra una menor producción de los mismos es $\Delta o y e 2$ (Figura 25). Al igual que en el $W T$, en todos los casos la adición de dicumarol impedía la acumulación de radicales (dato no mostrado). Si bien el mutante soye2 mostró generar menor acúmulo de ROS tras el tratamiento con beta-lapachona, la falta de función de esa deshidrogenasa fallaba en modular la toxicidad de la droga (Figura 24)

En conjunto, estos resultados indican que i) al igual que en mamíferos, el determinante de la toxicidad es una NADH deshidrogenasa, en este caso Nde2p; y ii) el mecanismo de modulación de la toxicidad no implica la producción de ROS. 


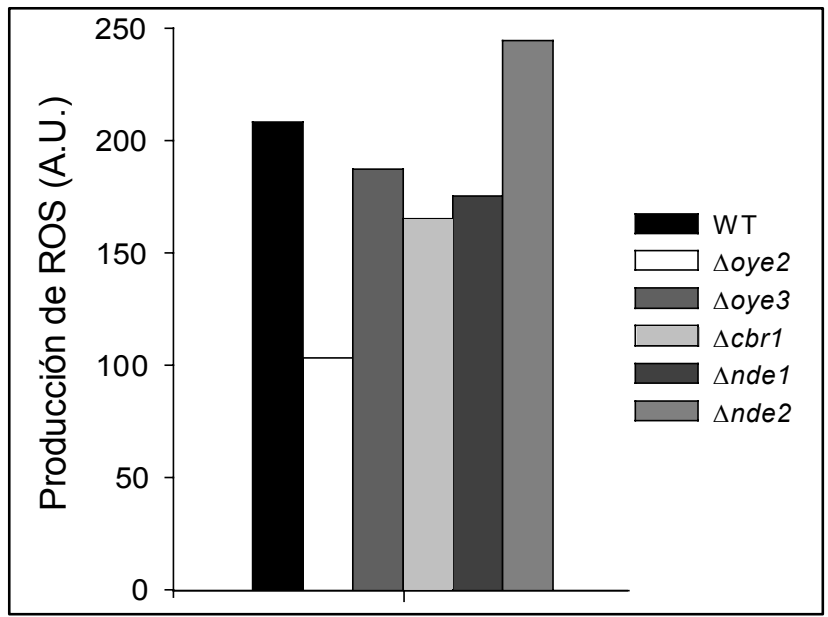

Figura 25: Representación gráfica de un experimento representativo mostrando la producción de radicales libres en cultivos celulares de distintos mutantes en la actividad deshidrogenasa tras tratamiento con $1 \mu \mathrm{g} / \mathrm{ml}$ de beta-lapachona. 


\section{Caracterización del mutante $\Delta$ nde2.}

\subsection{Estudios de la tolerancia del mutante $\Delta$ nde2 en distintas fuentes de carbono.}

Dado que NDE2 es una NADH deshidrogenasa mitocondrial que cataliza la oxidación del NADH citosólico en la cadena respiratoria mitrocondrial, decidimos evaluar el comportamiento de la cepa mutante en esta actividad en condiciones que favorecen la respiración, tanto como la toxicidad de beta-lapachona en estas condiciones. Para tal fin, crecimos células $W T$ y el mutante $\Delta n d e 2$ en medios con diferentes fuentes de carbono en presencia de distintas dosis de beta-lapachona. Del análisis de las curvas de crecimiento pudimos observar que el mutante $\Delta n d e 2$ era considerablemente más tolerante a la droga incluso en condiciones que favorecen la respiración en levaduras (Figura 26). También resultó notorio que la toxicidad de beta-lapachona se veía claramente incrementada cuando las cepas crecían sobre fuentes de carbono no fermentables, y además pudo evidenciarse que los medios de crecimiento en los que la droga mostraba mayor toxicidad, coincidían con aquellos en los cuales el mutante $\Delta$ nde 2 exhibía mayor defecto de crecimiento. 


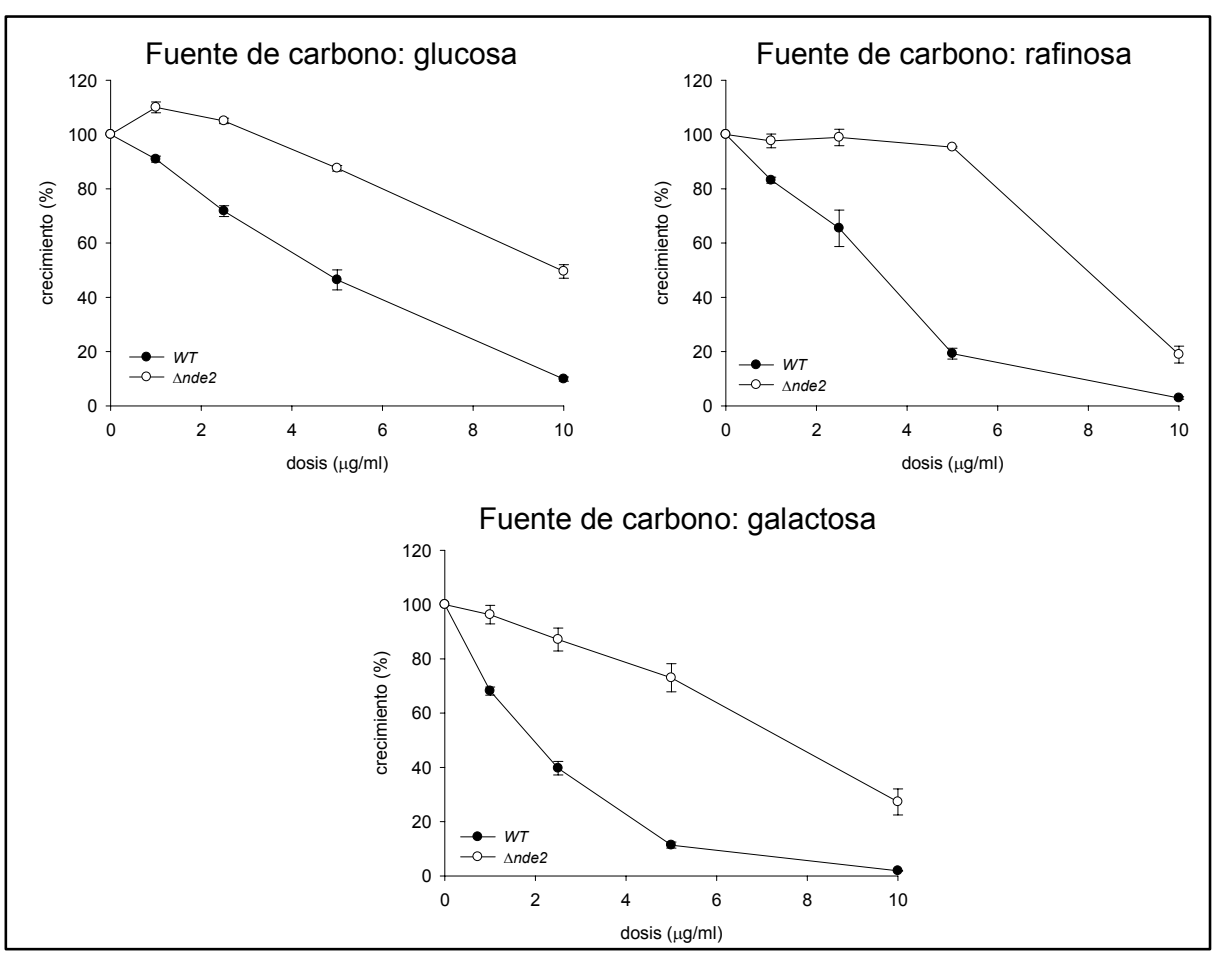

Figura 26: Análisis del crecimiento de las cepas $W T$ y $\Delta$ nde2 en microplacas conteniendo medio con distintas fuentes de carbono y diferentes concentraciones de beta-lapachona. Los resultados se expresan como el porcentaje de crecimiento de cada cepa a una dosis determinada respecto al control sin tratamiento. 


\subsection{Análisis de la respuesta de control del mutante $\Delta$ nde2.}

Dado que la falta de función de la deshidrogenasa Nde2p alivia la toxicidad de beta-lapachona en levadura, nos dispusimos a evaluar el estado de las rutas de control en este mutante en respuesta al tratamiento. Para tal fin realizamos un estudio de progresión de ciclo en la transición G1/S tras tratamiento con beta-lapachona en presencia y ausencia del agente dicumarol.

El tratamiento con la droga no indujo retraso en la transición G1/S en el mutante $\Delta$ nde2. Más aún, el mutante no sólo fallaba en activar un punto de control en estas condiciones, sino que incluso en condiciones normales demostró poseer una transición G1/S más lenta que la cepa WT (Figura 27A). Con el objeto de comprobar si esta falta de activación del mecanismo de control era de carácter general o específica de beta-lapachona, realizamos un análisis de progresión de ciclo en el mutante tras tratamiento con el agente MMS, pudiendo observar un retraso considerable en la progresión de ciclo tras el agregado de dicho lesionante (Figura 27B).

Por lo tanto, Nde2p media el retraso en la progresión G1/S producido por el tratamiento con beta-lapachona. La producción de ROS también media este retraso, aunque en menor medida. 


\subsection{Fosforilación de RAD53 e Histona H2A en el mutante $\Delta$ nde2.}

Siguiendo con el esquema de trabajo planteado, nos dispusimos a analizar el estado de fosforilación de la quinasa Rad53p y de la histona $\mathrm{H} 2 \mathrm{~A}$.

Para este fin, tratamos nuevamente cultivos de células $W T$ y del mutante $\Delta n d e 2$ con beta-lapachona y analizamos el estado de fosforilación de estas proteínas tras el tratamiento. En estas condiciones fuimos capaces de observar que mientras que el tratamiento incrementaba la fosforilación de Rad53p en células $W T$, esta fosforilación no era observada (o aparecía en mucha menor extensión) en el mutante $\Delta n d e 2$ incluso tras una hora de tratamiento con beta-lapachona (Figura 28A).

Interesantemente, tanto en cultivo asincrónico como en células arrestadas en $\mathrm{G} 1$, el mutante $\Delta$ nde2 mostraba fosforilación de histona $\mathrm{H} 2 \mathrm{~A}$ en su residuo Ser129 en una proporción similar a la de las células $W T$ (Figura 28B), sugiriendo la presencia de lesiones en este mutante tras el tratamiento.

Estos datos indican que todas las respuestas de control, con excepción de la fosforilación de histona H2A, son dependientes de la presencia de $\mathrm{Nde} 2 \mathrm{p}$ y sugieren que $\mathrm{Nde} 2 \mathrm{p}$ podría ser la diana molecular de beta-lapachona. 

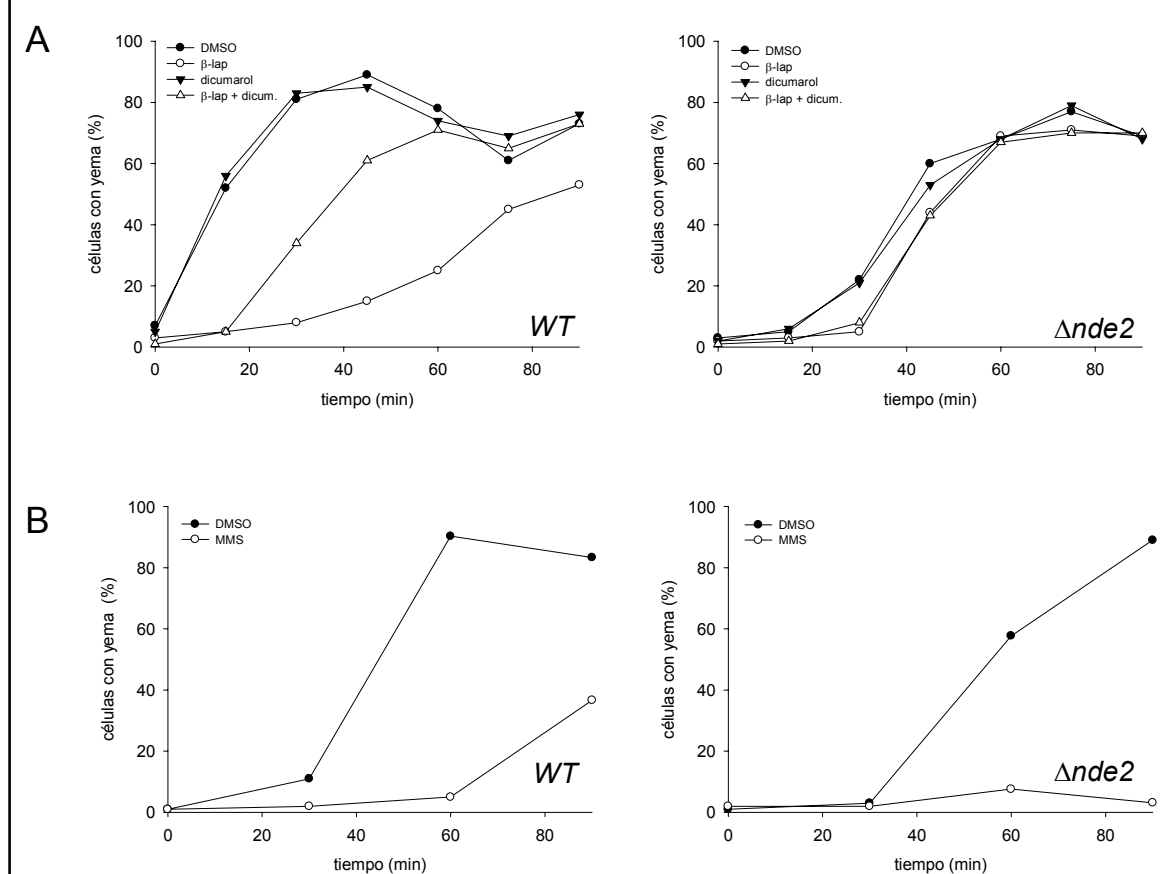

Figura 27: A, estudio de la progresión $\mathrm{G} 1 / \mathrm{S}$ de células $W T$ y $\Delta$ nde2 tras tratamiento con $10 \mu \mathrm{g} / \mathrm{ml}$ de beta-lapachona en presencia y ausencia de dicumarol. B, control de retraso en la progresión $\mathrm{G} 1 / \mathrm{S}$ de células $W T$ y $\Delta$ nde2 tratadas con MMS 0,1\%. 


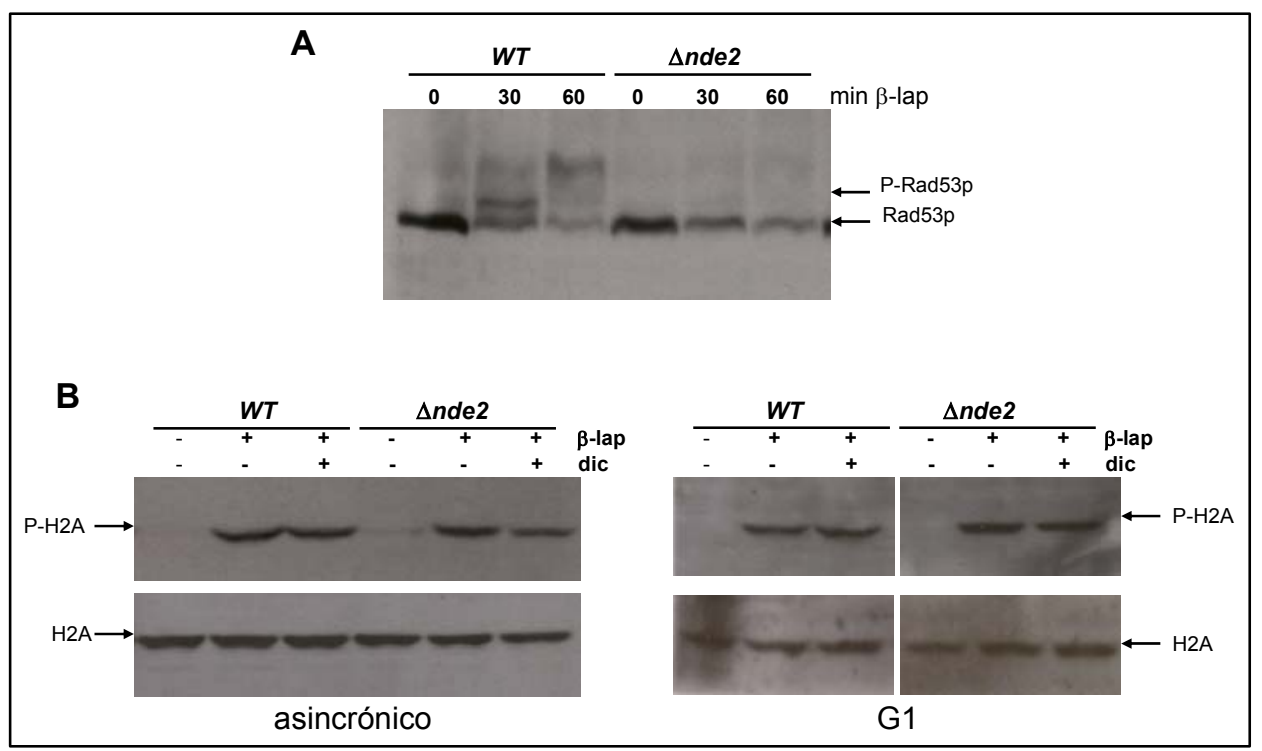

Figura 28: A, inmunodetección del estado de fosforilación de la quinasa Rad53p tras 30 minutos y una hora de tratamiento con $10 \mu \mathrm{g} / \mathrm{ml}$ de betalapachona en células $W T$ y $\Delta n d e 2 . \mathrm{B}$, inmunodetección de la forma fosforilada de la histona $\mathrm{H} 2 \mathrm{~A}$ tras tratamiento con beta-lapachona en presencia y ausencia de dicumarol, en células $W T$ y $\Delta n d e 2$ correspondientes a cultivos asincrónicos o arrestados en G1. 


\subsection{Sinergismos con otros agentes genotóxicos e implicación de NDE2.}

Una forma descrita de mejorar la eficacia de la terapia antitumoral es a través del desarrollo de combinaciones óptimas de drogas quimioterapéuticas. En este sentido, la combinación de betalapachona con taxol produce sinergismo debido a que la producción de un retraso simultáneo en las transiciones G1/S y G2/M del ciclo celular dispara la apoptosis (Li et al., 1999). Por otro lado, también está descrito que beta-lapachona sinergiza con la radiación ionizante y otros tratamientos que producen DSB (Park et al., 2005).

Con el objeto de analizar posibles sinergismos en la combinación de beta-lapachona con otros agentes genotóxicos, realizamos estudios de crecimiento en medio líquido en presencia de bajas concentraciones de nuestra droga en estudio, de hidroxiurea y phleomicina, y de combinaciones de éstas últimas con betalapachona.

Del análisis de las curvas de crecimiento pudimos observar que la combinación de dosis bajas de beta-lapachona tanto con hidroxiurea como con phleomicina, producía un sinergismo apreciable (Figura 29) en células $W T$.

Por lo tanto, en levadura beta-lapachona también coopera con otros lesionantes, extendiendo así el paralelismo entre las respuestas celulares a la droga en mamíferos y en levadura. 


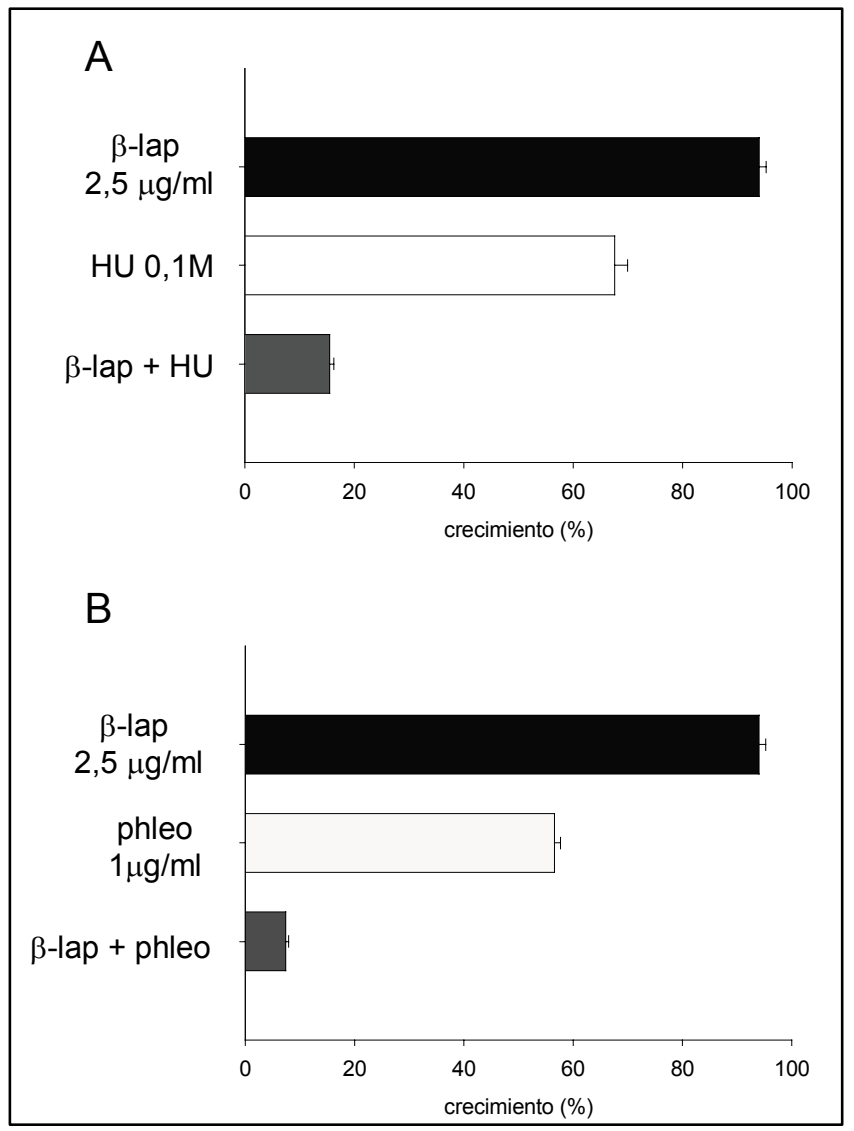

Figura 29: Estudio de la toxicidad de beta-lapachona en combinación con otras drogas. A, sinergismo entre hidroxiurea y beta-lapachona a dosis de $0,1 \mathrm{M}$ y $2,5 \mu \mathrm{g} / \mathrm{ml}$ respectivamente. $B$, sinergismo entre phleomicina y betalapachona a dosis de 1 y $2,5 \mu \mathrm{g} / \mathrm{ml}$ respectivamente. En todos los casos se representa el porcentaje de crecimiento de la cepa WT sometido a tratamiento respecto a su crecimiento normal sin agregado de droga. 


\subsection{Respuesta de $\Delta n d e 2$ a otros lesionantes.}

Beta-lapachona coopera también en levadura con otros tratamientos de quimioterapia. Si Nde2p es la diana molecular, entonces el mutante $\Delta$ nde2 debería mostrar sensibilidad a dichos tratamientos, mimetizando los efectos de beta-lapachona. Así, nos dispusimos a analizar el comportamiento del mutante $\Delta n d e 2$ frente a otros agentes lesionantes del ADN como hidroxiurea, phleomicina, metil metanosulfonato y radiación ultravioleta. Para esto, realizamos ensayos de crecimiento en medio líquido (excepto para radiación UV) y goteos en placa, en presencia de distintas concentraciones de estos lesionantes.

De los análisis de crecimiento pudimos observar que el mutante $\Delta$ nde2 exhibe mayor sensibilidad a algunos agentes genotóxicos que la cepa $W T$ (Figura 30), siendo principalmente notoria la sensibilidad a hidroxiurea y phleomicina. Estos datos son consistentes con el hecho de que Nde2p sea la diana intracelular de beta-lapachona, y sugieren que la cooperatividad de la droga observada previamente se debe a su acción sobre Nde2p. 


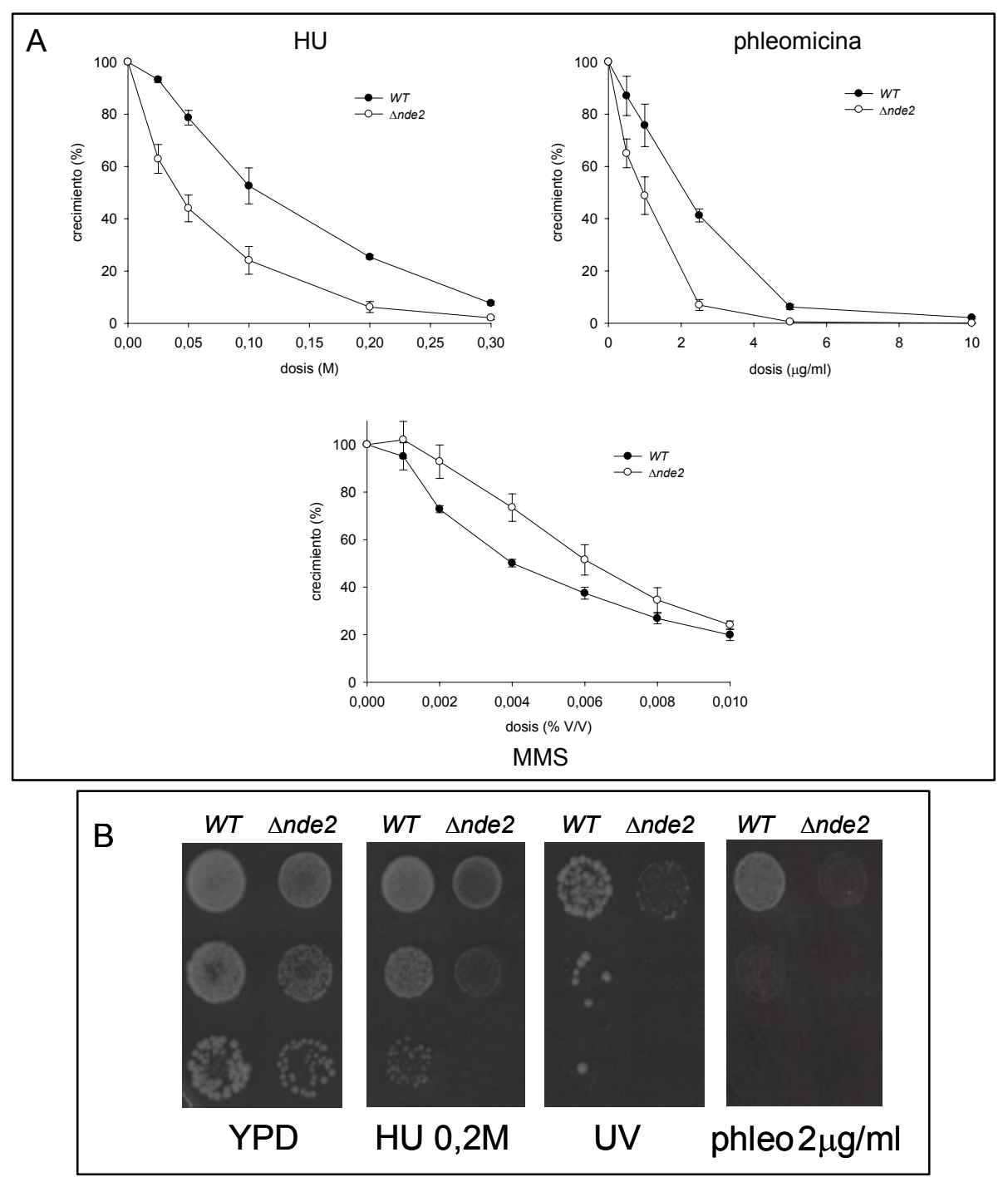

Figura 30: A, estudio del crecimiento de las cepas $W T$ y $\Delta n d e 2$ en medio con distintas concentraciones de Hidroxiurea, phleomicina, MMS o nocodazol. Los resultados se presentan como el porcentaje de crecimiento en presencia de droga respecto al control $\sin$ tratar. $B$, análisis del crecimiento de las cepas $W T$ y $\Delta$ nde2 en placas de YPD contiendo hidroxiurea o phleomicina, o expuestas a radiación ultravioleta. 


\subsection{Respuestas de los mecanismos de control del mutante $\Delta$ nde2 a phleomicina.}

Con el objeto de profundizar más en la sensibilidad a phleomicina exhibida por el mutante $\Delta$ nde2, nos dispusimos a observar las respuestas del mecanismo de control de este mutante frente a dicho tratamiento, y el estado de fosforilación de histona H2A en tales condiciones. Si la sensibilidad a phleomicina se debiera a un defecto en los puntos de control, la activación del mismo se vería disminuida. Si se debiera a un defecto de reparación, la activación del mecanismo de control se vería exacerbada.

Tras el tratamiento con phleomicina el mutante $\Delta$ nde2 motró un retraso mayor en la progresión de ciclo en comparación con la cepa WT (Figura 31B). Además, el tratamiento con phleomicina incrementó el grado de fosforilación de histona H2A en el mutante respecto a las mismas condiciones de tratamiento en la cepa WT (Figura 31A).

Estos datos sugieren que la sensibilidad del mutante $\Delta$ nde2 a phleomicina se debe a un defecto en la reparación del ADN. 


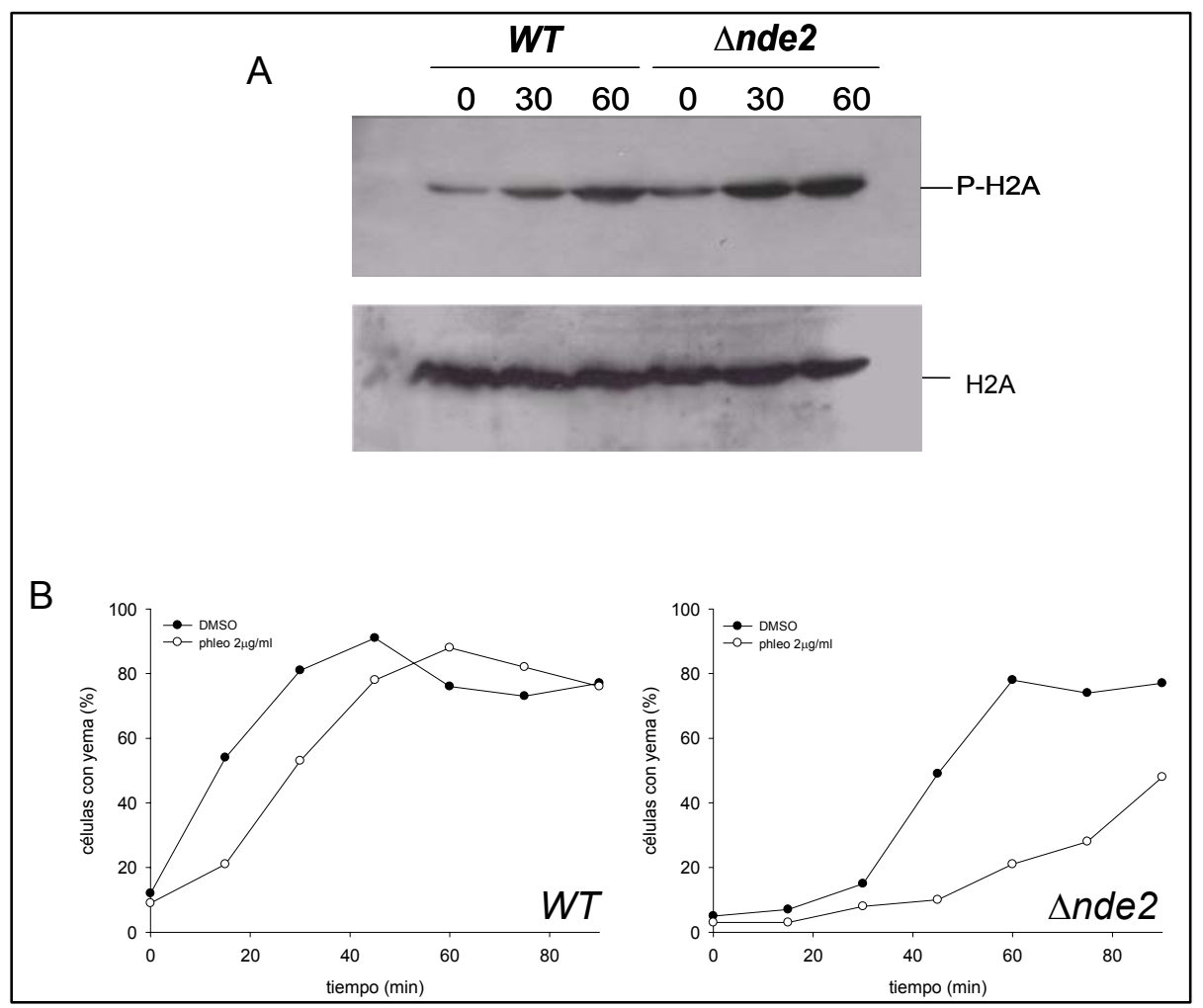

Figura 31: $A$, inmunodetección de la forma fosforilada de la histona $H 2 A$ tras tratamiento con $2,5 \mu \mathrm{g} / \mathrm{ml}$ de phleomicina en las cepas $W T$ y $\Delta n d e 2$. B, análisis de la progresión $\mathrm{G} 1 / \mathrm{S}$ de células $W T$ y $\Delta n d e 2$ tras tratamiento con $2,5 \mu \mathrm{g} / \mathrm{ml}$ de phleomicina. 


\subsection{Nde2p y el sistema de reparación de DSB.}

Dado que el mutante $\Delta$ nde 2 ha mostrado tener niveles basales elevados de fosforilación de histona $\mathrm{H} 2 \mathrm{~A}$, y que posee una transición G1/S más lenta, nos preguntamos si, de alguna manera, esta mutación estaba afectando al sistema de reparación de DSBs.

En eucariotas inferiores como la levadura Saccharomyces cerevisiae, las roturas de doble banda son reparadas principalmente por recombinación homóloga, la cual se basa en el intercambio de la información genética entre una molécula de ADN dañada y una copia sin dañar (Boulton et al., 1996). Los componentes mejor caracterizados del sistema de recombinación homóloga en levaduras son Rad51p y Rad52p. Sin embargo, en condiciones en las que las roturas de doble hebra en el ADN no pueden ser reparadas por recombinación homóloga, existen eventos de reparación mediante el sistema de unión de extremos no homólogos, cuyo componente más importante en levadura es Yku80p.

Para saber si cepas de levadura deficientes en Nde2p también muestran deficiencias en el sistema de religación de DSBs por unión de extremos no homólogos, empleamos un ensayo basado en la reparación de un plásmido (Boulton et al., 1996). En este ensayo se utilizan endonucleasas de restricción para generar un DSB en una región de un plásmido sin homologías al ADN cromosómico. Las muestras del plásmido lineal (como así también la cantidad equivalente de plásmido superenrollado) son luego utilizadas para transformar levaduras, y el número de transformantes es 
contabilizado. Así, la eficiencia de transformación usando plásmido lineal, normalizada con la correspondiente al plásmido sin cortar, proporciona una lectura cuantitativa de la capacidad de una cepa de reparar DSBs.

En nuestro caso realizamos este ensayo en las cepas $W T$ y $\Delta n d e 2$, llevando como control la cepa mutante $\Delta Y k u 80$. El recuento de los transformantes demostró que el mutante $\Delta$ nde2 poseía niveles de reparación sorprendentemente elevados cuando se los compara con la cepa WT (Figura 32), sugiriendo que de algún modo, la ausencia de Nde2 $p$ redunda directa o indirectamente en una activación de la vía de reparación de DSBs, probablemente, a través del sistema de unión de extremos no homólogos.

Como puede observarse en la figura la fracción de plásmido reparado por el mutante $\Delta Y k u 80$ es menor que en células $W T$, lo cual concuerda con la menor eficiencia de reparación descrita en la literatura para este mutante. 


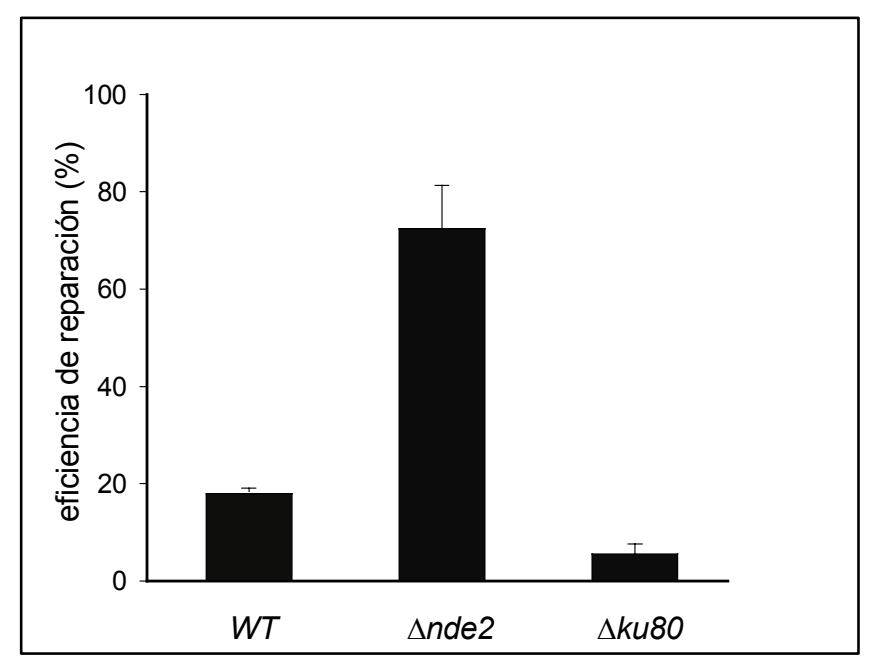

Figura 32: Estudio de la eficiencia de reparación de un plásmido linearizado en células $W T, \Delta n d e 2$ y $\Delta K u 80$. Los resultados se expresan como el porcentaje de células viables transformadas con el plásmido linearizado respecto a las obtenidas con la misma cantidad de plásmido sin cortar. 
Resultados 


\section{Beta-lapachona y la ruta de control general de nutrientes.}

\subsection{Genómica funcional con beta-lapachona.}

Con el propósito de profundizar en las respuestas al tratamiento con beta-lapachona en levadura, comparamos los perfiles de expresión génica de la cepa $W T$ tratada con beta-lapachona durante una hora, con los obtenidos con una cepa $W T$ sin tratar, utilizando micromatrices de ADNc. Para identificar genes expresados diferencialmente entre estas dos condiciones, realizamos un análisis SAM, de Análisis de Significancia de Micromatrices (Significance Análisis of Microarrays).

Siguiendo los criterios descritos en Materiales y Métodos, tras el tratamiento con beta-lapachona 212 genes resultaron inducidos y 52 reprimidos. Con estos datos realizamos una clasificación funcional de genes inducidos/reprimidos de acuerdo a los términos de GO (Gene Ontology, ontología génica), utilizando las bases de datos Go Finder y FatiGo plus.

Sorprendentemente, las categorías más representadas y significativamente enriquecidas en el grupo de genes expresados diferencialmente corresponden a biosíntesis de aminoácidos (Tabla 5). Como era de esperar, otra categoría representada en este análisis corresponde a la respuesta a estrés oxidativo. 


\section{CLASIFICACIÓN FUNCIONAL DE GENES INDUCIDOS}

\begin{tabular}{|c|c|c|}
\hline Proceso Biológico & valor de $p$ & Nivel \\
\hline Biosíntesis de aminas & $1,6 \mathrm{e}-11$ & 6 \\
\hline Biosíntesis de aminoácidos & $1,6 \mathrm{e}-11$ & 7 \\
\hline Metabolismo de aminoácidos & 9,3 e-10 & 6 \\
\hline Biosíntesis de aminoácidos de la familia de glutamina & 6,1 e-08 & 8 \\
\hline Metabolismo de lisina & 5,3 e-07 & 8 \\
\hline Biosíntesis de lisina & 6,7 e-07 & 9 \\
\hline Biosíntesis de arginina & 1,6 e-06 & 9 \\
\hline Metabolismo de arginina & $1,6 \mathrm{e}-06$ & 8 \\
\hline Metabolismo de aminoácidos de la familia de glutamina & 1,9 e-05 & 7 \\
\hline Metabolismo de aminoácidos de la familia del aspartato & 1,0 e-02 & 7 \\
\hline Metabolismo de aminoácidos no proteicos & 1,3 e-02 & 7 \\
\hline Catabolismo de aminoácidos & $1,5 \mathrm{e}-02$ & 7 \\
\hline Respuesta a especies reactivas de oxígeno & 1,8 e-02 & 6 \\
\hline $\begin{array}{l}\text { Procesos biosintéticos de aminoácidos de la familia } \\
\text { del aspartato }\end{array}$ & $2,3 e-02$ & 8 \\
\hline Procesos catabólicos de aminas & 2,9 e-02 & 6 \\
\hline Metabolismo de ornitina & 3,6 e-02 & 8 \\
\hline Biosíntesis de glutamato & 3,9 e-02 & 9 \\
\hline
\end{tabular}

Tabla 5: Clasificación funcional de los genes inducidos diferencialmente en la cepa $W T$ tras tratamiento durante una hora con beta-lapachona. Para hacer más simple el análisis, sólo se representan las categorías con un valor de $p<0,01$ correspondientes a niveles 6 o superior de acuerdo a Gene Ontology. 


\section{CLASIFICACION FUNCIONAL DE GENES REPRIMIDOS}

\begin{tabular}{|l|c|c|}
\hline \multicolumn{1}{|c|}{ Proceso biológico } & valor de $\mathbf{p}$ & Nivel \\
\hline Transporte de electrones & $1,2 \mathrm{e}-02$ & 5 \\
\hline
\end{tabular}

Tabla 6: Clasificación funcional de los genes reprimidos diferencialmente en la cepa $W T$ tras tratamiento durante una hora con beta-lapachona (sólo se representan las categorías con un valor de $p<0,01$ correspondientes a niveles 5 o superior de acuerdo a Gene Ontology). 


\subsection{Beta-lapachona y la ruta de control traduccional.}

Los resultados obtenidos en los experimentos de micromatrices en la cepa WT tras ser tratada durante una hora con beta-lapachona, indican que existe una clara activación de genes de biosíntesis de aminoácidos. Los genes de biosíntesis de aminoácidos se inducen en respuesta al ayuno de nutrientes en levadura. Ya que el ayuno de nutrientes en levadura activa la ruta de control general de nutrientes o ruta GCN, este resultado sugiere que la droga activa de alguna manera esta ruta. Con el propósito de verificar si beta-lapachona activaba la ruta de control traduccional analizamos el estado de fosforilación de elF $2 \alpha$, el cual es el sustrato fisiológico de la quinasa central de esta ruta, Gcn2p. El estado de fosforilación de elF2 $\alpha$ se examinó mediante inmunodetección con un anticuerpo que reconoce específicamente la forma fosforilada en la Ser-51 de la proteína.

Para realizar este análisis cogimos muestras de cultivos de células $W T, \Delta g c n 1, \Delta g c n 2$ y $\Delta g c n 20$ al comienzo del experimento, y tras 1, 2 y 3 horas de tratamiento con beta-lapachona.

Como podemos observar en la Figura 33, el tratamiento con betalapachona incrementó la fosforilación de elF2 $\alpha$ en la cepa $W T$ de un modo dependiente de tiempo. Este efecto era totalmente dependiente de Gcn2p, dado que la ausencia de esta quinasa impedía completamente la fosforilación de elF2 $\alpha$. Más aún, la activación de la quinasa Gcn2p bajos las condiciones analizadas parece estar sujeta a regulación por Gcn1p y al menos parcialmente por Gcn20p. 
Por lo tanto, el tratamiento con beta-lapachona activa de alguna manera la ruta $G C N$.

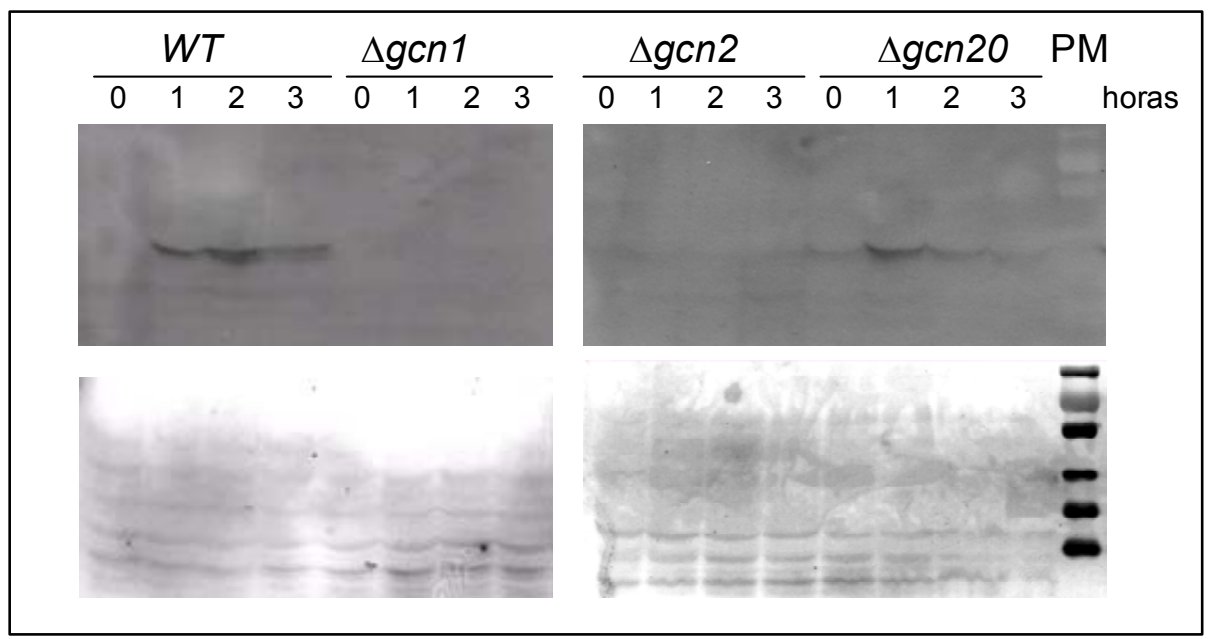

Figura 33: Inmunodetección de la forma fosforilada de la subunidad alfa del factor de iniciación elF2 en células $W T, \Delta g c n 1, \Delta g c n 2$ y $\Delta g c n 20$ tras tratamiento con $10 \mu \mathrm{g} / \mathrm{ml}$ de beta-lapachona. En la parte inferior se muestra el control de carga por tinción de la membrana con colorante Ponceau tras la transferencia. 


\subsection{Análisis de la implicación de la ruta $G C N$ en las respuestas disparadas por beta-lapachona.}

Tras haber observado que el tratamiento con beta-lapachona era capaz de activar la ruta de control traduccional en levadura, decidimos evaluar si esta activación respondía a la generación de un ayuno. Con tal motivo, analizamos el crecimiento de células WT sometidas a distintas dosis de beta-lapachona, en presencia de exceso de los aminoácidos leucina, histidina y metionina, y de la purina uracilo. Paralelamente estudiamos la fosforilación del factor elF2 $\alpha$ por tratamiento con beta-lapachona en células WT en presencia de un exceso de nuetrientes. El estudio de las curvas de crecimiento (Figura 34A) y del estado de fosforilación de elF2 $\alpha$ (Figura 34B) indicó que en las condiciones analizadas, la activación de la ruta de control traduccional no responde a la producción de un ayuno de aminoácidos.

Con objeto de analizar la implicación de la activación de la ruta GCN en las otras respuestas disparadas por el tratamiento, valoramos si mutaciones en esta ruta eran capaces de modular la viabilidad de cultivos tratados con beta-lapachona. Del análisis de las viabilidades de mutantes en los distintos componentes de esta ruta, pudimos apreciar que sólo el mutante $\Delta g c n 2$ mostró una apreciable caída en la supervivencia a tratamiento con la droga (Figura 34C). El hecho de que el mutante $\Delta g c n 4$ responda al tratamiento de manera similar a la cepa $W T$ refuerza el dato previo que indica la no generación de ayuno por beta-lapachona. Por otro lado, el hecho de que sólo el mutante $\Delta g c n 2$ sea sensible a la droga sugiere que la activación de 
la quinasa Gcn2p está involucrada de alguna manera en la toxicidad de la droga.

Para validad esta hipótesis, analizamos el comportamiento del mutante $\mathrm{GCN}^{c}$ frente al tratamiento con beta-lapachona. Este mutante presenta una actividad de la quinasa Gcn2p constitutivamente alta aún en ausencia de ayuno de nutrientes. En la Figura 35 se muestran los ensayos en placa y las curvas de crecimiento de este mutante y el $W T$ en presencia de distintas dosis de beta-lapachona. El mutante $G C N 2^{c}$, que mostró un defecto de crecimiento respecto al $W T$, evidenció una clara hipersensibilidad a la droga incluso a dosis muy bajas de la misma. 


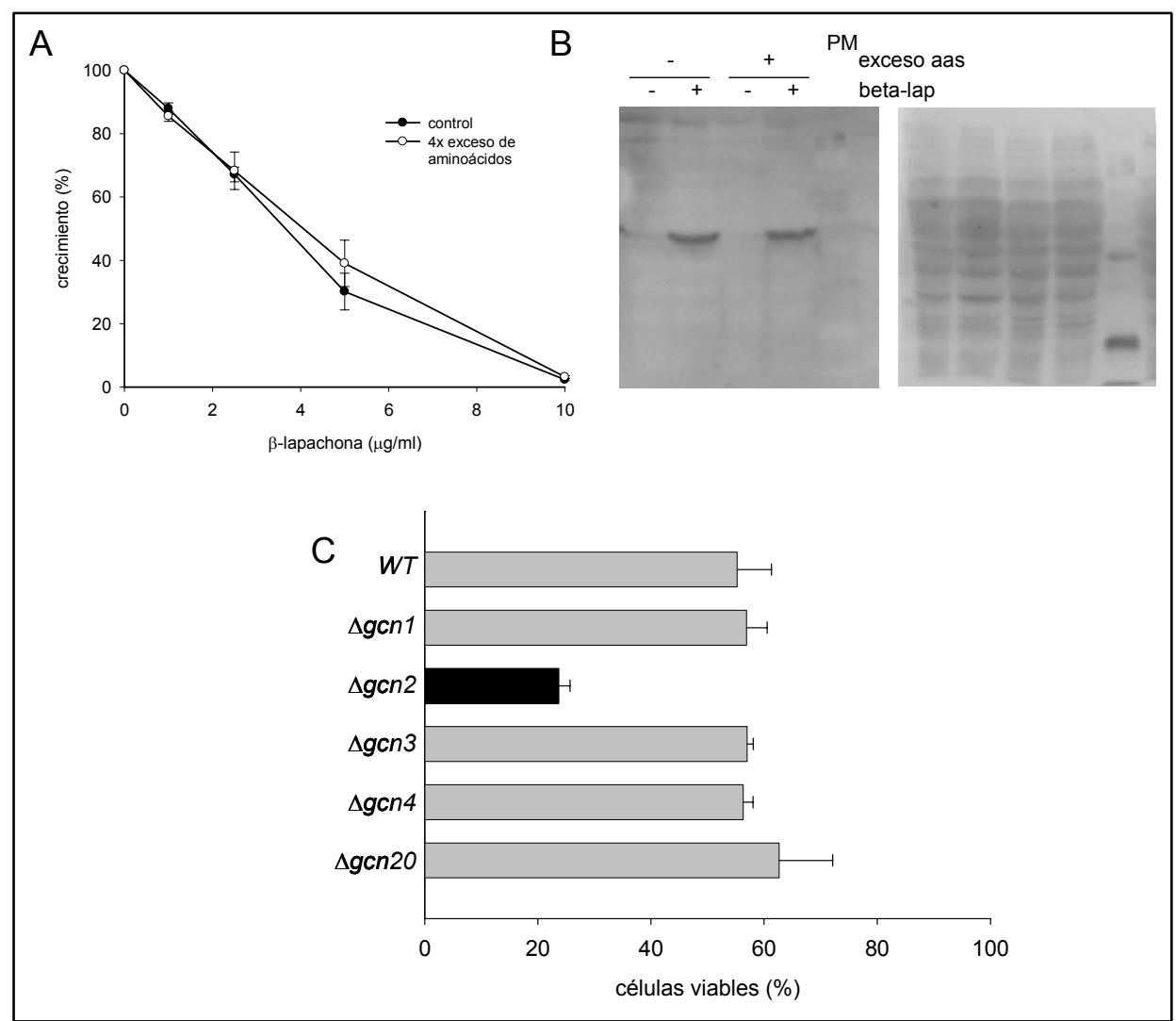

Figura 34: $\mathrm{A}$, análisis del crecimiento de cultivos de levadura tratados con distintas dosis de beta-lapachona en presencia de un exceso de leucina, histidina, metionina y uracilo. B, estudio de la fosforilación de elF2 $\alpha$ en células $W T$ tratadas con beta-lapachona en presencia de exceso de aminoácidos: izquierda, inmunodetección; derecha, tinción con Ponceau S. $\mathrm{C}$, estudio de la viabilidad de mutantes en la ruta GCN frente a tratamiento durante una hora con $10 \mu \mathrm{g} / \mathrm{ml}$ de beta-lapachona. 


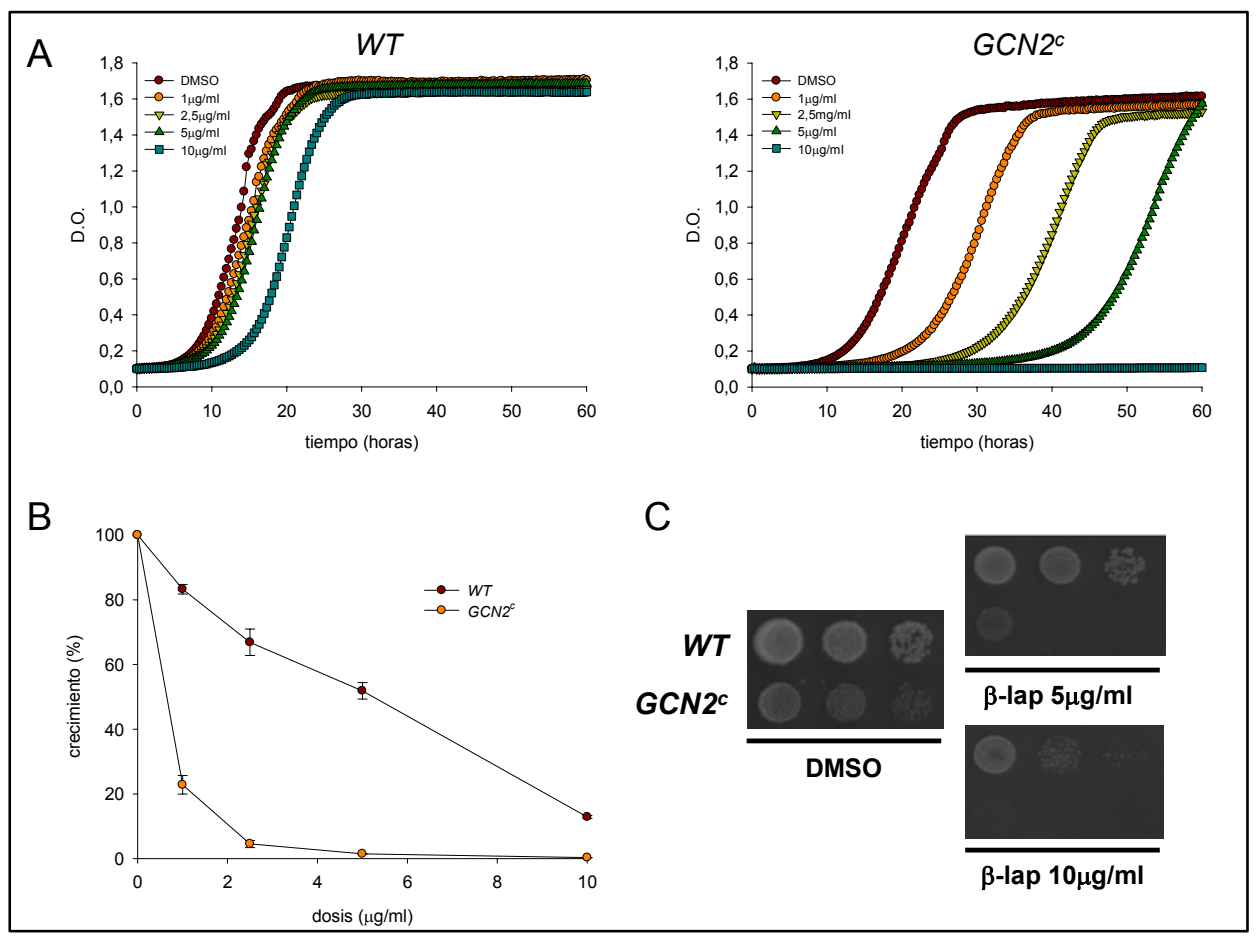

Figura 35: A, estudio de las curvas de crecimiento de las cepas $W T$ y $G C N 2^{c}$ en presencia de distintas dosis de beta-lapachona. B, representación del porcentaje de crecimiento de las cepas $W T$ y $G C N 2^{c}$ tras tratamiento con beta-lapachona respecto a su control sin tratar. C, análisis del crecimiento en placa de las cepas $W T, G C N 2^{c}$ y $\Delta g c n 2$ en presencia de diferentes dosis de beta-lapachona 


\subsection{Respuestas de las vías de control en mutantes en la ruta de control traduccional.}

Habiendo observado que el tratamiento con beta-lapachona es capaz de activar la ruta de control traduccional en levadura, nos dispusimos a evaluar la posible relevancia de esta activación en las respuestas de los puntos de control a tratamiento con beta-lapachona observadas previamente.

En primer lugar, estudiamos la progresión de ciclo a través de la transición G1/S en células $W T$ y en el mutante $\Delta g c n 2$. De este análisis pudimos observar que en el mutante $\Delta g c n 2$, el retraso en la progresión a través de G1/S producido por beta-lapachona es menor que en células $W T$ (Figura 36A). Este dato es consistente con evidencias recientes que asignan un papel a Gcn2p en las respuestas celulares de daño al ADN (Menacho-Márquez et al., 2007).

Seguidamente, procedimos a analizar el estado de fosforilación de la histona $\mathrm{H} 2 \mathrm{~A}$ tras el tratamiento con beta-lapachona, en los mutantes $\triangle g c n 2$ y $G C N 2^{c}$, como así también en la cepa $W T$, tanto en cultivos asincrónicos como en condiciones de arresto con factor alfa. En ambas condiciones de ciclo pudimos observar un marcado descenso en los niveles de fosforilación de histona $\mathrm{H} 2 \mathrm{~A}$, en el mutante $G C N 2^{c}$ (Figura 36B), indicando este hecho una ausencia de activación de las respuestas de control en este mutante. 


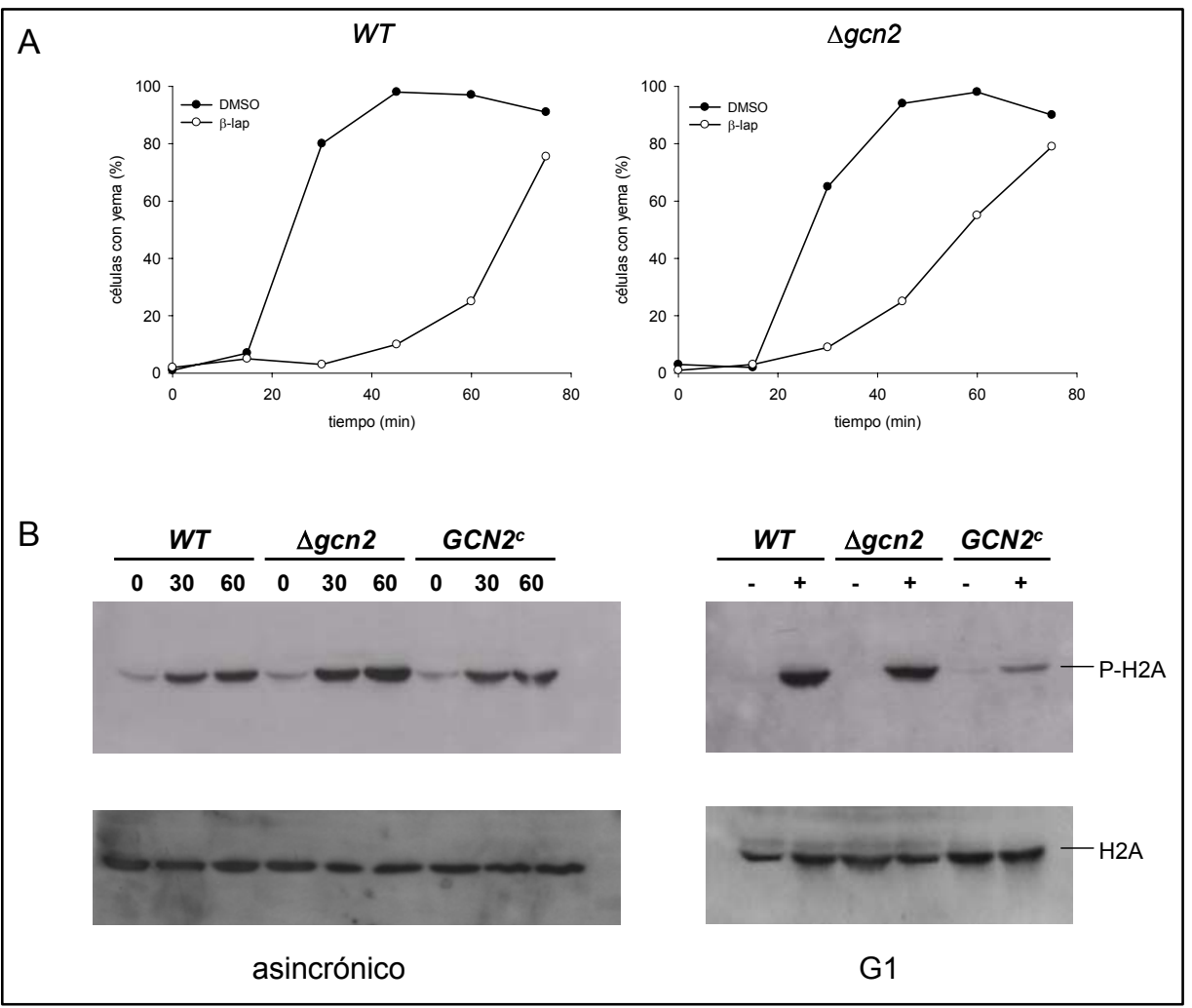

Figura 36: A, progresión a través de la transición $\mathrm{G} 1 / \mathrm{S}$ de células $W T$ y $\Delta g c n 2$ tras tratamiento con beta-lapachona. B, Inmunodetección del estado de fosforilación de histona $\mathrm{H} 2 \mathrm{~A}$ en células $W T, G C N 2^{c}$ y $\Delta g c n 2$ tras tratamiento con beta-lapachona en cultivos asincrónicos o arrestados en G1. 


\subsection{Activación de la ruta de control traduccional en los mutantes con mecanismos de control defectivos.}

Dado que es evidente la implicación de GCN2 en las respuestas de control de ciclo activadas por tratamiento con beta-lapachona, nos preguntamos si alguno de los componentes del mecanismo de control disparado por la droga sería capaz de modular el grado de activación de la quinasa Gcn2p. Con objeto de abordar esta cuestión, analizamos el estado de fosforilación de elF $2 \alpha$ tras tratamiento con beta-lapachona en células $W T$ y en los mutantes $\Delta m e c 1, \Delta t e l 1$, $\Delta m e c 1 \Delta t e l 1$ y $\Delta x m r$ (Figura 37). Sorprendentemente, la fosforilación de elF2 $\alpha$ por tratamiento con beta-lapachona requería la presencia del complejo XMR.

En conjunto, estos datos sugieren que la activación de Gcn2p por tratamiento con beta-lapachona requiere al complejo XMR. Este dato es de particular relevancia ya que constituye la primera evidencia que asigna una conexión funcional entre el complejo XMR y la ruta GCN. 


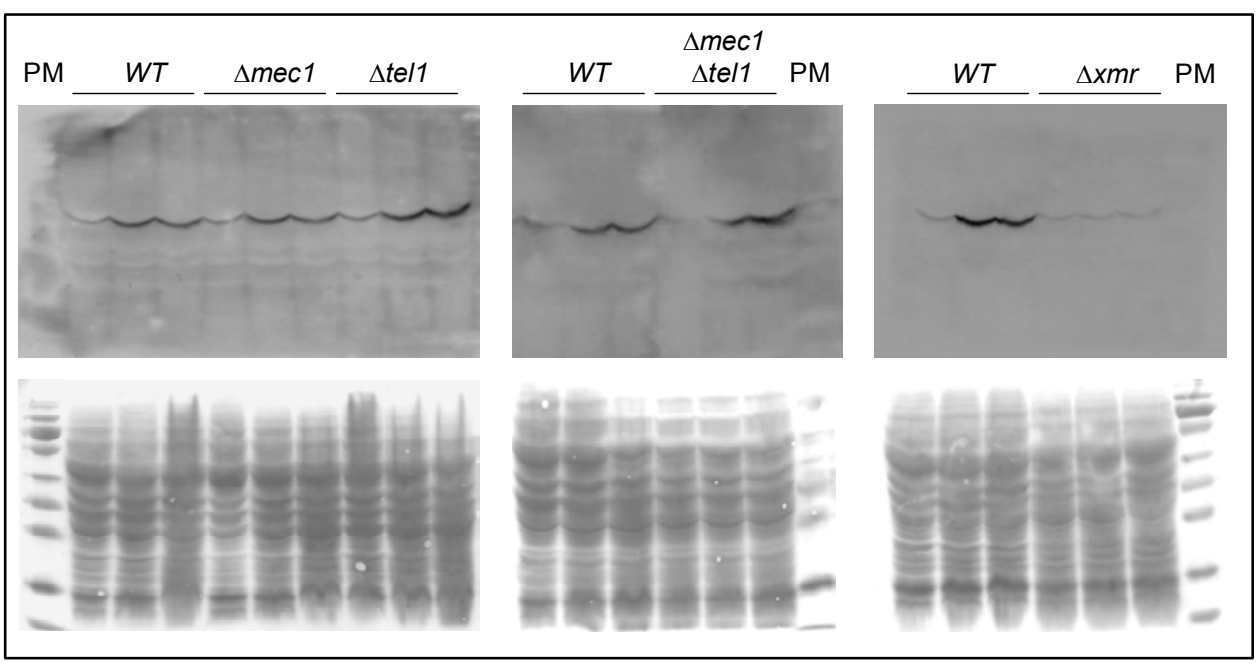

Figura 37: Inmunodetección de la forma fosforilada de la subunidad alfa del factor de iniciación elF2 en células $W T$ y en los mutantes $\Delta s m l 1, \Delta m e c 1$, $\Delta t e l 1, \Delta m e c 1 \Delta t e l 1$ y $\Delta x m r$ tras tratamiento con $10 \mu \mathrm{g} / \mathrm{ml}$ de beta-lapachona. En la parte inferior se muestra el control de carga por tinción de la membrana con colorante Ponceau tras la transferencia. 


\subsection{Beta-lapachona activa la ruta de control traduccional en una} forma dependiente de Nde2p.

Habiendo observado que el mutante $\Delta$ nde 2 es capaz de modular las respuestas disparadas por beta-lapachona, nos cuestionamos si la activación de la ruta GCN también estaría sujeta a modulación por esta actividad deshidrogenasa. Como podemos observar en la Figura 38, el tratamiento con beta-lapachona indujo una fosforilación importante de elF2 $\alpha$ en la cepa $W T$ de un modo dependiente de tiempo. Sorprendentemente, el mutante $\Delta n d e 2$ mostró negativamente afectada esta fosforilación, indicando que en dicho mutante la activación de la ruta de control traduccional se ve considerablemente menos inducida por tratamiento con betalapachona. 


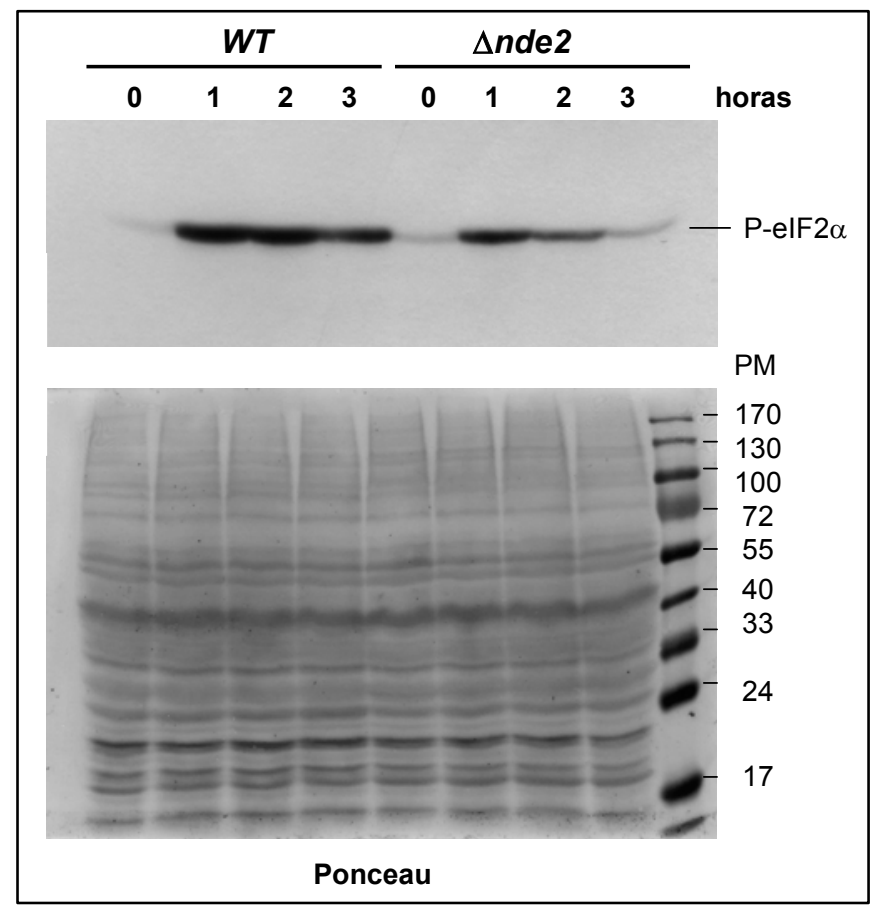

Figura 38: Inmunodetección de la forma fosforilada de la subunidad alfa del factor de iniciación elF2 en células $W T$ y $\Delta$ nde2 tras tratamiento con 10 $\mu \mathrm{g} / \mathrm{ml}$ de beta-lapachona. En la parte inferior se muestra el control de carga por tinción de la membrana con colorante Ponceau tras la transferencia. 

DISCUSIÓN 



\section{Beta-lapachona es citotóxica en levadura y activa un punto de control dependiente de Mre11p y Tel1p.}

El producto natural derivado de plantas, beta-lapachona, es un agente antitumoral que induce selectivamente la apoptosis en células humanas transformadas con amplio espectro de actividad, aunque no en células normales en proliferación (Li et al., 2003). También ha sido ampliamente demostrado que posee una potente actividad antitumoral en xenotrasplantes (Li et al., 1999). Sin embargo, el mecanismo por el cual se consigue esto no se comprende en su totalidad.

En un principio se había propuesto que beta-lapachona no era capaz de causar daños en el ADN, aunque actualmente se acepta que es capaz de inducir vías de control/respuesta al daño al ADN (Pardee et al., 2002). Se ha sugerido que la selectividad de beta-lapachona hacia células tumorales se debe a la activación de un punto de control de fase S (Li et al., 2002). La activación de este punto de control en células de mamíferos precede a la apoptosis disparada por la droga y se presenta como una diana importante para el desarrollo de agentes antitumorales más selectivos (Li et al., 2002).

En la presente tesis hemos caracterizado los mecanismos de citotoxicidad de beta-lapachona a nivel molecular en $S$. cerevisiae. Hemos comprobado la citotoxicidad de beta-lapachona en nuestro sistema modelo y vimos que la misma es dependiente de dosis (Figura 8), y pudimos observar también que la droga induce específicamente un retardo en la progresión G1/S del ciclo celular 
(Figura 9). Estas observaciones correlacionan con la evidencia descrita en la literatura (Pardee et al., 2002), y por lo tanto validan la utilización de levadura como sistema modelo para analizar a nivel molecular el mecanismo de acción del antitumoral beta-lapachona.

El tratamiento con beta-lapachona demostró ser citotóxico y activó varias respuestas de control de ciclo, como: i) una parada en la progresión G1/S (Figura 9), ii) fosforilación de la quinasa de control Rad53p (Figura 11), y iii) fosforilación de la histona H2A (Figura 15). Todas estas respuestas fueron completamente dependientes de las quinasas de control Mec1p/Tel1p y del complejo XMR (Figuras 1216). Más aún, XRS2 y TEL1 actúan epistáticamente respecto a la sensibilidad a beta-lapachona (Figura 17), y Xrs2p se fosforila tras el tratamiento de una manera dependiente de Tel1p (Figura 18). Por lo tanto la activación del mecanismo de control Mre11p-Tel1p regula la toxicidad de beta-lapachona en levadura (Menacho-Márquez et al., 2006). Dado que el mecanismo de control dependiente de Mre11Tel1p está conservado en eucariotas, estos hallazgos proveen nuevas evidencias acerca de los mecanismos moleculares involucrados en la toxicidad de beta-lapachona. En acuerdo con nuestros datos, se ha demostrado recientemente en células MCF-7 que la exposición a beta-lapachona resulta en la activación del complejo Mre11-Rad50-Nbs1 (MRN) y fosforilación de ATM en su serina 1981 (Bentle MS et al., 2007).

Este hallazgo explica porqué beta-lapachona es capaz de activar un mecanismo de control en células tumorales con maquinarias de control defectivas. Este hecho tiene una relevancia muy importante 
en la terapia antitumoral, ya que en más del $50 \%$ de los tumores el control de G1 está inactivo debido a mutaciones en p53. Los genes del complejo MRN son esenciales en mamíferos, y las células tumorales no presentan mutaciones en los mismos, por lo cual la activación del complejo MRN se presenta como una importante herramienta para el desarrollo de fármacos antitumorales. La activación de un punto de control en células con respuestas de control defectivas por tratamiento con beta-lapachona se ve reflejada en levadura por el comportamiento del mutante $\Delta m e c 1$, que muestra una parada en la progresión G1/S similar a la observada en células WT (Figura 12).

El mecanismo por el cual beta-lapachona activa la vía Mre11p-Tel1p actualmente es desconocido. La ruta dependiente de Mre11p-Tel1p es activada por agentes que inducen DSBs tanto en levaduras como en eucariotas superiores. La explicación más simple podría ser que la exposición a beta-lapachona de alguna manera indujera DSBs promoviendo así la activación de esta ruta de control. Esta teoría se apoya en que: i) mutantes de levadura con sistemas de reparación de DSBs defectivos son hipersensibles al tratamiento con betalapachona (Figura 14), y ii) beta-lapachona induce la fosforilación en serina 129 de la histona H2A (Figura 15), un marcador bien establecido de generación/reparación de DSBs. Aun queda por determinarse si la generación de DSBs es por acción directa o indirecta de esta droga sobre el ADN. Aunque beta-lapachona puede unirse al ADN in vitro, su afinidad por el ADN no parece correlacionar con su actividad antineoplásica (Renou et al., 2003). Por otro lado, enzimas implicadas en el metabolismo del ADN son inhibidas in vitro 
por beta-lapachona (Parde et al., 2002). En este aspecto, las ADN topoisomerasas podrían ser buenos candidatos ya que: i) betalapachona inhibe in vitro las topoisomerasas I y Il $\alpha$ (Li et al., 2003), y ii) beta-lapachona induce in vitro daño al ADN mediado por la topoisomerasa II (Renou et al., 2003). Sin embargo los mutantes de levadura $\Delta t o p 1$ y $\Delta t o p 3$ exhiben el mismo grado de sensibilidad al tratamiento que las células $W T$, además de mostrar similares niveles de fosforilación de Rad53p tras exposición a la droga (Figura 19). Además, en nuestros estudios no hemos podido detectar diferencias respecto a la sensibilidad a beta-lapachona entre un mutante termosensible top2-1 y su cepa WT parental (Figura 19). Por lo tanto las topoisomerasas Top1p, Top2p y Top3p podrían ser excluidas como dianas primarias para generar la activación de la ruta de control dependiente de Mre11p-Tel1p por beta-lapachona.

Se ha propuesto que la selectividad de beta-lapachona hacia células tumorales podría ocurrir en el paso de inducción de E2F1 en una forma independiente del estado de la proteína retinoblastoma ( $\mathrm{Li}$ et al., 2003), induciendo rápida y directamente E2F1 y convirtiéndolo así de un regulador de la proliferación en un regulador de la apoptosis mediada por mecanismos de control (Figura 39). Sin embargo el mecanismo preciso por el cual beta-lapachona induce E2F1 permanece indefinido. Basados en nuestros hallazgos en levadura, podríamos especular que la droga induce E2F1 en células tumorales en un modo dependiente del complejo MRN y de ATM. Existen varias evidencias consistentes con este hipótesis: i) el daño al ADN induce la actividad de E2F1 a través de la fosforilación dependiente de ATM y de la subsiguiente estabilización de E2F1 (Lin 
et al., 2001), ii) el complejo MRN se asocia físicamente con miembros de la familia de E2F a través del ortólogo mamífero de Xrs2p, Nbs1, durante la síntesis del ADN (Maser et al., 2001), y iii) la apoptosis asociada a E2F1 es dependiente de las proteínas ATM, Nbs1 y Chk2, los ortólogos en mamíferos de Tel1p, Xrs2p y Rad53p respectivamente (Rogoff et al., 2004).

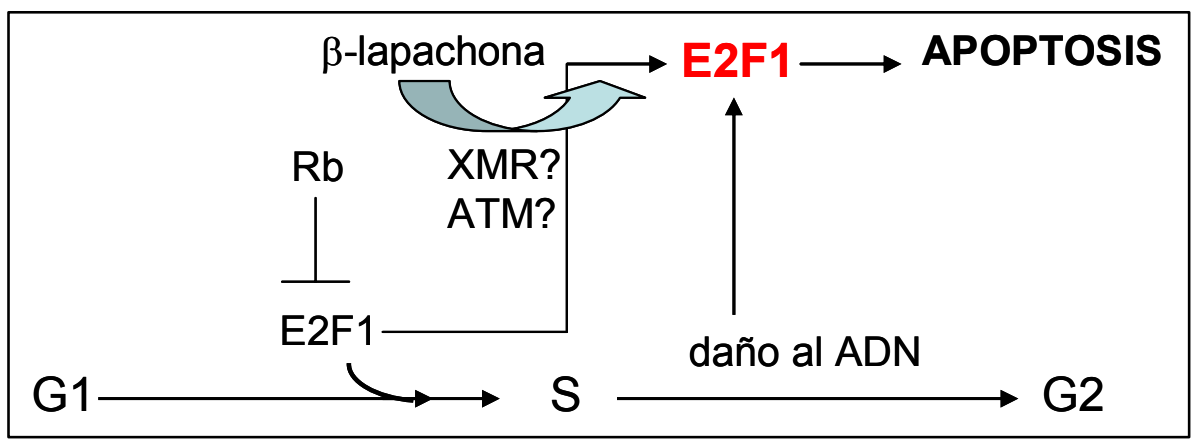

Figura 39: Mecanismo propuesto para la activación de E2F y subsiguiente apoptosis por beta-lapachona (adaptado de Li et al., 2003). 


\section{Generación de radicales libres y sus efectos sobre la citotoxicidad de beta-lapachona en levadura.}

Se ha demostrado que un mecanismo de citotoxicidad de betalapachona en células tumorales está mediado por la $\mathrm{NAD}(\mathrm{P}) \mathrm{H}$ dehisdrogenasa NQO1 (Pink et al., 2000). La reducción de betalapachona por parte de NQO1 lleva a un ciclo fútil entre las formas quinona e hidroquinona, con una pérdida de la forma reducida del nucleótido $\mathrm{NAD}(\mathrm{P}) \mathrm{H}$, lo cual induce muerte celular. En acuerdo con este mecanismo: i) el dicumarol, un inhibidor de NQO1, inhibía la letalidad disparada por la droga (Pink et al., 2000), ii) un precursor de beta-lapachona no resulta letal hasta que la droga es convertida a beta-lapachona por NQO1 (Reinicke et al., 2005), y iii) la muerte celular generada por beta-lapachona es dependiente de calcio y calpaína, y regulada por NQO1 y dicumarol (Tagliarino et al., 2001). Además se ha propuesto que la reducción de beta-lapachona por NQO1 es inestable y revierte espontáneamente al compuesto parental, creando una reacción lateral que podría causar la generación de especies reactivas de oxígeno (Figura 20; Pink et al., 2000). Así la formación de ROS podría luego inducir daño en el ADN y resultar en la formación de DSBs, con la posterior activación de un mecanismo de control dependiente de Mre11p-Tel1p.

En acuerdo con estos datos hemos observado que el tratamiento con beta-lapachona induce fuertemente la generación de ROS en levadura, la cual es eficientemente bloqueada por la presencia de dicumarol (Figura 21). Sin embargo, la generación de ROS no es el determinante clave de la toxicidad de beta-lapachona, ya que el 
tratamiento con dicumarol no afecta la viabilidad de las células ni suprime la activación de los puntos de control (Figuras 22 y 23).

Existe cierta controversia respecto al papel que desempeña la generación de ROS por tratamiento con beta-lapachona. Hay en la literatura reportes que argumentan que aún en líneas celulares que expresan NQ01, la producción de ROS no es el principal responsable de la muerte celular ya que el tratamiento con detoxificantes no afecta la letalidad de la droga de manera significativa (Pink et al., 2000). Incluso se ha propuesto que más que el aumento de ROS, podría ser la caída en los niveles de $\mathrm{NAD}(\mathrm{P}) \mathrm{H}$ y NADH asociada a la reducción de beta-lapachona por NQO1 la responsable de disparar la apoptosis (Figura 20). Más aún, datos recientes en células humanas indican que la generación de especies reactivas de oxígeno dependiente de NQO1 es necesaria, pero no suficiente, para la muerte celular mediada por beta-lapachona (Bentle et al., 2007). Nuestros resultados están de acuerdo con estas evidencias e indican claramente que la generación de ROS no es el determinante de la toxicidad de la droga.

Sin embargo, existen evidencias que asocian la generación de radicales libres con la activación del control de ciclo tras tratamiento con beta-lapachona. Datos recientes en células de mamífero afirman que la oxidorreducción de beta-lapachona vía NQO1 conduce a la producción de ROS, daños en el ADN, formación de focos de $\gamma-\mathrm{H} 2 \mathrm{AX}$ y activación del complejo MRE11-RAD50-NBS1 (Bentle et al., 2007). 
En nuestro trabajo hemos estudiado las NADH deshidrogenasas de levadura con el objetivo de determinar el mediador de la generación de ROS. Tras un rastreo de cepas mutantes en actividades deshidrogenasa, hemos descubierto que la generación de radicales en levadura tras exposición a beta-lapachona está mediada por la deshidrogena Oye2p, ya que el mutante $\Delta$ oye2 fue el único en mostrar menor acumulación de ROS tras tratamiento (Figura 25). Así, Oye2p sería el equivalente en levadura de NQO1. Sin embargo en ausencia de Oye2p, otras deshidrogenasas podrían ser capaces de llevar a cabo la reducción de beta-lapachona con la consiguiente generación de radicales, aunque quizás con menor eficiencia.

De acuerdo con nuestros datos, en Tripanosoma cruzi, se ha propuesto un rol clave del enzima TcOYE (homólogo de Oye2p) en la acción trypanocida de beta-lapachona a través de la reducción de la droga con generación de especies reactivas de oxígeno (Kubata et al., 2002). 


\section{Nde2 $p$ modula la toxicidad de beta-lapachona}

Durante el rastreo realizado con las NADH deshidrogenasas descubrimos que el mutante $\Delta$ nde 2 es resistente al tratamiento con beta-lapachona (Figura 24). Nde2p es una NADH deshidrogenasa mitocondrial externa, que cataliza la oxidación del NADH citosólico, y junto con Nde1p participa en la incorporación del NADH citosólico en la cadena respiratoria mitocondrial (Pahlman et al., 2002). La baja toxicidad de beta-lapachona en el mutante $\Delta$ nde 2 es probablemente debida a la modulación de varias de las respuestas disparadas por la droga. Sin embargo, la ausencia de esta deshidrogenasa no modula la generación de ROS tras tratamiento (Figura 25).

El mutante $\Delta$ nde2 no activa las respuestas de control de ciclo en respuesta a beta-lapachona, ya que recupera el retraso en la progresión a través de la transición G1/S (Figura 27) y no muestra evidencias de fosforilación de la quinasa Rad53p (Figura 28A). Sin embargo, los niveles de fosforilación de histona H2A permanecen elevados tras el tratamiento, en un grado similar al observado en células WT (Figura 28B). Estos datos indican que en el mutante $\Delta n d e 2$ la droga genera lesiones en el ADN, pero su magnitud no es suficiente como para activar una respuesta de los mecanismos de control. Alternativamente, podría proponerse que la falta de función de la NADH deshidrogenasa Nde2p media el correcto acoplamiento entre la detección de un DSB en el ADN y los eventos posteriores implicados en la parada en la progresión de ciclo tras exposición a beta-lapachona. 
A este respecto, existe un modelo que propone que las respuestas de daño al ADN dependen ampliamente de la velocidad con que las células son capaces de reparar el mismo (Rouse and Jackson, 2002; Figura 40). En este modelo, el daño al ADN es detectado inicialmente por factores de reparación específicos con alta afinidad por determinados tipos de lesiones primarias. En algunos casos estas lesiones pueden ser fáciles de reparar, tal que el daño al ADN es rápidamente revertido tras la detección inicial. Bajo estas circunstancias, la reparación ocurriría con la suficiente rapidez como para prevenir el reconocimiento por componentes de las redes de señalización compuestas por Mec1p/Tel1p, y el comienzo de una respuesta al daño. En otros casos, la lesión en el ADN podría persistir por no poder ser reparada con tanta rapidez, debido quizás a la naturaleza de la lesión y/o a su localización genómica. En tales casos, los complejos Mec1p-Lcd1p/Tel1p se unen a los sitios de daño probablemente en un modo que dependería de la actividad de los factores de reparación específicos de la lesión. Posteriormente, la fosforilación de histona $\mathrm{H} 2 \mathrm{~A}$ y la alteración en la estructura de la cromatina en las proximidades de la lesión, promoverían la reparación del $A D N$ de un modo eficaz que es capaz de prevenir una respuesta global al daño. En contraste, si en este punto la reparación del ADN no se ha completado, la lesión deberá sufrir una procesamiento más extenso, y es en este caso cuando se produciría la activación de Rad53p y Chk1p con la consecuente respuesta al daño que incluye el arresto del ciclo celular y el aumento de la capacidad de reparación de la célula. 


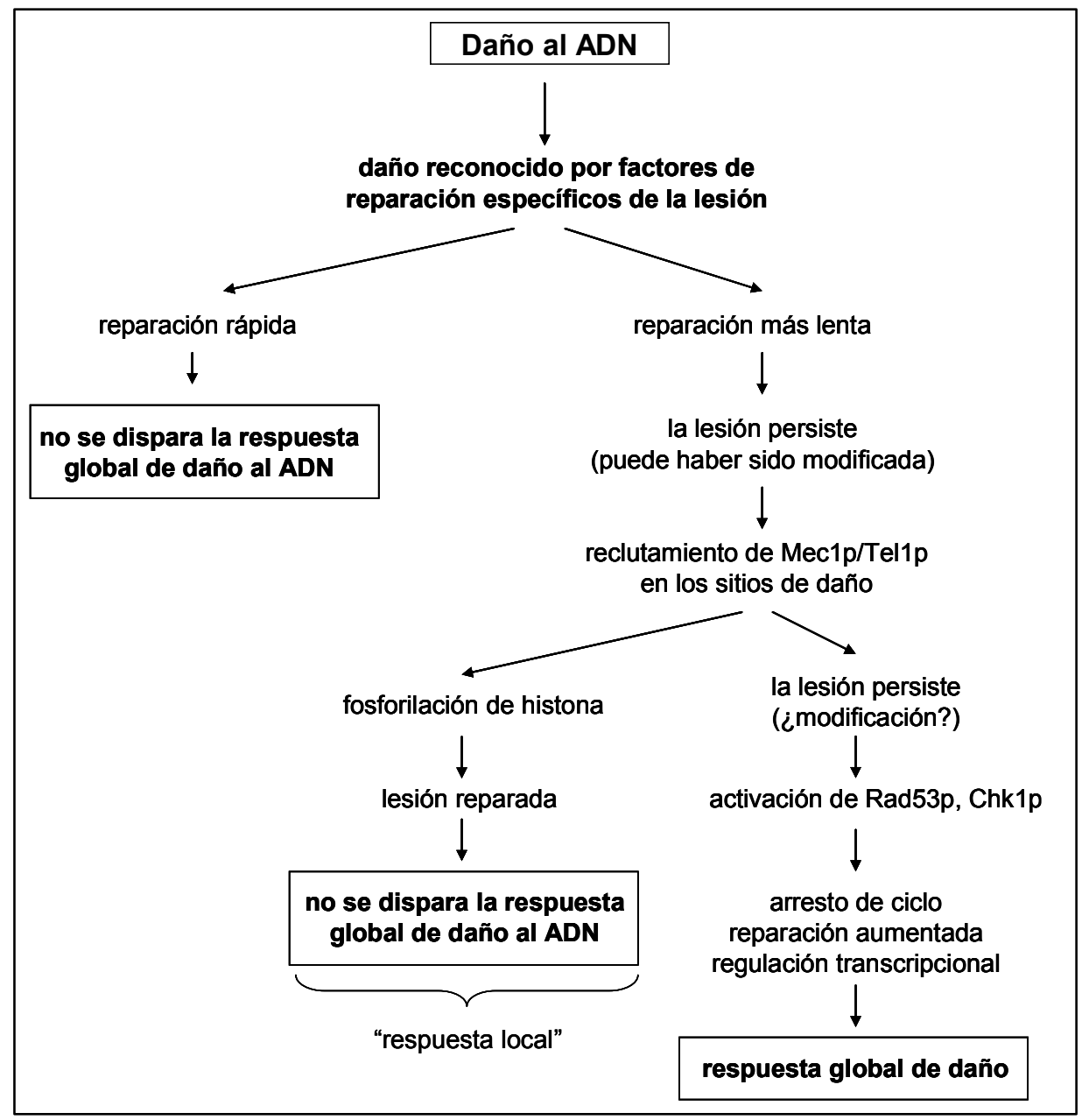

Figura 40: Modelo de señalización y reparación del daño al ADN. Tras la detección, el daño puede ser reparado rápidamente o persistir, dependiendo de la naturaleza de la lesión y/o del contexto genómico. Si la lesión persiste, puede dispararse una respuesta local (con fosforilación de histona H2A) o una respuesta global al daño. (Basado en Rouse and Jackson, 2006) 
De acuerdo a este modelo, el mutante $\Delta$ nde2 sería capaz de reparar más rápidamente las lesiones inducidas por el tratamiento con betalapachona sin disparar completamente las respuestas de control de daño al ADN. Esto podría deberse a las lesiones acumuladas son más fáciles de reparar y/o a que el daño se produce en menor extensión. En este sentido, una posible explicación es que Nde2 intervenga de alguna manera en la bioactivación de la droga, convirtiéndola así en una forma que es la responsable de generar la lesión. En ausencia de Nde2p, la forma tóxica no se produciría y sólo persistiría un tipo de lesión fácilmente reparable. Esto sugeriría un comportamiento de Nde2p similar al de NQO1, de manera tal que la toxicidad de beta-lapachona incrementaría con el aumento en los niveles de esta proteína, aunque no en un modo dependiente de la generación de ROS. Esta hipótesis se está evaluando actualmente en el laboratorio mediante la generación de NDE2 recombinante.

Alternativamente, Nde2p podría tener una función de modulador de las rutas de control y/o reparación del ADN, y esa función resultar inhibida por la droga. Apoyando esta hipótesis, hemos visto que la capacidad de reparación del mutante $\Delta$ nde2 está alterada, ya que el mismo muestra mayor eficiencia de reparación (Figura 32). La mayor eficiencia podría deberse a una acumulación intrínseca de daño en el mutante, ya que muestra niveles basales de fosforilación de histona $\mathrm{H} 2 \mathrm{~A}$ significativamente mayores que las células WT (Figura 31A). Este hecho podría dar cuenta además de la sensibilidad que muestra el mutante a otros agentes genotóxicos como phleomycina o $\mathrm{HU}$ (Figura 30). Una hipótesis atractiva podría ser que beta-lapachona, a través de su efecto sobre $\mathrm{NADH}$ deshidrogenadas y/o sobre los 
niveles de $\mathrm{NADH}$, regulara de algún modo las funciones de control de daño al ADN. Recientemente se ha descrito que NQO1 regula la estabilidad de las proteínas de control p53 y p73. NQ01 se une a p53 y p73 en un modo dependiente de NADH y las protege de ser degradadas por el proteosoma 20S, mediando así respuestas celulares dependientes de p53 tras daño al ADN (Asher et al., 2001 y 2002). Otra posibilidad es que la acción de beta-lapachona directa o indirecta sobre Nde2p genere una alteración en los niveles de $\mathrm{NADH} / \mathrm{NAD}+$, depletando a la célula de $\mathrm{NAD}(+)$ y ATP. En base a datos recientes se ha propuesto que la depleción de NAD+ es un factor crítico en la letalidad inducida por beta-lapachona, junto con la concomitante pérdida de ATP (Bey EA et al., 2007). Así la exposición a beta-lapachona podría simultáneamente causar daños en el ADN e inhibir su reparación por una pérdida de los niveles de NAD+ y ATP.

El cuerpo de evidencias presentado en el presente trabajo apunta a un papel de la deshidrogenasa Nde2p en la toxicidad de betalapachona como: i) diana molecular de acción de la beta-lapachona, y/o 2) cumpliendo un rol en el metabolismo de "bioactivación" de la droga. A este respecto se puede decir que Nde2p no actúa del mismo modo que lo hace NQO1 en células de mamífero, ya que la magnitud de producción de ROS tras el tratamiento con betalapachona en el mutante $\Delta$ nde2 es similar a la correspondiente a células WT (Figura 25).

Un dato importante a favor de un rol de Nde2p como blanco de acción de beta-lapachona es que la falta de función de esta proteína mimetiza el comportamiento de células $W T$ sometidas a exposición a 
la droga: (1) el mutante $\Delta$ nde2 muestra un crecimiento más lento que las células $W T$; (2) el mutante $\Delta n d e 2$ posee un retraso en la transición G1/S aún en ausencia de tratamiento, y muestra niveles basales de fosforilación de histona H2A significativamente más elevados (Figuras 27 y 31); (3) el mutante $\Delta$ nde2 posee severos defectos de crecimiento en fuentes de carbono no fermentables y es precisamente en estas condiciones donde beta-lapachona muestra mayor toxicidad sobre células WT (Figura 26); y finalmente, (4) el mutante $\Delta n d e 2$ es más sensible a drogas cuya acción muestran un marcado sinergismo con beta-lapachona, como hidroxiurea y phleomicina (Figura 30).

Resulta interesante que el mutante $\Delta$ nde1 no muestre un comportamiento similar a $\Delta$ nde2, ya que Nde1p también es una $\mathrm{NADH}$-deshidrogenasa de tipo II que oxida $\mathrm{NADH}$ en la cara citosólica de la membrana interna mitocondrial, y su ORF exhibe una considerable similitud de secuencia tanto con NDE2 como con NDI1 (Marijke AH et al., 1998). Incluso ha sido descrito que Nde1p sería la más importante de las dos $\mathrm{NADH}$ deshidrogenadas externas. De hecho, la expresión relativa de las deshidrogenadas Nde1p y Nde2p parece depender de las condiciones de crecimiento, siendo ambas transcriptas durante el crecimiento en glucosa, pero observándose una fuerte inducción de la transcripción de NDE2 en crecimiento sobre etanol (De Risi et al., 1997). De este modo, quizás sea el aumento en los niveles de Nde2p en condiciones de crecimiento que favorecen la respiración una posible causa del aumento de toxicidad de beta-lapachona en estas condiciones. Este hecho apuntaría a un papel de Nde2 $p$ como biactivador de la droga, y refutaría la hipótesis 
de basada en los niveles de $\mathrm{NAD}(+)$ como mediadores del daño, ya que en condiciones normales, Nde1p sería capaz de mantener estos niveles estables.

Otra proteína mitocondrial con importante homología con Nde2p es la deshidrogenasa interna Ndi1p. Se ha especulado que Ndi1p es el homólogo más cercano en levadura a la proteína humana AMID (mitochondrion-associated inducer of death, inductor de muerte asociado a mitocondria). Incluso existen reportes que indican que una sobreexpresión de Ndi1p, y no de su homólogo Nde1p, induce muerte celular con características apoptóticas en levadura ( $\mathrm{Li}$ et al., 2006). También se ha reportado que la deleción de NDI1, como así también la de $N D E 1$, es capaz de prolongar el tiempo de vida cronológica en levadura (Li et al., 2006)

Interesantemente, se considera actualmente a Ndi1p como el homólogo más cercano a AMID, mostrando una identidad del $28 \%$ y similitud del $46 \%$, mientras que la homología que exhibe Nde2p corresponde a valores muy cercanos al anterior (25\% homología y $46 \%$ similitud; comparaciones realizadas a través de la base de datos BLASTp del NCBI).

No existen datos hasta la fecha acerca de los efectos de Nde2p sobre la viabilidad y longevidad celular. Sin embargo, teniendo en cuenta que la regulación transcripcional por niveles de glucosa de NDE2 es similar a la de NDE1 y NDI1, y dada la amplia homología entre estos tres genes, no puede descartarse un posible rol de Nde2p en la regulación de las señales apoptóticas y en la longevidad 
cronológica. Si esta hipótesis, que se esta explorando en nuestro laboratorio, se validase, podría especularse acerca de un uso potencial de beta-lapachona como modulador de la longevidad celular. 


\section{Beta-lapachona y la ruta de control traduccional.}

\subsection{Activación de la ruta GCN por tratamiento con beta- lapachona.}

Con el objeto de caracterizar en mayor profundidad los efectos del tratamiento con beta-lapachona, hemos analizado el perfil de expresión génica de células $W T$ tratadas con dicha droga. Siguiendo los criterios descritos en la sección Materiales y Métodos, observamos que 212 genes resultaron inducidos y 52 reprimidos tras el tratamiento. Tras realizar una clasificación funcional de los genes inducidos/reprimidos, pudimos observar claramente la presencia de categorías funcionales correspondientes a biosíntesis de aminoácidos y estrés oxidativo (Tablas 5 y $\mathbf{6}$ ). La presencia de esta última categoría era esperada ya que habíamos comprobado previamente que beta-lapachona producía generación de ROS también en levadura.

Es importante destacar que en el análisis de genes diferencialmente expresados tras tratamiento con beta-lapachona no aparecen categorías funcionales correspondientes a rutas de señalización/reparación de daño al ADN. La ausencia de estas categorías funcionales se debe probablemente a las características del tratamiento utilizadas para este ensayo: $4 \mu \mathrm{g} / \mathrm{ml}$ de betalapachona durante una hora. La elección de estas condiciones de tratamiento se basó principalmente en que a esas dosis el crecimiento de las células $W T$ se veía claramente afectado, pero no el del mutante $\Delta n d e 2$. Sin embargo, a esa dosis y en esa ventana de tiempo no hemos sido capaces de observar fosforilación de Rad53p. 
Resultados paralelos de análisis con micromatrices en nuestro laboratorio, indicaron que la categoría de biosíntesis de aminoácidos estaba igualmente representada entre el grupo de genes expresados diferencialmente en una cepa mutante $G C N 2^{c}$ (Menacho-Márquez et al., 2007), con la ruta de control general de nutrientes constitutivamente activa. Este dato sugería que, de algún modo, el tratamiento era capaz de inducir esta ruta. Así, pudimos observar que el tratamiento con beta-lapachona produjo una activación de la ruta de control general de nutrientes de una manera muy efectiva, como se pudo comprobar por el aumento en la fosforilación del factor elF2 en su subunidad alfa (Figura 33). La fosforilación observada de elF2a resultó ser dependiente de Gcn2p y de los activadores Gcn1p y Gcn20p (Figura 33). Con posterioridad comprobamos que de alguna manera Gcn2 $p$ media las respuestas disparadas por betalapachona, ya que tanto la falta de función como la sobreactivación de esta quinasa rinden una mayor sensibilidad al tratamiento (Figuras 34 y 35).

Sin embargo, esta activación de la ruta GCN no parece que se deba a la producción de un ayuno de aminoácidos o purinas, ya que la adición de un exceso de éstos al medio de crecimiento no altera la sensibilidad de células $W T$ a la droga ni el estado de fosforilación de elF2 $\alpha$ (Figuras 34A y B) y la falta de función de GCN1, GCN3, GCN4 o GCN20 no modula de ningún modo la toxicidad a betalapachona (Figura 34C). Estos datos sugieren que: i) Gcn2p parece activarse por situaciones de estrés que no llevan a ayuno de nutrientes, y ii) la función de Gcn2p en respuesta a la droga no es regular la traducción de proteínas. Estos datos están en acuerdo con 
evidencias previas que asignan a Gcn2p una función no traduccional (Rodríguez-Hernández et al., 2003).

Es notorio que la activación de Gcn2p en estas condiciones en las que no hay ayuno de nutriente siga dependiendo de Gcn1p y Gcn20p. Gcn1p y Gcn20p facilitan el seguimiento de los niveles de ARNt descargados por parte de las secuencias relacionadas con HisRS de Gcn2p en condiciones de ayuno de purinas o aminoácidos (Vazquez de Aldana et al., 1995). Por lo tanto, beta-lapachona podría estar induciendo la activación de Gcn2p a través de mecanismos alternativos. Curiosamente MMS, otro agente lesionante del ADN, también parece activar a Gcn2p en condiciones en las que no hay ayuno y de un modo dependiente de Gcn1/20p (Natarajan et al., 2001). Puede haber varias explicaciones para este hecho:

i) Gcn2p podría activarse por los niveles de ARNt endógenos, aumentando su afinidad por los mismos debido a algún tipo de modificación post-traduccional. El hecho de que rapamicina, un inhibidor de las quinasas TOR, activa a Gcn2p por defosforilación de la serina 577 mediada por el regulador de fosfatasas TAP42 apoya esta hipótesis (Cherkasova and Hinnebusch, 2003).

ii) Otra posibilidad consiste en que la droga inhiba una/varias ARNt sintetasas. Como resultado de este efecto se acumularían moléculas de ARNt descargadas, activando así la ruta sin la existencia de condiciones de ayuno. Esta hipótesis se ve apoyada por evidencias en la literatura que indican que el mecanismo de acción de muchos antifúngicos y antitumorales se basa en la inhibición de ARNt sintetasas (Lee et al., 2004; Rock et al., 2007). 
iii) Por último, es tentador especular una activación de Gcn2p por la interacción de Gcn1p y Gcn20p con alguna estructura anómala en el ADN generada por beta-lapachona. Esto explicaría por qué otros agentes lesionantes también son capaces de inducir la ruta, no sólo en $S$. cerevisiae sino también en $S$. pombe y en mamíferos.

Un dato inesperado que apoya esta última hipótesis es que la activación de Gcn2p por beta-lapachona, resultó depender del complejo XMR (Figura 37 y anexo I). Esto, junto con el hecho de que no dependa de Mec1p y/o Tel1p, sugiere que Gcn2p actuaría por debajo del complejo XMR, en una rama independiente de Mec1p y Tel1p. Este hecho es de particular interés ya que no existen reportes previos referentes a esta interacción. Podría sugerirse que de algún modo la activación del compejo XMR o el procesamiento del daño por parte del mismo, serían capaces de activar a la quinasa Gcn2p. Tampoco puede descartarse la interacción de Gcn2p con alguna estructura en el ADN intermediaria en la reparación ya que esta proteína posee un sitio de unión a ARNt (Figura 7, Ramírez et al., 1992).

Así, una vez activo, Gcn2p podría regular traduccional o posttraduccionalmente a una serie de efectores cuya misión sería fortalecer el mecanismo de control y/o la reparación de las lesiones. A favor de esta hipótesis está el hecho de que el mutante $\Delta g c n 2$ modula las respuestas de control de ciclo disparadas por betalapachona (Figura 36). 


\subsection{Implicación de la activación de la ruta GCN en los eventos disparados por beta-lapachona.}

La activación de la quinasa Gcn2p produce un retraso en la transición G1/S en S. cerevisiae y S. pombe (Tvegård T et al., 2007; Menacho-Márquez et al., 2007). Esta nueva función de Gcn2p en la regulación del control de ciclo podría estar mediada por la fosforilación de elF2 $\alpha$ y el subsiguiente bloqueo en la iniciación de la traducción. En respuesta a beta-lapachona, pudimos observar que, de algún modo, la función de la quinasa Gcn2p media el control de G1/S disparado por la droga, ya que un mutante $\Delta g c n 2$ muestra un retraso en la progresión de ciclo más breve que el $W T$ tras tratamiento con la droga (Figura 36).

Por otro lado, analizando el estado de fosforilación de la histona H2A tras tratamiento con beta-lapachona, pudimos observar que el mutante $\Delta g c n 2$ acumulaba mayores niveles de fosforilación de histona, mientras que ocurría todo lo contrario en el mutante GCN2 ${ }^{c}$ (Figura 36). Así, Gcn2p y/o algún efector podría requerirse para sensar y/o reparar el daño generado por beta-lapachona, aunque la sobreactivación de esta quinasa exacerba los efectos sobre la viabilidad desplegados por la droga (Figura 35).

La naturaleza de los efectores regulados por Gcn2p se desconoce. A este respecto, en los análisis de micromatrices realizados con el mutante $G C N 2^{c}$ hemos podido observar que aparecen reprimidos genes implicados en la biogénesis/ensamblaje de ribosomas y genes de replicación del ADN (Menacho-Márquez et al., 2007). La 
expresión de genes de biogénesis de ribosoma y de replicación del ADN está críticamente ligada a la proliferación celular y sirve como una medida de la progresión del ciclo celular G1/S (Jorgensen et al., 2004). Todos estos genes están regulados por el complejo MBF, un factor de trasncripción que regula la expresión de genes durante la transición G1/S (Koch et al., 1993). Sin embargo, no puede descartarse que algún otro componente de la maquinaria de control/reparación implicado en la respuesta a tratamiento con betalapachona esté sujeto a control traduccional, o algún otro regulador de ciclo no conectado directamente con el control de daño al ADN. A este respecto, se ha reportado previamente una conexión entre Gcn2p y Hog1p (Rodríguez-Hernández et al., 2003) que sustenta esta posibilidad.

Es conveniente evaluar si estas respuestas están conservadas en mamíferos. Recientemente se ha observado que el tratamiento con beta-lapachona en líneas celulares MCF7 también provoca un incremento en los niveles de fosforilación del factor elF2 en su subunidad alfa (Belandia B, datos no publicados). Este hecho extiende el paralelismo entre los efectos observados por la acción de beta-lapachona en levaduras y eucariotas superiores. No se puede asegurar qué quinasa está implicada en la fosforilación de elF2 $\alpha$ en células tumorales, ya que en mamíferos existen cuatro posibles candidatos, pero en estos momentos se están llevando a cabo experimentos con el propósito de identificar la quinasa responsable. 


\subsection{Implicación de NDE2 en estas respuestas}

Tal como ocurriese con las otras respuestas disparadas por el tratamiento con beta-lapachona, la mutación de NDE2 modulaba también la activación de la ruta GCN tras tratamiento (Figura 38). Sin embargo, la fosforilación del factor elF $2 \alpha$ no era totalmente evitada como en el mutante $\Delta g c n 2$ (Figura 33). Esta observación, junto con el hecho de que el mutante no muestre niveles basales de fosforilación de elF2 $\alpha$ elevados, sustentan más la hipótesis basada en una función de Nde2p en la bioactivación de la droga. En otras palabras, respecto a la activación de la ruta $G C N$, el mutante $\triangle$ nde2 no mimetiza los efectos observados por tratamiento con betalapachona. Sin embargo, no puede descartarse que la falta de activación de la ruta $G C N$ en el mutante se deba a la ausencia de activación del punto de control dependiente del complejo XMR (Figura 27 ). 


\section{Modelo de acción de beta-lapachona en levadura.}

Las observaciones obtenidas en este trabajo nos permiten proponer un modelo provisional para la toxicidad de beta-lapachona en células de levadura (Figura 41).

La exposición a beta-lapachona induce la generación de daño en el ADN del tipo DSBs. La generación de estos DSBs induce una disminución en la progresión celular en la transición G1/S a través de la activación de un punto de control dependiente de Mre11p-Tel1p. La activación de este punto de control es crucial para inducir la muerte celular disparada por beta-lapachona. La activación de este control de ciclo por tratamiento con beta-lapachona, es totalmente dependiente de Nde2p, proteína que proponemos como la principal diana mediadora de los efectos biológicos observados.

Paralelamente, el tratamiento con beta-lapachona induce la producción de ROS, principalmente a través de la acción de la deshidrogenasa Oye2p. La generación de estos ROS no es suficiente para determinar la muerte celular, pero podría contribuir a la misma. Por otro lado, beta-lapachona induce la activación de la ruta GCN, que contribuye a mediar el control de G1/S.

Juntos, la generación de daño al ADN, el aumento en la producción de radicales libres, la activación de la ruta $\mathrm{GCN}$ y principalmente la activación del mecanismo de control dependiente de Mre11p-Tel1p, contribuyen a la inducción de la muerte celular por tratamiento con beta-lapachona 


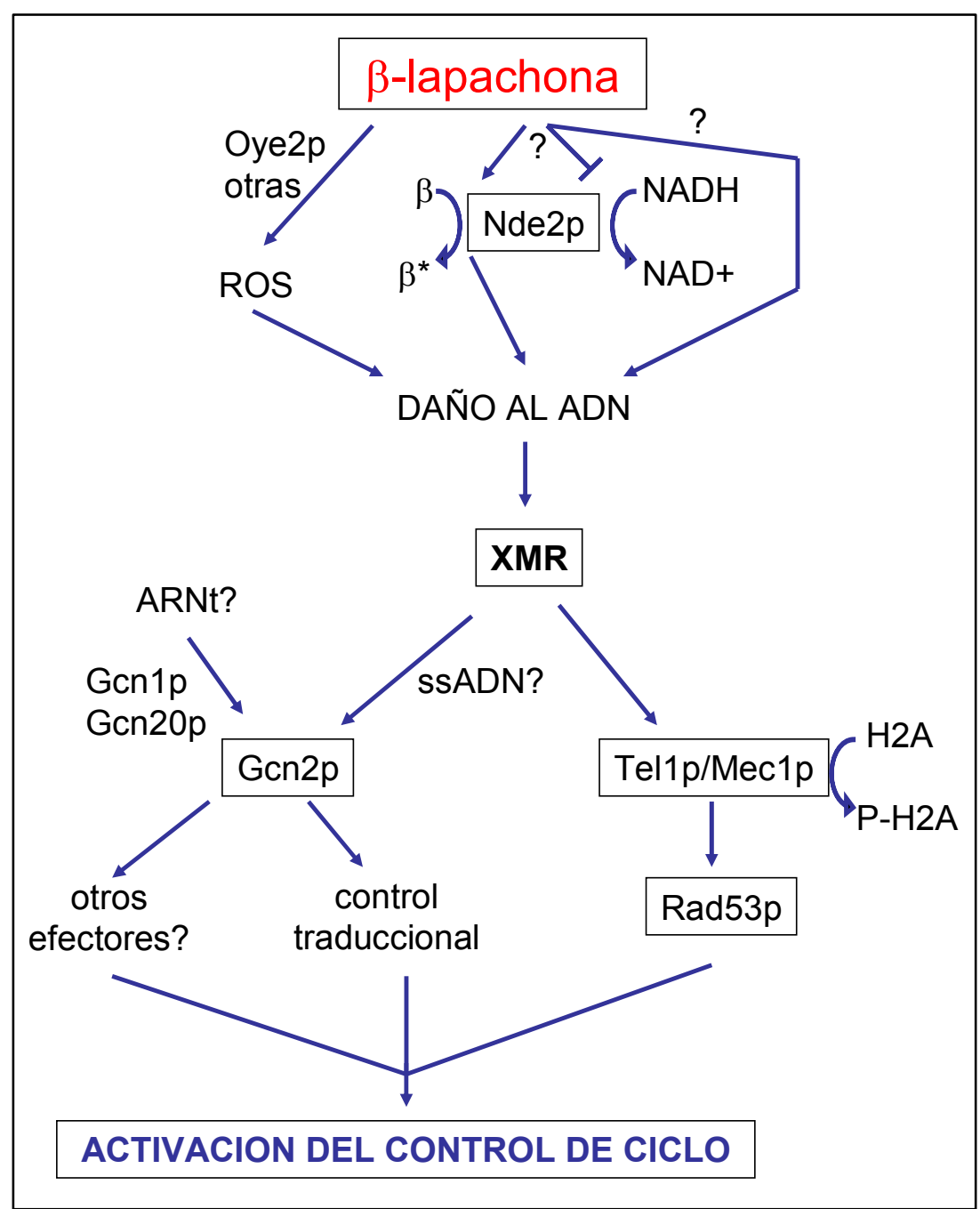

Figura 41: Modelo propuesto del mecanismo de acción de beta-lapachona en S. cerevisiae. 
Paralelamente, nuestros hallazgos nos permiten remarcar los siguientes aspectos:

- La modulación farmacológica del punto de control dependiente de Mre11p-Tel1p (MRN-ATM en mamíferos) podría tener gran relevancia en el tratamiento antitumoral.

- Nde2p media los efectos de beta-lapachona en levadura, con lo cual el homólogo humano de esta deshidrogenasa podría ser una potencial diana terapéutica por sí mismo o en conjunción con agentes como phleomicina.

- Los niveles del homólogo humano de NDE2 se plantean como un marcador pronóstico/diagnóstico de la respuesta de un tumor a tratamiento con beta-lapachona.

- La modulación farmacológica de la ruta GCN se presenta como un importante medio de potenciar la letalidad de beta-lapachona

- El mecanismo de acción de beta-lapachona sugiere que Gcn2p tiene funciones adicionales además del control traduccional, y que consisten en la regulación del ciclo celular.

- La activación de la ruta GCN por beta-lapachona ofrece nuevos usos terapéuticos posibles para esta molécula. Así, sería atractivo explorar la potencialidad terapéutica de beta-lapachona en otros procesos patológicos en los cuales la ruta GCN es relevante, como:

1) infecciones virales: la quinasa PKR es un regulador esencial en la respuesta a infecciones virales (revisado en Kaempfer, 2003);

2) diabetes: múltiples estudios han desvelado el protagonismo de quinasas de elF2 $\alpha$ en síndromes diabéticos (Delepine et al., 2000), hiperglicemia y muerte de células beta en ratones (Harding et al., 
2001), así como la importancia del control traduccional del ARNm de la insulina (Scheuner et al., 2005);

3) Alzheimer: existen evidencias de que la fosforilación de elF2 $\alpha$ y la activación de PKR están asociadas a la enfermedad de Alzheimer y otros desórdenes neurodegenerativos (Chang et al., 2002);

4) problemas cardíacos: se ha definido un rol protector de la quinasa PKR en miocarditis viral (Stewart et al., 2003);

5) neo-angiogénesis: se ha descrito que la vascularización de tumores está regulada traduccionalmente (DeFatta et al., 1999); 6) preservación de órganos: recientemente se ha reportado que una fosforilación basal de elF2 $\alpha$ tiene efectos citoprotectores (Lu et al., 2004).

Saccharomyces cerevisiae se ha convertido en una herramienta indispensable en el rastreo de nuevos fármacos, así como en el estudio de sus mecanismos de acción. Su facilidad de manipulación y el conocimiento de su genoma y proteoma facilitan y abaratan el proceso de desarrollo de terapias farmacológicas. Nuestros resultados han permitido no sólo identificar los mecanismos implicados en la acción del antitumoral beta-lapachona, sino también: 1) identificar nuevos moduladores de respuestas de control de ciclo 2) identificar genes que median las respuestas celulares a esta droga y que presentan un gran potencial en estudios farmacogenómicos y farmacogenéticos; 3) identificar dianas moleculares que permitan el desarrollo de nuevos fármacos para tratamiento antitumoral y 4) desarrollar una plataforma de rastreo para esos fármacos. 



\section{CONCLUSIONES}



1- El antitumoral beta-lapachona es citotóxico en la levadura $S$. cerevisiae. La exposición a esta droga induce la formación de daño al $A D N$ del tipo $D S B$, produce un retraso en la progresión G1/S e induce fosforilación de la quinasa Rad53p e Histona H2A.

2- El tratamiento con beta-lapachona activa en levadura un punto de control dependiente de Mre11p-Tel1p.

3- La generación de radicales libres por tratamiento con betalapachona en levadura no es esencial para la citotoxicidad de la droga, aunque contribuye parcialmente a tal efecto.

4- Al menos en levadura, la deshidrogenasa mitocondrial Nde2p modula la toxicidad de la droga, siendo la principal diana de acción de este compuesto.

5- NDE2 modula además la respuesta a otros lesionantes del ADN.

6- Beta-lapachona activa la ruta de Control General de Nutrientes $(G C N)$ en levadura.

7- La activación de la ruta GCN media las respuestas disparadas por la droga en levadura.

8- La quinasa Gcn2p podría tener funciones adicionales además del control traduccional implicadas principalmente en el control de ciclo. 
9- El complejo XMR es necesario para la correcta activación de la ruta GCN por tratamiento con beta-lapachona, estableciéndose un nexo entre la ruta de control traduccional, y los mecanismos de respuesta al daño en el ADN. 


\section{BIBLIOGRAFÍA}



Abraham, R. T. (2001). "Cell cycle checkpoint signaling through the ATM and ATR kinases." Genes Dev 15(17): 2177-96.

Adams KE, Medhurst A, Dart DA, Lakin ND. (2006). "Recruitment of ATR to sites of ionising radiation-induced DNA damage requires ATM and components of the MRN protein complex." Oncogene 25(28): 3894-904.

Aktas H, Fluckiger R, Acosta JA, Savage JM, Palakurthi SS, Halperin JA. (1998). "Depletion of intracellular $\mathrm{Ca} 2+$ stores, phosphorylation of eIF2alpha, and sustained inhibition of translation initiation mediate the anticancer effects of clotrimazole." Proc Natl Acad Sci U S A 95(14): 82805.

Al-Shahrour F, Minguez P, Tárraga J, Montaner D, Alloza E, Vaquerizas JM, Conde L, Blaschke C, Vera J \& Dopazo J. (2006). "BABELOMICS: a systems biology perspective in the functional annotation of genome-scale experiments." Nucleic Acids Res 34: W472-W476.

Alani E, Thresher R, Griffith JD, Kolodner RD. (1992). "Characterization of DNA-binding and strand-exchange stimulation properties of y-RPA, a yeast single-strand-DNA-binding protein." J Mol Biol 227(1): 54-71.

Alcasabas AA, Osborn A, Bachant J, Hu F, Werler PJ, Bousset K, Furuya K, Diffley JF, Carr AM, Elledge SJ (2001). "Mrc1 transduces signals of DNA replication stress to activate Rad53." Nat Cell Biol 3(11): 958-65.

Asher G, Lotem J, Cohen B, Sachs L, Shaul Y (2001). "Regulation of p53 stability and p53 dependent apoptosis by NADH quinone oxidoreductase 1." Proc Natl Acad Sci U S A 98(3): 1188-93.

Asher G, Lotem J., Kama R, Sachs L, Shaul Y (2002). "NQO1 stabilizes p53 through a distinct pathway." Proc Natl Acad Sci U S A 99 (5): 3099-104. 
Chang M, Bellaoui M, Boone C, Brown GW (2002). "A genome-wide screen for methyl methanesulfonate-sensitive mutants reveals genes required for S phase progression in the presence of DNA damage." Proc Natl Acad Sci U S A 99(26): 16934-9.

Chang RC, Wong A, Ng HK, Hugon J. (2002). "Phosphorylation of eukaryotic initiation factor-2alpha (eIF2alpha) is associated with neuronal degeneration in Alzheimer's disease." Neuroreport 13(18): 2429-32.

Cherkasova VA, Hinnebusch A. (2003). "Translational control by TOR and TAP42 through dephosphorylation of eIF2alpha kinase GCN2." Genes Dev 17(7): 859-72.

D'Amours D, Jackson S. (2001). "The yeast Xrs2 complex functions in S phase checkpoint regulation." Genes Dev 15(17): 2238-49.

de la Torre-Ruiz MA, Green CM, Lowndes NF. (1998). "RAD9 and RAD24 define two additive, interacting branches of the DNA damage checkpoint pathway in budding yeast normally required for Rad53 modification and activation." EMBO J 17(9): 2687-98.

DeFatta RJ, Turbat-Herrera E, Li BD, Anderson W, De Benedetti A. (1999). "Elevated expression of eIF4E in confined early breast cancer lesions: possible role of hypoxia." Int J Cancer 80(4): 516-22.

Delepine M, Nicolino M, Barrett T, Golamaully M, Lathrop GM, Julier C. (2000). "EIF2AK3, encoding translation initiation factor 2-alpha kinase 3, is mutated in patients with Wolcott-Rallison syndrome." Nat Genet 25(4): 4069.

DeRisi JL, Iyer V, Brown PO (1997). "Exploring the metabolic and genetic control of gene expression on a genomic scale." Science 278(5338): 680-6.

Docampo R, Cruz F, Boveris A, Muniz RP, Esquivel DM (1979). "betaLapachone enhancement of lipid peroxidation and superoxide anion and 
Asher G, Lotem J, Sachs L, Kahana C, Shaul Y (2002). "Mdm-2 and ubiquitin-independent p53 proteasomal degradation regulated by NQO1." Proc Natl Acad Sci U S A 99(20): 13125-30.

Bartek J, Lukas J. (2007). "DNA damage checkpoints: from initiation to recovery or adaptation." Curr Opin in Cell Biology 19(2): 1-8.

Bentle MS, Reinicke K, Dong Y, Bey EA, Boothman DA (2007). "Nonhomologous End Joining Is Essential for Cellular Resistance to the Novel Antitumor Agent beta-lapachone." Cancer Res 67(14): 6936-45.

Bey EA, Bentle MS, Reinicke KE, Dong Y, Yang CR, Girard L, Minna JD, Bornmann WG, Gao J, Boothman DA (2007). "An NQO1- and PARP-1mediated cell death pathway induced in non-small-cell lung cancer cells by beta-lapachone." PROC NATL ACAD SCI U S A 104(28): 11832-7.

Bjornsti MA. (2002). "Cancer therapeutics in yeast." Cancer Cell 2(4): 26773.

Boothman DA, Greer S, Pardee AB (1987). "Potentiation of halogenated pyrimidine radiosensitizers in human carcinoma cells by beta-lapachone (3,4-dihydro-2,2-dimethyl-2H-naphtho[1,2-b]pyran- 5,6-dione), a novel DNA repair inhibitor." Cancer Res 47(20): 5361-6.

Boulton SJ, Jackson SP. (1996). "Saccharomyces cerevisiae Ku7O potentiates illegitimate DNA double-strand break repair and serves as a barrier to error-prone DNA repair pathways." EMBO J 15(18): 5093-103.

Branzei D, Foiani M. (2005). "The DNA damage response during DNA replication." Curr Opin Cell Biol 17(6): 568-75.

Branzei D, Foiani M. (2006). "The Rad53 signal transduction pathway: Replication fork stabilization, DNA repair, and adaptation." Exp Cell Res 312(14): 2654-9. 
Brill SJ, Sternglanz. R. (1988). "Transcription dependent DNA supercoiling in yeast DNA topoisomerase mutants." Cell 54: 403-11.

Brown PO, Botstein D. (1999). "Exploring the new world of the genome with DNA microarrays." Nat Genet 21(1Suppl): 33-7.

Brunelli JP, Pall ML. (1993). "A series of yeast/Escherichia coli lambda expression vectors designed for directional cloning of cDNAs and cre/loxmediated plasmid excision." Yeast 9(12): 1309-18.

Burke D, Dawson D, Stearns T. (2000). Methods in yeast genetics (A Cold Spring Harbor Laboratory course manual) 2000 Edition. Cold Spring Harbor, New York, Cold Spring Harbor Laboratory Press.

Bushman JL, Foiani M, Cigan AM, Paddon CJ, Hinnebusch AG. (1993). "Guanine nucleotide exchange factor for eukaryotic translation initiation factor 2 in Saccharomyces cerevisiae: interactions between the essential subunits GCD2, GCD6, and GCD7 and the regulatory subunit GCN3." Mol Cell Biol 13(8): 4618-31.

C.Li JN, N. S., G. Edelman, S. Glasner, G. Dombal, A. Dovholuk, C. Cunnigham (2006). "A phase Ib trial of ARQ 501, a selective checkpoint activator, in combination with docetaxel in patients with advanced solid tumors." Journal of Clinical Oncology 24:13053.

Clemens MJ. (2001). "Initiation factor eIF2 alpha phosphorylation in stress responses and apoptosis." Prog Mol Subcell Biol 27: 57-89.

Clemens MJ. (2004). "Targets and mechanisms for the regulation of translation in malignant transformation." Oncogene 23(18): 3180-8.

Cullen JJ, Hinkhouse M, Grady M, Gaut AW, Liu J, Zhang YP, Weydert CJ, Domann FE, Oberley LW. (2003). "Dicumarol inhibition of NADPH:quinone oxidoreductase induces growth inhibition of pancreatic cancer via a superoxide-mediated mechanism." Cancer Res 63(17): 5513-20. 
hydrogen peroxide formation by sarcoma 180 ascites tumor cells." Biochem Pharmacol 28(6): 723-8.

Downs JA, Lowndes N, Jackson SP. (2000). "A role for Saccharomyces cerevisiae histone H2A in DNA repair." Nature 408(6815): 1001-4.

Edwards YH, Potter J, Hopkinson DA (1980). "Human FAD-dependent NAD(P)H diaphorase." Biochem J 187(2): 429-36.

Engel RH, Kaklamani V. (2007). "HER2-Positive Breast Cancer : Current and Future Treatment Strategies." Drugs 67(9): 1329-41.

Frei C, Gasser SM. (2000). "The yeast Sgs1p helicase acts upstream of Rad53p in the DNA replication checkpoint and colocalizes with Rad53p in S-phase-specific foci." Genes Dev 14(1): 81-96.

Garcia-Barrio M, Dong J, Cherkasova VA, Zhang X, Zhang F, Ufano S, Lai R, Qin J, Hinnebusch AG. (2002). "Serine 577 is phosphorylated and negatively affects the tRNA binding and eIF2alpha kinase activities of GCN2." J Biol Chem 277(34): 30675-83.

Gavin AC, Aloy P, Grandi P, Krause R, et al. (2006). "Proteome survey reveals modularity of the yeast cell machinery." Nature 440(7084): 631-6.

Gavin AC, Bösche M, Krause R, Grandi P, et al. (2002). "Functional organization of the yeast proteome by systematic analysis of protein complexes." Nature 415(6868): 123-4.

Giaever G, Chu A, Ni L, Connelly C, Riles L, et al. (2002). "Functional profiling of the Saccharomyces cerevisiae genome." Nature 418(6896): 38791

Gietz RD, Schiestl RH, Willems AR, Woods RA (1995). "Studies on the transformation of intact yeast cells by the LiAc/SS-DNA/PEG procedure." Yeast 11(4): 355-60. 
Gilbert CS, Green C, Lowndes NF. (2001). "Budding yeast Rad9 is an ATP dependent Rad53 activating machine." Mol Cell 8(1): 129-36.

Goffeau A, Barrel B, Bussey H, Davis RW, Dujon B, Feldmann H, Galibert F, Hoheisel JD, Jacq C, Johnston M, Louis EJ, Mewes HW, Murakami Y, Philippsen P, Tettelin H, Oliver SG (1996). "Life with 6000 genes." Science 274(5287): 546, 563-7.

Grenon M, Gilbert C, Lowndes NF. (2001). "Checkpoint activation in response to double strand breaks requires the Mre11/Rad50/Xrs2 complex." Nat Cell Biol 3(9): 844-7.

Guillemain G, Ma E, Mauger S, Miron S, Thai R, Guérois R, Ochsenbein F, Marsolier-Kergoat MC (2007). "Mechanisms of checkpoint kinase Rad53 inactivation after a double-strand break in Saccharomyces cerevisiae." Mol Biol Cell 27(9): 3378-89.

Haaf T, Golub E, Reddy G, Radding CM, Ward DC (1995). "Nuclear foci of mammalian Rad51 recombination protein in somatic cells after DNA damage and its localization in synaptonemal complexes." Proc Natl Acad Sci U S A 92(6): 2298-302.

Haber JE. (1998). "The many interfaces of Mre11." Cell 95(5): 583-6.

Hamanaka RB, Bennett B, Cullinan SB, Diehl JA (2005). "PERK and GCN2 contribute to eIF2alpha phosphorylation and cell cycle arrest after activation of the unfolded protein response pathway." Mol Biol Cell 16(12): 5493-5.

Hanahan D. Ed. (1986). Techniques for transformation of E. coli. DNA cloning. Oxford, IRL Press.

Harlow E, Lane D. (1988). Antibodies. A Laboratory manual. Cold Spring Harbor, New York, Cold Spring Harbor Laboratory Press. 
Hartwell LH, Kastan MB. (1994). "Cell cycle control and cancer." $\underline{\text { Science }}$ 266(5192): 1821-8.

He CH, Masson J, Ramotar D (1996). "A Saccharomyces cerevisiae phleomycin-sensitive mutant, ph140, is defective in the RAD6 DNA repair gene." Can J Microbiol 42(12): 1263-6.

Hinnebusch AG. (1997). "Translational regulation of yeast GCN\$: a window on factors that control initiator-trna binding to the ribosome." J Biol Chem 272(35): 21661-4.

Hinnebusch AG. (2005). "Translational regulation of GCN4 and the general amino acid control of yeast." Annu Rev Microbiol 59: 407-50.

Hinnebusch AG, Natarajan K. (2002). "Gcn4p, a master regulator of gene expression, is controlled at multiple levels by diverse signals of starvation and stress." Eukaryot Cell 1(1): 22-32.

Irby RB, Yeatman T. (2000). "Role of Src expression and activation in human cancer " Oncogene 19(49): 5636-42.

Jagus R, Joshi B, Barber GN. (1999). "PKR, apoptosis and cancer." Int J Biochem Cell Biol 31(1): 123-38.

Jorgensen P, Rupes I, Sharom JR, Schneper L, Broach JR, Tyers M (2004). "A dynamic transcriptional network communicates growth potential to ribosome synthesis and critical cell size." Genes Dev 18(20):2491-505.

Kaempfer RJ. (1999). "RNA sensors: novel regulators of gene expression." EMBO Rep 4(11): 1043-7.

Koch C, Moll T, Neuberg M, Ahorn H, Nasmyth K (1993). "A role for the transcription factors Mbp1 and Swi4 in progression from G1 to S phase." Science 261(5128):1551-7. 
Kondo T, Wakayama T, Naiki T, Matsumoto K, Sugimoto K. (2001). "Recruitment of Mec1 and Ddc1 checkpoint proteins to double-strand breaks through distinct mechanisms." Science 294(5543): 867-70.

Korotzer JL, Bergquist LM, Searcy RL (1961). "Use of cellulose acetate and Ponceau S for electrophoretic serum protein analysis." Am J Med Technol 27: $197-203$

Krishnan P, Bastow KF. (2001). "Novel mechanism of cellular DNA topoisomerase II inhibition by the pyranonaphthoquinone derivatives alphalapachone and beta-lapachone." Cancer Chemother Pharmacol 47(3): 18798.

Kubata BK, Kabututu Z, Nozaki T, Munday CJ, Fukuzumi S, Ohkubo K, Lazarus M, Maruyama T, Martin SK, Duszenko M, Urade Y. (2002). "A key role for old yellow enzyme in the metabolism of drugs by Trypanosoma cruzi." J Exp Med 196(9): 1241-51.

Kumar A, Harrison P, Cheung KH, Lan N, Echols N, Bertone P, Miller P, Gerstein MB, Snyder M (2002). "An integrated approach for finding overlooked genes in yeast." Nat Biotechnol 20(1): 58-63.

Lazaris-Karatzas A, Montine KS, Sonenberg N. (1990). "Malignant transformation by a eukaryotic initiation factor subunit that binds to mRNA 5' cap." Nature 345(6275): 544-7.

Lee AC, Fernández-Capetillo O, Pisupati V, Jackson SP, Nussenzweig A (2005). "Specific association of mouse MDC1/NFBD1 with NBS1 at sites of DNA-damage." Cell Cycle 4(1): 177-82.

Lee SW, Cho BH, Park SG, Kim S (2004). "Aminoacyl-tRNA synthetase complexes: beyond translation”. J. Cell Sci. 117: 3725-34. 
Li CJ, Averboukh L, Pardee AB. (1993). "beta-Lapachone, a novel DNA topoisomerase I inhibitor with a mode of action different from camptothecin." J Biol Chem 268(30): 22463-8.

Li CJ, Li YZ, Pinto AV, Pardee AB (1999). "Potent inhibition of tumor survival in vivo by beta-lapachone plus taxol: combining drugs imposes different artificial checkpoints." Proc Natl Acad Sci U S A 96(23): 1336974.

Li CJ, Wang C, Pardee AB (1995). "Induction of apoptosis by betalapachone in human prostate cancer cells." Cancer Res 55(17): 3712-5.

Li W, Sun L, Liang Q, Wang J, Mo W, Zhou B. (2006). "Yeast AMID homologue Ndilp displays respiration-restricted apoptotic activity and is involved in chronological aging." Mol Biol Cell 17(4): 1802-11.

Li Y, Sun X, LaMont JT, Pardee AB, Li CJ (2003). "Selective killing of cancer cells by beta -lapachone: direct checkpoint activation as a strategy against cancer." Proc Natl Acad Sci U S A 100(5): 2674-8.

Li YZ, Li CJ, Pinto AV, Pardee AB (1999). "Release of mitochondrial cytochrome $\mathrm{C}$ in both apoptosis and necrosis induced by beta-lapachone in human carcinoma cells." Mol Med 5(4): 232-9. .

Lin WC, Lin FT, Nevins JR. (2001). "Selective induction of E2F1 in response to DNA damage, mediated by ATM dependent phosphorylation." Genes Dev 15(14): 1833-44.

Liu Q, Guntuku S, Cui XS, Matsuoka S, Cortez D, Tamai K, Luo G, Carattini-Rivera S, DeMayo F, Bradley A, Donehower LA, Elledge SJ. (2000). "Chk1 is an essential kinase that is regulated by Atr and required for the G(2)/M DNA damage checkpoint." Genes Dev 14(12):1448-59.

Lowndes NF, Murguía JR. (2000). "Sensing and responding to DNA damage." Curr Opin Genet Dev 10(1): 17-25. 
Lu PD, Jousse C, Marciniak SJ, Zhang Y, Novoa I, Scheuner D, Kaufman RJ, Ron D, Harding HP. (2004). "Cytoprotection by pre-emptive conditional phosphorylation of translation initiation factor 2." EMBO J 23(1): 169-79.

Lukas C, Falck J, Bartkova J, Bartek J, Lukas J. (2003). "Distinct spatiotemporal dynamics of mammalian checkpoint regulators induced by DNA damage." Nat Cell Biol 5(3): 255-60.

Lydall D,Weinert T. (1996). "From DNA damage to cell cycle arrest and suicide: a budding yeast perspective." Curr Opin Genet Dev 6(1): 4-11.

Maser RS, Mirzoeva OK, Wells J, Olivares H, Williams BR, Zinkel RA, Farnham PJ, Petrini JH. (2001). "Mre11 complex y DNA replication: linkage to E2F and sites of DNA synthesis " Mol Cell Biol 21(17): 6006-16.

Matthews DJ, Kopczynski J. (2001). "Using model-system genetics for drugbased target discovery." Drug Discov Today 6(3): 141-149.

McNeish IA, Bell S, Lemoine NR (2004). "Gene therapy progress and prospects: cancer gene therapy using tumour suppressor genes." Gene Ther 11(6): 497-503.

Melchionna R, Chen XR, Blasina A, McGowan CH. (2000). "Threonine 68 is required for radiation-induced phosphorylation and activation of Cds1." Nat Cell Biol 2(10): 762-5.

Menacho-Márquez M, Murguía JR. (2006). "Beta-lapachone activates a Mre11p-Tel1p G1/S checkpoint in budding yeast." Cell Cycle 5(21): 250916.

Menacho-Márquez M, Pérez-Valle J, Ariño J, Gadea J, Murguía JR. (2007). "Gcn2p regulates a G1/S cell cycle checkpoint in response to DNA damage." Cell Cycle 6 (18):2302-5. 
Mills KD, Sinclair DA, Guarente L. (1999). "MEC1-dependent redistribution of the Sir3 silencing protein from telomeres to DNA doublestrand breaks." Cell 97(5): 609-20.

Myung K, Kolodner R. (2002). "Suppression of genome instability by redundant S-phase checkpoint pathways in Saccharomyces cerevisiae." Proc Natl Acad Sci U S A 99(7): 4500-7.

Nakada D, Shimomura T, Matsumoto K, Sugimoto K. (2003). "The ATMrelated Tell protein of Saccharomyces cerevisiae controls a checkpoint response following phleomycin treatment." Nucleic Acids Res 31(6): 171524.

Natarajan K, Meyer MR, Jackson BM, Slade D, Roberts C, Hinnebusch AG, Marton MJ (2001). "Transcriptional profiling shows that Gen4p is a master regulator of gene expression during amino acid starvation in yeast." Mol Cell Biol 21(13): 4347-68.

Niederberger P, Aebi M, Hütter R (1986). "Identification and characterization of four new GCD genes in Saccharomyces cerevisiae." Curr Genet 10(9): 657-64.

Niedner H, Christen R, Lin X, Kondo A, Howell SB (2001). "Identification of genes that mediate sensitivity to cisplatin." Mol Pharmacol 60(6): 115360 .

Nyber KA, Michelson R, Putnam CW, Weinert TA. (2002). "Towards maintaining the genome: DNA damage and replication checkpoints." Annual Review Genetics 36: 617-656.

Oliver SG. (1996). "From DNA sequence to biological function." Nature 379(6566): 597-600.

Outeiro TF, Giorgini F. (2006). "Yeast as a drug discovery platform in Huntington's and Parkinson's diseases." Biotechnol J 1(3): 258-69. 
Paciotti V, Clerici M, Lucchini G, Longhese MP. (2000). "The checkpoint protein Ddc2, functionally related to S. pombe Rad26, interacts with Mec1 and is regulated by Mec1-dependent phosphorylation in budding yeast." Genes Dev 14(16): 2046-59.

Pahlman IL, Larsson C, Averét N, Bunoust O, Boubekeur S, Gustafsson L, Rigoulet M. (2002). "Kinetic regulation of the mitochondrial glycerol-3phosphate dehydrogenase by the external NADH dehydrogenase in Saccharomyces cerevisiae." J Biol Chem 277(31):27991-5

Painter RB, Young BR. (1980). "Radiosensitivity in ataxia-telangiectasia: a new explanation." Proc Natl Acad Sci U S A 77(12): 7315-7.

Pardee AB, Li Y, Li CJ (2002). "Cancer therapy with beta-lapachone." Curr Cancer Drug Targets 2(3): 227-42.

Park HJ, Ahn KJ, Ahn SD, Choi E, Lee SW, Williams B, Kim EJ, Griffin R, Bey EA, Bornmann WG, Gao J, Park HJ, Boothman DA, Song CW (2005). "Susceptibility of cancer cells to beta-lapachone is enhanced by ionizing radiation." Int J Radiat Oncol Biol Phys 61(1):212-9.

Pellicioli A, Lucca C, Liberi G, Marini F, Lopes M, Plevani P, Romano A, Di Fiore PP, Foiani M. (1999). "Activation of Rad53 kinase in response to DNA damage and its effect in modulating phosphorylation of the lagging strand DNA polymerase." EMBO J 18(22): 6561-72.

Pink JJ, Planchon SM, Tagliarino C, Varnes ME, Siegel D, Boothman DA (2000). "NAD(P)H:Quinone oxidoreductase activity is the principal determinant of beta-lapachone cytotoxicity." J Biol Chem 275(8): 5416-24.

Planchon SM, Pink JJ, Tagliarino C, Bornmann WG, Varnes ME, Boothman DA (2001). "beta-Lapachone-induced apoptosis in human prostate cancer cells: involvement of NQO1/xip3." Exp Cell Res. 267(1): 95-106. 
Ploger R, Zhang J, Bassett D, Reeves R, Hieter P, Boguski M, Spencer F (2000). "XREFdb: cross-referencing the genetics and genes of mammals and model organisms." Nucleic Acids Res 28(1): 120-2.

Prinz W (2003). Guide to yeast genetics and molecular and cell biology. New York, Academic Press.

Ramírez M, Wek RC, Vazquez de Aldana CR, Jackson BM, Freeman B, Hinnebusch AG (1992). "Mutations activating the yeast eIF-2 alpha kinase GCN2: isolation of alleles altering the domain related to histidyl-tRNA synthetases." Mol Cell Biol 12(12): 5801-15.

Redon C, Pilch DR, Rogakou EP, Orr AH, Lowndes NF, Bonner WM.. (2003). "Yeast histone 2A serine 129 is essential for the efficient repair of checkpoint blind DNA damage." EMBO Rep 4(7): 678-84.

Reinicke KE, Bey EA, Bentle MS, Pink JJ, Ingalls ST, Hoppel CL, Misico RI, Arzac GM, Burton G, Bornmann WG, Sutton D, Gao J, Boothman DA. (2005). "Development of beta-lapachone prodrugs for therapy against human cancer cells with elevated NAD(P)H:quinone oxidoreductase 1 levels." $\underline{\text { Clin }}$ Cancer Res 11(8): 3055-64.

Renou SG, Asis SE, Abasolo MI, Bekerman DG, Bruno AM. (2003). "Monoarylhydrazones of alpha lapachone: synthesis, chemical properties and antineoplastic activity." Pharmazie 58(10): 690-5.

Rich T, Allen RL, Wyllie AH. (2000). "Defying death after DNA damage". Nature 407(6895):777-783.

Riley DJ, Lee EY, Lee WH. (1994). "The retinoblastoma protein: more than a tumor suppressor." Annu Rev Cell Biol 10: 1-29.

Rock FL, Mao W, Yaremchuk A, Tukalo M, Crepin T, Zhou H, Zhang YK, Hernandez V, Akama T, Baker SJ, Plattner JJ, Shapiro L, Martinis SA, Benkovic SJ, Cusack S, Alley MR. (2007).”An antifungal agent inhibits an 
aminoacyl-tRNA synthetase by trapping tRNA in the editing site." Science 316(5832):1759-61.

Rodríguez-Hernández CJ, Sánchez-Pérez I, Gil-Mascarell R, RodríguezAfonso A, Torres A, Perona R, Murguía JR. (2003) "The immunosuppressant FK506 uncovers a positive regulatory cross-talk between the Hog1p and Gcn2p pathways." J. Biol Chem 278 (36): 33887-95.

Rogoff HA, Pickering MT, Frame FM, Debatis ME, Sanchez Y, Jones S, Kowalik TF. (2004). "Apoptosis associated with deregulated E2F activity is dependent on E2F1 and Atm/Nbs1/Chk2." Mol Cell Biol 24(7): 2968-77.

Ross-Macdonald P, Cohelo PS, Roemer T, Agarwal S, Kumar A, Jansen R, Cheung KH, Sheehan A, Symoniatis D, Umansky L, Heidtman M, Nelson FK, Iwasaki H, Hager K, Gerstein M, Miller P, Roeder GS, Snyder M (1999). "Large-scale analysis of the yeast genome by transposon tagging and gene disruption." Nature 402(6760): 413-8.

Rosenwald IB. (2004). "The role of translation in neoplastic transformation from a pathologist's point of view." Oncogene 23(18): 3230-47.

Rouse J, Jackson S. (2002). "Interfaces between the detection, signaling, and repair of DNA damage." Science 297(5581): 547-51.

Rouse J, Jackson S. (2002). "Lcd1p recruits Mec1p to DNA lesions in vitro and in vivo." Mol Cell 9(4) 857-69.

Sambrook J, Russell DW (2001). "Molecular Cloning. A laboratory Manual" Cold Spring Harbor, New York, Cold Spring Harbor Laboratory Press.

Sandell LL, Zakian VA. (1993). "Loss of a yeast telomere: arrest, recovery and chromosome loss." Cell 75(4): 729-39. 
Santocanale C, Diffley JF. (1998). "A Mec1- and Rad53-dependent checkpoint controls late-firing origins of DNA replication." Nature 395(6702): 615-8.

Scully R, Chen J, Ochs RL, Keegan K, Hoekstra M, Feunteun J, Livingston DM (1997). "Dynamic changes of BRCA1 subnuclear location and phosphorylation state are initiated by DNA damage." Cell 90(3): 425-35.

Schaffner-Sabba K, Schmidt-Ruppin KH, Wehrli W, Schuerch AR, Wasley JW (1984). "beta-Lapachone: synthesis of derivatives and activities in tumor models." J Med Chem 27(8): 990-4.

Scheuner D, Vander Mierde D, Song B, Flamez D, Creemers JW, Tsukamoto K, Ribick M, Schuit FC, Kaufman RJ. (2005). "Control of mRNA translation preserves endoplasmic reticulum function in beta cells and maintains glucose homeostasis." Nat Med 11(7): 757-64.

Sherr CJ, McCormick F. (2002). "The RB and p53 pathways in cancer." Cancer Cell 2(2): 103-12.

Sidorova JM, Verdeen LL. (1997). "Rad53-dependent phosphorylation of Swi6 and down-regulation of CLN1 and CLN2 transcription occur in response to DNA damage in Saccharomyces cerevisiae." Genes Dev 11(22): 3032-45.

Smits VA, Klompmaker R, Arnaud L, Rijksen G, Nigg EA, Medema RH. (2000). "Polo-like kinase-1 is a target of the DNA damage checkpoint." Nat Cell Biol 2(9): 672-6.

Smolka M, Albuquerque C, Chen S and Zhou H. (2007). "Proteome-wide identification of in vivo targets of DNA damage checkpoint kinases." Proc Natl Aacad Sci U S A 104 (25): 10364-9.

Srivastava SP, Kumar KU, Kaufman RJ. (1998). "Phosphorylation of eukaryotic translation initiation factor 2 mediates apoptosis in response to 
activation of the double-stranded RNA-dependent protein kinase." J Biol Chem 273(4) 2416-23.

Stewart MJ, Blum M, Sherry B (2003). "PKR's protective role in viral myocarditis." Virology 314(1): 92-100.

Stucki M, Clapperton J, Mohammad D, Yaffe MB, Smerdon SJ, Jackson SP (2005). "MDC1 directly binds phosphorylated histone H2AX to regulate cellular responses to DNA double-strans breaks." Cell 123(7): 1213-26.

Su TT. (2006). "Cellular responses to DNA damage: one signal, multiple choices." Annu Rev Genet 40: 187-208.

Sun X, Li Y, Li W, Zhang B, Wang AJ, Sun J, Mikule K, Jiang Z, Li CJ (2006). "Selective induction of necrotic cell death in cancer cells by betalapachone through activation of DNA damage response pathway." Cell Cycle 5(17): 2029-35.

Szekeres T, Fritzer-Szekeres M, Elford HL. (1997). "The enzyme ribonucleotide reductase: target for antitumor and anti-HIV therapy." $\underline{\text { Crit }}$ Rev Clin Lab Sci 34(6): 503-28.

Tagliarino C, Pink J, Dubyak GR, Nieminen AL, Boothman DA. (2001). "Calcium Is a Key Signaling Molecule in beta Lapachone mediated Cell Death." J Biol Chem 276(22): 19150-9.

Tagliarino C, Pink J, Reinicke KE, Simmers SM, Wuerzberger-Davis SM, Boothman DA (2003). "Mu-calpain activation in beta-lapachone-mediated apoptosis." Cancer Biol Ther 2(2): 141-52.

Takai H, Tominaga K, Motoyama N, Minamishima YA, Nagahama H, Tsukiyama T, Ikeda K, Nakayama K, Nakanishi M, Nakayama K. (2000). "Aberrant cell cycle checkpoint function and early embryonic death in Chk1(-/-) mice." Genes Dev. 14(12): 1439-47. 
Teixeira MC, Monteiro P, Jain P, Tenreiro S, Fernandes AR, Mira NP, Alenquer M, Freitas AT, Oliveira AL, Sa-Correia I (2006). "The YEASTRACT database: a tool for the analysis of transcription regulatory associations in Saccharomyces cerevisiae." Nucleic Acids Res 34(Database issue): D446-D451.

Tusher VG, Tibshirani R, Chu G (2001). "Significance analysis of microarrays applied to the ionizing radiation response." Proc Natl Acad Sci U S A 98(9): 5116-21.

Tvegård T, Soltani H, Skjølberg HC, Krohn M, Nilssen EA, Kearsey SE, Grallert B, Boye E. (2007). "A novel checkpoint mechanism regulating the G1/S transition." Gene Dev 21(6): 649-54.

Varley J, Haber DA. (2003). "Familial breast cancer and the hCHK2 1100delC mutation: assessing cancer risk." breast cancer res 5(3): 123-5.

Vazquez de Aldana CR, Marton MJ, Hinnebusch AG. (1995). "GCN20, a novel ATP binding cassette protein, and GCN1 reside in a complex that mediates activation of the eIF-2 alpha kinase GCN2 in amino acid-starved cells." EMBO J 14(13): 3184-99.

Velculescu VE, Zhang L, Zhou W, Vogelstein J, Basrai MA, Bassett DE Jr, Hieter P, Vogelstein B, Kinzler KW (1997). "Characterizaion of the yeast transcriptome." Cell 88(2): 243-51.

Wang H, Elledge S. (1999). "DRC1, DNA replication and checkpoint protein 1, functions with DPB11 to control DNA replication and the S-phase checkpoint in Saccharomyces cerevisiae." Proc Natl Acad Sci U S A 96(7): 3824-9.

Wang Y, Burke D. (1995). "Checkpoint genes required to delay cell division in response to nocodazole respond to impaired kinetochore function in the yeast Saccharomyces cerevisiae." Mol Biol Cell 15(12): 6838-44. 
Wright AP, Burns M, Hartley BS (1989). "Extraction and rapid inactivation of proteins from Saccharomyces cerevisiae by trichloroacetic acid precipitation." Yeast 5(1): 51-3.

Wright JA, Keegan KS, Herendeen DR, Bentley NJ, Carr AM, Hoekstra MF, Concannon P (1998). "Protein kinase mutants of human ATR increase sensitivity to UV and ionizing radiation and abrogate cell cycle checkpoint control." Proc Natl Acad Sci U S A 95(13): 7445-50.

Wu X, Ranganathan V, Weisman DS, Heine WF, Ciccone DN, O'Neill TB, Crick KE, Pierce KA, Lane WS, Rathbun G, Livingston DM, Weaver DT. (2000). "ATM phosphorylation of Nijmegen breakage syndrome protein is required in a DNA damage response." Nature 405(6785): 477-82.

Zhang F, Hamanaka RB, Bobrovnikova-Marjon E, Gordan JD, Dai MS, Lu H, Simon MC, Diehl JA (2006). "Ribosomal stress couples the unfolded protein response to p53-dependent cell cycle arrest." J Biol Chem 281(40): 30036-45.

Zhao S, Weng YC, Yuan SS, Lin YT, Hsu HC, Lin SC, Gerbino E, Song MH, Zdzienicka MZ, Gatti RA, Shay JW, Ziv Y, Shiloh Y, Lee EY. (2000). "Functional link between ataxia telangiectasia and Nijmegen breakage syndrome gene products." Nature 405(6785): 473-7.

Zhao X, Chabes A, Domkin V, Thelander L, Rothstein R (2001). "The ribonucleotide reductase inhibitor Sml1 is a new target of the Mec1/Rad53 kinase cascade during growth and in response to DNA damage." EMBO J 20(13): 3544-53.

Zhou BB, Elledge SJ. (2000). "The DNA damage response: putting checkpoints in perspective." Nature 408(6811): 433-9.

Zhou Z, Elledge SJ. (1993). "DUN1 encodes a protein kinase that controls the DNA damage response in yeast." Cell 75(6): 1119-27. 
Zou L, Cortez D, Elledge SJ. (2002). " Regulation of ATR substrate selection by Rad17-dependent loading of Rad9 complexes onto chromatin." Genes Dev 16(2): 198-208. 

ANEXOS 

ANEXO I

Inmunodetección de la forma fosforilada del factor elF2 $\alpha$ en mutantes del complejo XRM tras tratamiento con beta-lapachona.

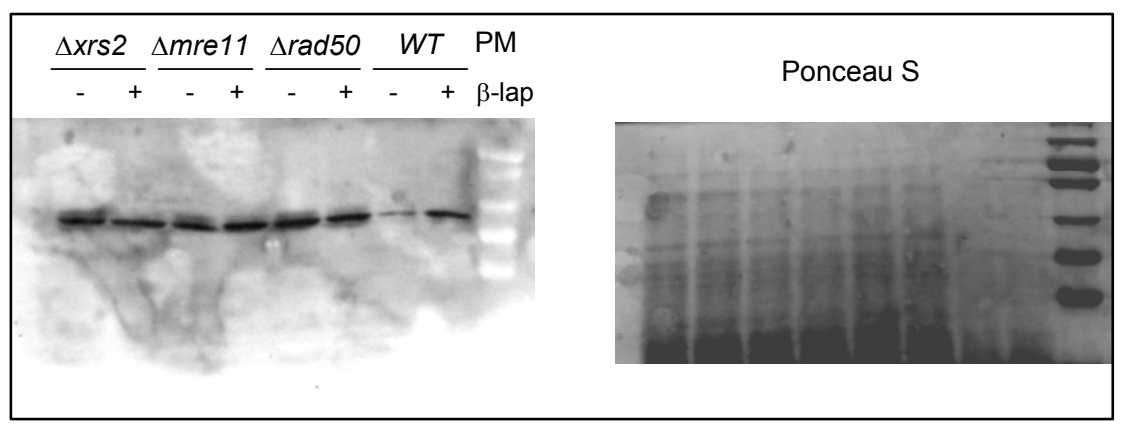




\section{ANEXO II}

\section{Selección de Artículos Publicados.}

Mauricio Menacho-Márquez, Jorge Pérez-Valle, Joaquín Ariño, Jose Gadea, and José R. Murguía. "Gcn2p regulates a G1/S cell cycle checkpoint in response to DNA damage". Cell Cycle. 2007 Sep 15; 6 (18)

M. Menacho-Márquez and J.R. Murguía. "Yeast on drugs: Saccharomyces cerevisiae as a tool for anticancer drug research". Clinical \& Translational Oncology. 2007 Apr; 9 (4): 221-8

Mauricio Menacho-Márquez and José Ramón Murguía. "Beta- lapachone triggers a Mre11-Tel1 dependent G1/S checkpoint in S. cerevisiae". Cell Cycle. 2006 Nov 1; 5(21)

Boto A, Gallardo A, Hernández R, Ledo F, Muñoz A, Murguía JR, MenachoMárquez M, Orjales A, Saavedra CJ. "Genotoxic activity of halogenated phenylglycine derivatives". Biorg Med Chem Lett. 2006 Dec 1; 16(23):6073-7

Andrés Barrilli, Sara Molinas, Guillermo Petrini, Mauricio Menacho and María Mónica Elías "Losartan reverses fibrotic changes in cortical renal tissue induced by ischemia or ischemia-reperfusion without changes in renal function". Molecular and Cellular Biochemistry. 2004 May; 260 (1): 161-170

Mauricio Menacho-Márquez \& José Ramón Murguía. "DNA damage signalling in eukaryotes: learning from budding yeast". Revista de Oncología Española. 2002 Apr; 5 (3): 139-145 
